\title{
Interventional therapy in Complex Regional Pain Syndrome type 1 : predicting the outcome
}

Citation for published version (APA):

van Eijs, F. (2012). Interventional therapy in Complex Regional Pain Syndrome type 1 : predicting the outcome. [Doctoral Thesis, Maastricht University]. Datawyse / Universitaire Pers Maastricht. https://doi.org/10.26481/dis.20120126fe

Document status and date:

Published: 01/01/2012

DOI:

10.26481/dis.20120126fe

Document Version:

Publisher's PDF, also known as Version of record

\section{Please check the document version of this publication:}

- A submitted manuscript is the version of the article upon submission and before peer-review. There can be important differences between the submitted version and the official published version of record.

People interested in the research are advised to contact the author for the final version of the publication, or visit the DOI to the publisher's website.

- The final author version and the galley proof are versions of the publication after peer review.

- The final published version features the final layout of the paper including the volume, issue and page numbers.

Link to publication

\footnotetext{
General rights rights.

- You may freely distribute the URL identifying the publication in the public portal. please follow below link for the End User Agreement:

www.umlib.nl/taverne-license

Take down policy

If you believe that this document breaches copyright please contact us at:

repository@maastrichtuniversity.nl

providing details and we will investigate your claim.
}

Copyright and moral rights for the publications made accessible in the public portal are retained by the authors and/or other copyright owners and it is a condition of accessing publications that users recognise and abide by the legal requirements associated with these

- Users may download and print one copy of any publication from the public portal for the purpose of private study or research.

- You may not further distribute the material or use it for any profit-making activity or commercial gain

If the publication is distributed under the terms of Article $25 \mathrm{fa}$ of the Dutch Copyright Act, indicated by the "Taverne" license above, 


\section{Interventional therapy in \\ Complex Regional Pain Syndrome type 1 \\ Predicting the outcome}


Cover: A woman with complex regional pain syndrome of the leg has gone to a fortune teller, and asked for a prediction of her outcome using a crystal ball. The woman is clearly worried about her future and wonders whether she will ever be able to walk again. The lightning flashing in the dark blue sky represents her pain and the central sensitisation she experiences. Who the fortune teller is, remains unclear.

C) Frank van Eijs, Maastricht 2012

ISBN 9789461591135

Production: Datawyse | Universitaire Pers Maastricht 


\title{
Interventional therapy in Complex Regional Pain Syndrome type 1 \\ Predicting the outcome
}

\author{
PROEFSCHRIFT \\ Ter verkrijging van de graad van doctor aan de Universiteit Maastricht, \\ op gezag van de Rector Magnificus, Prof. mr. G.P.M.F. Mols \\ volgens het besluit van het College van Decanen, in het openbaar te verdedigen \\ op donderdag 26 januari 2012 om 16.00 uur \\ door
}

Frank van Eijs

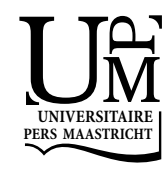




\section{Promotor}

Prof. dr. M. van Kleef

\section{Copromotoren}

Dr. C.G. Faber

Dr. J. van Zundert

\section{Beoordelingscommissie}

Prof. dr. L.W. van Rhijn (voorzitter)

Prof. dr. F.J.P.M. Huygen (Erasmus MC Rotterdam)

Dr. R.J. van Oostenbrugge

Prof. dr. J.A. Roukema (Universiteit van Tilburg)

Prof. dr. R.J.E.M. Smeets

\section{Financial support:}

A substantial part of this study was performed within TREND (Trauma Related Neuronal Dysfunction), a knowledge consortium that integrates research on complex regional pain syndrome type 1 . The project is supported by a Dutch government grant (BSIK03016). 


\section{Table of content}

$\begin{array}{lll}\text { CHAPTER I General introduction } & 7\end{array}$

CHAPTER II Complex Regional Pain Syndrome: Evidence-based 15

Interventional Pain Medicine according to clinical diagnoses

CHAPTER III Predictors of Pain Relieving Response to Sympathetic

Blockade in Complex Regional Pain Syndrome type 1

CHAPTER IV Brush evoked allodynia predicts outcome of Spinal Cord

Stimulation in Complex Regional Pain Syndrome - Type 1

CHAPTER V Spinal Cord Stimulation in Complex Regional Pain Syndrome type 1 of less than twelve months duration. A prospective observational study

CHAPTER VI Ketamine therapy in lower extremity Complex Regional Pain Syndrome type 1 patients with intractable pain. Effect on pain and functional impairment.

CHAPTER VII General discussion

CHAPTER VIII Summary

Samenvatting

CHAPTER IX Curriculum Vitae

List of publications

CHAPTER X Dankwoord

List of Abbreviations 

CHAPTER I

\section{General introduction}


Complex Regional Pain Syndrome (CRPS) still remains a complex problem with a wide area of different possible pathophysiological mechanisms involved and an even wider range of suggested possible therapeutic approaches.

The syndrome, also known as reflex sympathetic dystrophy, posttraumatic dystrophy, algodystrophy and causalgia is characterized by persisting pain in one or more extremities. The pain usually is initiated by a traumatic event such as a fracture, sprain or operation but spontaneous development has been described too. ${ }^{1}$ Distinction is made between CRPS type 1 (CRPS-1) formerly called reflex sympathetic dystrophy, without demonstrable large fiber nerve lesion and CRPS type 2 (CRPS-2) with demonstrable large fiber nerve lesion, formerly called causalgia. CRPS- 2 may have all the signs and symptoms seen in CRPS-1 but they may be mechanistically rather different syndromes.

The many casualties of the deadliest war in American History, the American Civil War (1861-1865) which resulted in the deaths of 620,000 soldiers and an undetermined number of civilians, triggered the interest of Silas Weir Mitchell in nerve injuries. Mitchell, an American neurologist at Turner's Lane Hospital in Philadelphia, was the first to make a reference to the causalgia syndrome in 1864 in his published work "Gunshot Wounds and Other Injuries of Nerves". ${ }^{2}$ In 1872 the causalgia syndrome was described in more detail in "Injuries of Nerves and their consequences". In 1900 the German surgeon Paul Südeck described the syndrome we now know as CRPS-1. He introduced the term "knochenatrophie" or bone atrophy. ${ }^{4}$ He was the first to notice the inflammatory aspects of the disease. The syndrome was named after him and later referred to as Morbus Südeck. In 1946 James Evans, a physician from Boston, Massachusetts, suggested that sympathetic reflexes were responsible for maintaining the pain and dystrophy. ${ }^{5}$ This hypothesis lead to term reflex sympathetic dystrophy, which has guided (and misguided) researchers over many years. In the same period, in 1947 Philip Foisie, another Boston physician, suggested that traumatic arterial vasospasms played an important role, ${ }^{6}$ but this hypothesis never received much attention for the following fifty to sixty years. In 1993 the IASP recognized the minor role of the sympathetic nervous system and the similar signs and symptoms of the two syndromes by introducing the term CRPS. ${ }^{7}$

The duration of signs and symptoms typically exceed the expected natural course of the initial trauma. Signs and symptoms have a tendency to spread distally in the affected limb. Besides pain, other signs and symptoms include sensory disturbances like allodynia and hyperalgesia or hypoesthesia and hypoalgesia; vasomotor dysfunction with discoloration and abnormal skin temperature; sudomotor dysfunction with edema and abnormal sweating of the extremity; and finally trophic signs and symptoms such as abnormal hair growth on the skin of the involved limb or abnormal nail growth. Motor disorders such as loss of strength, tremor, myoclonus, limited range of motion and bradykinesia may also be present. ${ }^{8}$ Diagnosis is made by history and clinical examination. No laboratory tests to confirm the diagnosis of 
CRPS are available. The IASP were the first to introduce an internationally accepted set of diagnostic criteria (table 1 ). ${ }^{7}$ These criteria, although being very sensitive in diagnosing the syndrome, suffer from a lack of specificity. This may lead to overdiagnosis of CRPS. Furthermore, the IASP criteria fail to incorporate motor and trophic features. So a new set of criteria has been developed, the presently called Budapest clinical criteria (table 2) which are more specific than the IASP criteria while retaining its high sensitivity. ${ }^{9}$

The estimated incidence of CRPS varies from 5.46 to 26.2 per 100,000 person years. CRPS in adults occurs slightly more often in the upper extremities. A fracture is the most common initial event when it occurs in the upper extremity. Women are affected 3.4 to 4 times more often than men. The mean age at diagnosis does not differ between men and women and varies between 47 and 52 years. ${ }^{10,11}$

Table 1: IASP criteria (Merskey, 1994)

1. Develops after tissue damage (CRPS type-1) or nerve damage (CRPS type-2)

2. Continuous pain, allodynia or hyperalgesia disproportional to the inciting event.

3. Evidence at some time of edema, abnormal skin blood flow and sudomotor abnormalities in the region of pain.

4. Other causes of pain or dysfunction are excluded

Criteria 2,3 and 4 must be fulfilled

Table 2: Modified diagnostic criteria (Budapest)

1. Continuous pain, disproportionate to the inciting event

2. Patients should have at least one symptom in three of the following categories and one sign in two or more categories.

Categories:

1. Sensory (allodynia, hyperalgesia)

2. Vasomotor (temperature or skin colour abnormalities)

3. Sudomotor (edema or sweating abnormalities)

4. Motor/trophic (muscle weakness, tremor, hair, nail, skin abnormalities)

In the early phase of the syndrome the involved limb may show inflammatory symptoms with swelling, redness, pain, warm skin temperature and dysfunction. Later in the course of the disease, the CRPS may become chronic and patients develop a dysfunctional, cold atrophic limb with motor impairment. ${ }^{12}$

Chronification of the disease does not necessarily occur. In a retrospective study of 168 patients, diagnosed with CRPS according to IASP criteria, 121 (= 72\%) had a successful outcome with physical therapy, medical therapy and sympathetic blockade. ${ }^{13}$ Another study demonstrated that after one year, if improvement did not occur, signs and symptoms in patients with CRPS-1 became well developed with pain refractory to treatment. The majority of patients even demonstrated a moderate increase in symptoms over the following years. ${ }^{14}$ In a population based cohort study of 102 CRPS patients, 31\% remained incapable to work after two or more 
years. ${ }^{15}$ These three studies show that CRPS, despite treatment, may become chronic in about $30 \%$ of patients at one year after onset.

So, the major goal of therapy in the early phase of the syndrome should be preventing chronification of CRPS. According to guidelines, invasive treatments may be applied if the signs and symptoms are refractory to a conservative approach with medication and physical therapy. ${ }^{16}$ However in order to prevent chronicity some advocate early aggressive treatment with interventional techniques like sympathetic blockade (SB) ${ }^{17}$ and spinal cord stimulation (SCS). ${ }^{18}$

To prevent this chronicity, clinical predictors of bad outcome would help to identify patients at risk for developing chronic CRPS. Also when considering an interventional technique in the management of CRPS patients, the identification of patients that respond positively to these interventional treatments is of great importance. To improve patient selection for interventional procedures, we need clinically useful predictors of success or failure. Research in this area however is rather scarce and included only two studies. Taylor investigated potential predictors of outcome of SCS therapy in CRPS, but could not identify any statistically significant predictor of pain relief. ${ }^{19}$ In another study, Hartrick found allodynia, characterized by non-painful stimuli being perceived as painful, to be a predictor of positive response to initial SB. ${ }^{20}$ So evidently there is a need for further studies on possible predictors of outcome. After treating CRPS-1 patients according to our study criteria and present guidelines, a significant number of patients remained with intractable, therapy resistant pain. At the time, successful treatment of chronic CRPS-1 pain, with intravenous ketamine was reported by several groups. ${ }^{21,22}$ The effect of intravenous ketamine on brush evoked allodynia and physical functioning was not known. Therefore a pilot study was performed, aiming to investigate the effect of ketamine on different aspects of pain and on physical functioning, in CRPS-1 patients with intractable pain, as part of this thesis.

The research done to address these issues of outcome prediction and chronicity was conducted in the pain management departments of both the Saint Elisabeth Hospital Tilburg, the Netherlands and the Maastricht University Medical Centre in Maastricht, the Netherlands. Patients of both centers were included in different studies involving the management of Complex Regional pain syndrome In order to obtain a more uniform patient group and because CRPS-1 is much more prevalent than CRPS-2, we focused on CRPS-1 patients only and excluded patients with CRPS2. 
The material in this thesis addresses the following research questions:

1. What is the actual medical evidence for the various existing interventional treatments of CRPS? (chapter 2)

2. Are there specific clinical signs, symptoms or demographic data in patients with CRPS-1 in the first year after onset that predict a pain relieving response to SB with local anesthetics? (chapter 3)

3. Are there specific clinical signs, symptoms or demographic data in patients with CRPS-1 that predict a pain relieving response to SCS one year after implantation of the SCS? (chapter 4)

4. Is there any additional benefit of SCS on pain and functional outcome in CRPS-1 if applied within one year after onset of the disease (early treatment with SCS)? (chapter 5)

5. What is the effect of intravenous ketamine on spontaneous pain, brush evoked pain, exercise induced pain and walking function in intractable CRPS-1? (chapter 6) 


\section{Outline of the thesis}

We firstly focused on the actual existing evidence for the various interventional treatments that are proposed for this syndrome by thoroughly reviewing the literature (chapter 2).

The second objective was to look for possible predictors of a positive response to $\mathrm{SB}$. If it would be possible to identify clinical predictors of a positive response to SB this would lead to a better selection of patients that would benefit from SB (chapter 3).

Our third objective was to identify possible predictors of good outcome of SCS therapy in chronic CRPS-1. This by retrospectively looking at a population of chronic CRPS-1 patients that were treated with SCS for their pain and by looking at the influence of the existence of allodynia, hypoesthesia, initial pain intensity and disease duration on the pain relieving effect of SCS (chapter 4).

The fourth objective was to study if application of SCS early in the course of the disease, i.e. less than 12 months duration after the initiating event, could prevent the syndrome from getting chronic (chapter 5).

The last objective was to investigate the influence of intravenous ketamine, a recently rediscovered old drug, on spontaneous pain, brush evoked pain (allodynia), exercise induced pain, and walking function in patients with CRPS-1 of the leg (chapter 6).

In the general discussion we comment on our findings and provide suggestions for the therapeutic approach of CRPS-1 patients and directions for future research (chapter 7). 


\section{References}

1. de Rooij AM, Perez RS, Huygen FJ, van Eijs F, van Kleef M, Bauer MC, et al. Spontaneous onset of complex regional pain syndrome. Eur J Pain;14:510-513.

2. Mitchell SW, Morehouse G, Keen W, eds. Gunshot wounds and other injuries of nerves. Philadelphia, PA: Lippincot \& Co; 1964.

3. Mitchell SW, ed. Injuries of nerves and their conseuqences. Philadelphia: Lippincot; 1872.

4. Sudeck P. Uber die acute entzundliche knochenatrophie. Arch Klin Chir. 1900;62:147.

5. Evans JA. Reflex sympathetic dystrophy. Surg Clin North Am. 1946;26:780-790.

6. Foisie PS. Traumatic arterial vasospasm. N Engl J Med. 1947;237:295-302.

7. Merksey, Bogduk N. Descriptions of Chronic Pain Syndromes and Definitions of Pain Terms, 2 Edition ed. Seattle, Washington: IASP press; 1994.

8. Veldman PH, Reynen HM, Arntz IE, Goris RJ. Signs and symptoms of reflex sympathetic dystrophy: prospective study of 829 patients. Lancet. 1993;342:1012-1016.

9. Harden RN, Bruehl S, Perez RS, Birklein F, Marinus J, Maihofner C, et al. Validation of proposed diagnostic criteria (the "Budapest Criteria") for Complex Regional Pain Syndrome. Pain. 2010;150:268-274.

10. de Mos M, de Bruijn AG, Huygen FJ, Dieleman JP, Stricker BH, Sturkenboom MC. The incidence of complex regional pain syndrome: a population-based study. Pain. 2007;129:12-20.

11. Sandroni P, Benrud-Larson LM, McClelland RL, Low PA. Complex regional pain syndrome type I: incidence and prevalence in Olmsted county, a population-based study. Pain. 2003;103:199-207.

12. Bruehl S. An update on the pathophysiology of complex regional pain syndrome. Anesthesiology. 2010;113:713-725.

13. Duman I, Dincer U, Taskaynatan MA, Cakar E, Tugcu I, Dincer K. Reflex sympathetic dystrophy: a retrospective epidemiological study of 168 patients. Clin Rheumatol. 2007;26:1433-1437.

14. Schwartzman RJ, Erwin KL, Alexander GM. The natural history of complex regional pain syndrome. Clin J Pain. 2009;25:273-280.

15. de Mos M, Huygen FJ, van der Hoeven-Borgman M, Dieleman JP, Ch Stricker BH, Sturkenboom MC. Outcome of the complex regional pain syndrome. Clin J Pain. 2009;25:590-597.

16. Perez RS, Zollinger PE, Dijkstra PU, Thomassen-Hilgersom IL, Zuurmond WW, Rosenbrand KC, et al. Evidence based guidelines for complex regional pain syndrome type 1. BMC Neurol. 2010;10:20.

17. Nelson DV, Stacey BR. Interventional therapies in the management of complex regional pain syndrome. Clin J Pain. 2006;22:438-442.

18. Kumar K, Rizvi S, Bishop S. Spinal cord stimulation is effective in management of complex regional pain syndrome (CRPS) I: Fact or Fiction. Neurosurgery. 2011.

19. Taylor RS, Van Buyten JP, Buchser E. Spinal cord stimulation for complex regional pain syndrome: a systematic review of the clinical and cost-effectiveness literature and assessment of prognostic factors. Eur J Pain. 2006;10:91-101.

20. Hartrick CT, Kovan JP, Naismith P. Outcome prediction following sympathetic block for complex regional pain syndrome. Pain Pract. 2004;4:222-228.

21. Correll GE, Maleki J, Gracely EJ, Muir JJ, Harbut RE. Subanesthetic ketamine infusion therapy: a retrospective analysis of a novel therapeutic approach to complex regional pain syndrome. Pain Med. 2004;5:263-275.

22. Kiefer RT, Rohr P, Ploppa A, Dieterich HJ, Grothusen J, Koffler S, et al. Efficacy of ketamine in anesthetic dosage for the treatment of refractory complex regional pain syndrome: an open-label phase Il study. Pain Med. 2008;9:1173-1201. 



\section{CHAPTER II}

\section{Complex Regional Pain Syndrome:}

\section{Evidence-based Interventional Pain Medicine}

according to clinical diagnoses

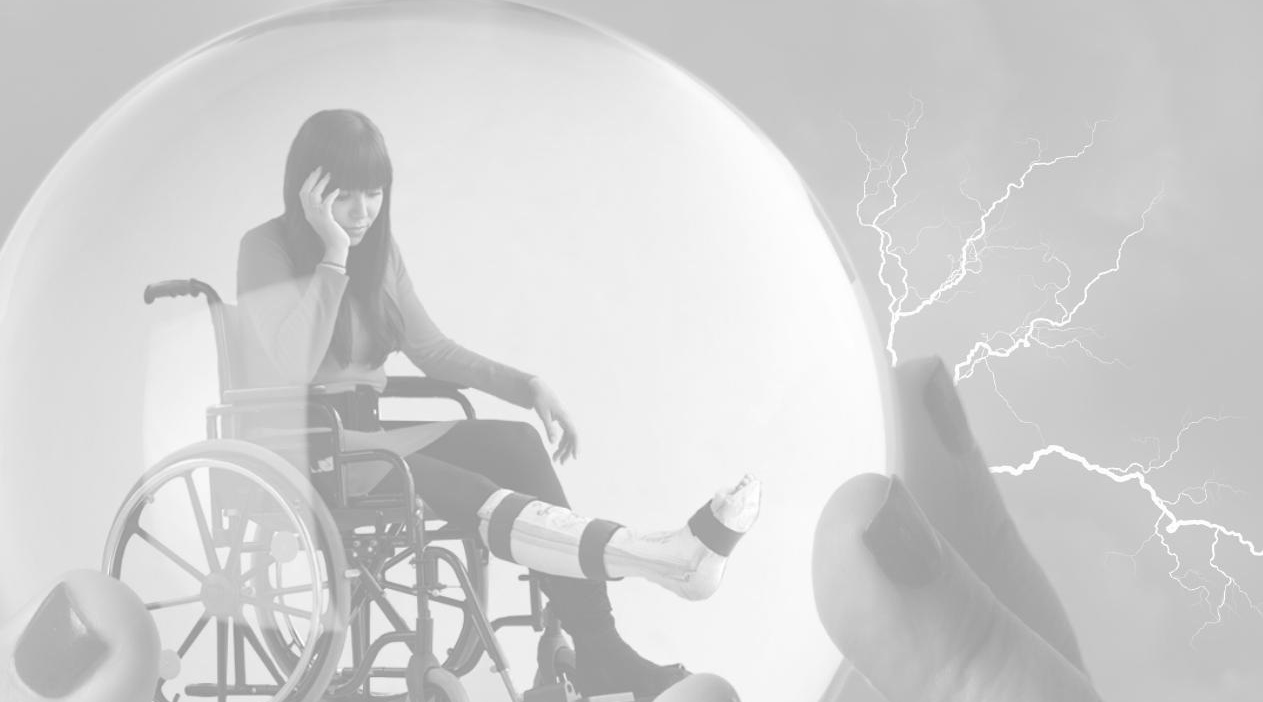

Frank van Eijs MD, Michael Stanton-Hicks MD, FIPP, Jan Van Zundert MD, PhD, FIPP, Catharina G Faber MD, PhD, Timothy R Lubenow MD, FIPP, Nagy Mekhail MD, PhD, FIPP, Maarten van Kleef MD, PhD, FIPP, Frank Huygen MD, PhD, FIPP

Pain Practice; 2011, 11 (1): 70-87 


\begin{abstract}
Complex regional pain syndrome (CRPS), formerly known as reflex sympathetic dystrophy is a pain syndrome with an unclear pathophysiology and unpredictable clinical course. The disease is often therapy resistant, the natural course not always favorable. The diagnosis of CRPS is based on signs and symptoms derived from medical history and physical examination. Pharmacological pain management and physical rehabilitation of limb function are the main pillars of therapy and should be started as early as possible. If, however, there is no improvement of limb function and persistent severe pain, interventional pain management techniques may be considered.

Intravenous regional blocks with guanethidine did not prove superior to placebo and frequent side effects occurred. Therefore this technique receives a negative recommendation (2 A-). Sympathetic block is the interventional treatment of first choice and has a 2 B+ rating. Ganglion stellatum (stellate ganglion) block with repeated local anesthetic injections or by radiofrequency denervation after positive diagnostic block is documented in prospective and retrospective trials in patients suffering from upper limb CRPS. Lumbar sympathetic blocks can be performed with repeated local anesthetic injections. For a more prolonged lumbar sympathetic block radiofrequency treatment is preferred over phenol neurolysis because effects are comparable whereas the risk for side effects is lower $(2 \mathrm{~B}+)$. For patients suffering CRPS refractory to conventional treatment and sympathetic blocks, plexus brachialis block or continuous epidural infusion analgesia coupled with exercise therapy may be tried $(2 \mathrm{C}+)$. Spinal cord stimulation is recommended if other treatments fail to improve pain and dysfunction $(2 \mathrm{~B}+)$. Alternatively peripheral nerve stimulation can be considered, preferentially in study conditions $(2 \mathrm{C}+)$.
\end{abstract}




\section{Introduction}

This article on Complex Regional Pain Syndrome (CRPS) is part of the series "Interventional practice guidelines based on clinical diagnosis". Recommendations formulated are based on "Grading strength of recommendations and quality of evidence in clinical guidelines" described by Guyatt et al. ${ }^{1}$, and adapted by van Kleef et al. in the editorial accompanying the first paper of this series. ${ }^{2}$ (see table 1 )

In the description of the interventional therapy we focused primarily on therapies used in anesthesiological practice. The latest literature update for this manuscript was performed in December 2009.

Complex Regional Pain Syndrome (CRPS) is a syndrome occurring as a complication of surgery or trauma, most often in one extremity but CRPS in multiple extremities has been described. Spontaneous development can also occur. ${ }^{3}$ The most recent definition from the International Association for the Study of Pain (IASP), is that CRPS is a collection of locally appearing painful conditions following a trauma, which chiefly occur distally and exceed in intensity and duration the expected clinical course of the original trauma, often resulting in considerably restricted motor function. CRPS is characterized by a variable progression over time.

The clinical picture was first described more than 100 years ago by Sudeck and in the 1860's by Mitchell. A review of the literature reveals 72 different names for this syndrome like Sudeck's atrophy, algodystrophy, posttraumatic dystrophy and most frequently used: reflex sympathetic dystrophy. Since a consensus meeting of the IASP in Orlando in 1993 "Complex Regional Pain Syndrome" has been the term agreed upon. A distinction is made between Type 1, without and Type 2, with demonstrable nerve damage. ${ }^{4}$

Bruehl et al $^{5}$ defined a number of subtypes, namely: a relatively limited syndrome with predominating vasomotor symptoms, a relatively limited syndrome with predominating neuropathic pain/sensory disturbances and a florid CRPS comparable to the classic description of reflex sympathetic dystrophy with the highest levels of motor and trophic signs. More recently a third type has been added, namely CRPS Not Otherwise Specified (NOS), involving a syndrome which only partially complies with the diagnostic criteria but where no other diagnosis can be made.

The estimated incidence varies from 5.46 to 26.2 per 100,000 person years. CRPS in adults occurs slightly more often in the upper extremities. A fracture is the most common initial event when it occurs in the upper extremity. Women are affected 3.4 to 4 times more often than men. The mean age at diagnosis does not differ between men and women and varies between 47 and 52 years. ${ }^{6,7}$ 
Table 1: Summary of evidence scores and implications for recommendation

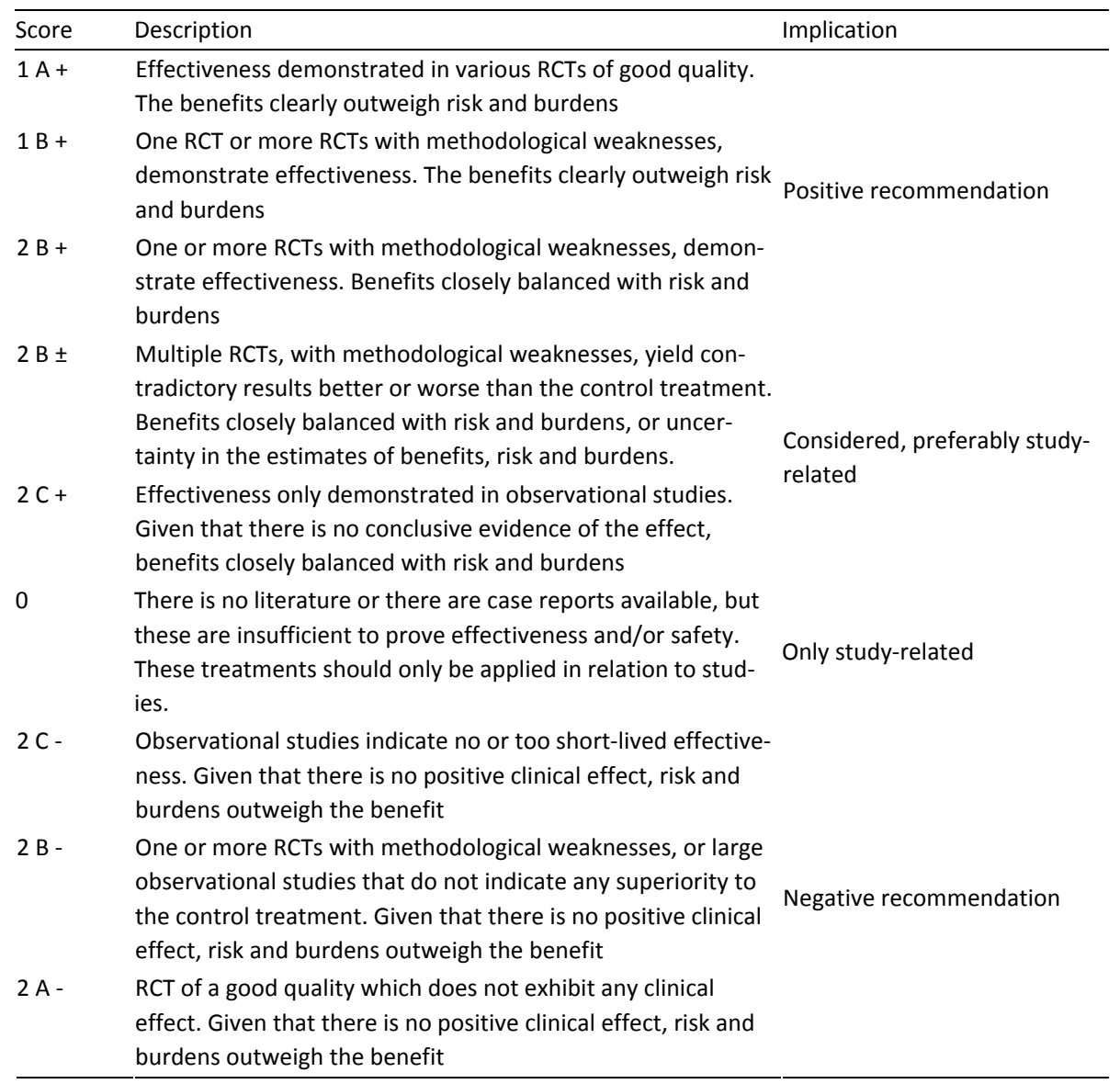

\section{Pathophysiology}

In the literature there is ongoing debate on the pathophysiology of CRPS.

Current understandings involve peripheral, afferent, efferent and central mechanisms.

Peripheral mechanisms include hypoxia caused by vasoconstriction induced by endothelial dysfunction leading to a decreased level of nitric oxide (NO) and increased level of endothelin-1 (ET-1) in the affected extremity. Sterile inflammation has been demonstrated by increased levels of pro-inflammatory cytokines such as interleukin 6 (IL-6) and tumor necrosis factor alpha (TNF-alpha). ${ }^{8}$ Neurogenic inflammation is caused by excretion of neuropeptides from nociceptive C-fibers which was demonstrated by elevated levels of substance $\mathrm{P}$, bradykinin and calcitonin 
gene-related peptide (CGRP). ${ }^{9}$ Denervation hypersensitivity can be caused by peripheral degeneration of small fiber neurons in the skin of affected limbs leading to inappropriate firing. ${ }^{10}$ Nociceptive afferent input may be caused by an increase in the number of alpha 1 receptors in the affected extremity, increased peripheral alpha adrenergic receptor hypersensitivity and chemical coupling between sympathetic and nociceptive neurons in the skin of CRPS affected limbs. ${ }^{11}$ Possible efferent mechanisms are sympathetic dysfunction leading to variable vasoconstriction, hypoxia and sweating abnormalities. Dysfunctional efferent motor pathways may lead to involuntary movements, dystonia and decreased range of motion.

Central mechanisms such as (supra)spinal sensitization through $\mathrm{N}$-methyl-Daspartate (NMDA) and neurokinin-1 (NK-1) receptor interaction also have been described as well as (secondary) psychological factors like pain related fear and movement anxiety. ${ }^{12}$

\section{Diagnosis}

\section{I.A History}

CRPS is usually preceded by trauma or surgery, the affected area usually extends beyond the original injury. The disease arises mostly glove-like in an arm or sock-like in a leg. The symptoms consist of a combination of continuous pain, sensory dysfunction, vasomotor and sudomotor dysfunction and motor and trophic signs. Case reports of CRPS-like symptoms without pain are mentioned, yet these are rare.

\section{I.B Physical examination}

Sensory dysfunction of the skin may include hyperalgesia and mechanical allodynia but also hypoalgesia and mechanical hypoesthesia. Asymmetry of skin temperature and changes in skin color occur as well as edema and hyper- or hypohidrosis. Signs of motor dysfunction include a reduction in the "range of motion" of affected joints and/or weakness, tremor, involuntary movements, bradykinesia and dystonia. Abnormal skin hair growth and changes in nail growth may be observed. Symptoms may vary over time, pain and other symptoms are often exacerbated with exertion of the affected extremity. ${ }^{4}$

\section{I.C Additional tests}

There is no specific diagnostic test available but various additional tests can be important in excluding other diagnoses. Laboratory tests such as full blood count, erythrocyte sedimentation rate and C-reactive protein are normal in CRPS but may 
help to exclude infection or rheumatologic disease. Duplex scanning and ultrasound may exclude peripheral vascular disease. Nerve conduction studies are helpful in excluding peripheral neuropathic disease or confirming nerve involvement in CRPS2. Plain radiographs of the skeleton and contrast-enhanced magnetic resonance imaging may demonstrate osteoporosis in the affected limb but are of no diagnostic value. ${ }^{13}$ Three-phase bone scanning may demonstrate increased uptake of technetium Tc $99 \mathrm{~m}$ biphosphonates due to increased bone metabolism. ${ }^{14}$ Skin temperature measurements by infrared thermometry may reveal long-term changes in skin temperature and skin temperature dynamics between the affected and nonaffected side. ${ }^{15}$ Other tests may only be of value to quantify or substantiate the clinical symptoms and are predominantly of use in scientific research. These include: quantitative sensory testing; resting sweat output; provocative sweat output test by the quantitative sudomotor axon reflex test; sympathetic skin response; volumetry in edema of the extremities; visual analogue scales for pain; impairment level sumscore; skills questionnaires; walking, rising and sitting down skills questionnaires and upper limb activity monitoring. ${ }^{16}$

\section{I.D Differential diagnosis}

Diagnosis is based upon criteria obtained from medical history and physical examination. The most commonly used criteria are the original IASP-criteria and the modified diagnostic criteria according to Harden and Bruehl. ${ }^{17-19}$ The criteria as described by Veldman are often used in The Netherlands. ${ }^{3}$ All criteria have essentially been determined empirically and overlap partially, whereby the IASP criteria are the most sensitive and the modified criteria according to Harden and Bruehl the most specific (Tables 2, 3 and 4)..$^{18,19}$

Table 2: IASP criteria (Merskey, 1994)

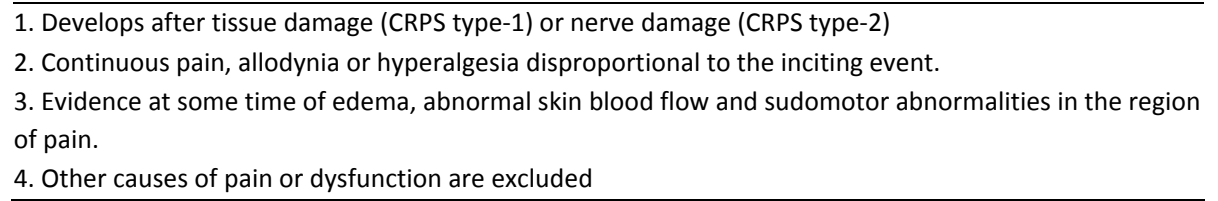

Criteria 2,3 and 4 must be fulfilled 
Table 3: Modified diagnostic criteria (Harden, 2007)

1. Continuous pain, disproportionate to the inciting event

2. Patients should have at least one symptom in each of the following categories and one sign in two or more categories.

Categories:

1. Sensory (allodynia, hyperalgesia, hypoesthesia)

2. Vasomotor (temperature or skin colour abnormalities)

3. Sudomotor (edema or sweating abnormalities)

4. Motor/trophic

(muscle weakness, tremor, hair, nail, skin abnormalities)

Table 4: Dutch criteria (Veldman 1993)

A. 4 of the following 5 symptoms:

1. Inexplicable diffuse pain;

2. Difference in skin colour between affected and contralateral extremity;

3. Diffuse edema;

4. Difference in skin temperature between affected and contralateral extremity;

5. Limited "active range of motion"

B. The occurrence or increase of above-mentioned symptoms with use of the involved extremity.

C. Above-mentioned symptoms are present in an area that is greater than the area of original trauma or surgery and distal to this area.

CRPS requires an extensive differential diagnosis, because many of the symptoms can also be caused by other diseases. Distinction should be made with vascular and myofascial pain syndromes, inflammation, vascular diseases and psychological problems. (Table 5)

Table 5: Differential diagnosis of Complex Regional Pain Syndrome

\begin{tabular}{ll}
\hline Neuropathic pain syndromes & Inflammation \\
- Peripheral (poly)neuropathy & - Erysipelas \\
- Nerve entrapment & - Inflammation NOS \\
- Radiculopathy & - Bursitis \\
- Postherpetic neuralgia & - Seronegative arthritis \\
- Deafferentation pain after CVA & - Rheumatologic diseases \\
- Plexopathy & Myofascial pain \\
& - Overuse \\
Vascular diseases & - Disuse \\
- Thrombosis & - Tennis elbow \\
- Acrocyanosis & - Repetitive strain injury \\
- Atherosclerosis & - Fibromyalgia \\
- Raynaud's disease & Psychical problems \\
- Erythromelalgia & - Somatoform pain disorders \\
- Charcot & - Munchhausen syndrome \\
\hline
\end{tabular}




\section{Treatment Options}

\section{II.A Conservative management}

The primary treatment of CRPS consists of early active mobilization physical therapy combined with pharmacological pain treatment. Physical therapy proved superior to occupational therapy and social work therapy in a randomized controlled trial of 135 CRPS-1 patients. ${ }^{20}$ More recently good results with a high level of evidence have been described with graded motor imagery therapy with imagined hand movements and mirror therapy for upper extremity CRPS. ${ }^{21-23}$ The use of pharmacological agents is guided by the involved mechanism (symptom oriented treatment, see algorithm in Figure 1). Psychological support may be initiated if there is no improvement with the above mentioned regime.

\section{Anti-inflammatory therapy}

Nonsteroidal anti-inflammatory drugs (NSAID's) for the treatment of CRPS were only studied in a small trial comparing scintigraphic outcome of calcitonin with NSAID's. NSAID's were inferior to calcitonin. ${ }^{24}$

A number of RCT's studied the effect of oxygen radical scavengers. Topical application of dimethyl sulfoxide $50 \%$ (DMSO-50\%) has been found superior to placebo and oral $\mathrm{N}$-acetylcysteine was generally equally effective as DMSO in the treatment of CRPS- $1 .{ }^{25,26}$

Intravenous mannitol however, another free radical scavenger, has proven to be ineffective. ${ }^{27}$ Biphosphonates, that reduce the increased bone turnover, such as oral alendronate or intravenous pamidronate were studied in 2 RCT's showing effect in favor of the biphosphonates. ${ }^{28,29}$

Calcitonin, a polypeptide hormone with a similar mode of action as the biphosphonates, can be administered subcutaneously or by intranasal spray. The different studies on these preparations for the management of CRPS show mixed results. A critical review concluded that in well-designed trials the effectiveness cannot be demonstrated. ${ }^{30}$

In a placebo controlled RCT with 23 CRPS patients, the use of prednisone maximum $10 \mathrm{mg}$ thrice daily for 3 weeks and then taper the dose during the next weeks until a maximum treatment period of 12 weeks, led to $75 \%$ improvement in all 13 treated patients as compared to only two out of 10 patients who received placebo. ${ }^{31}$ Another RCT compared the use of $40 \mathrm{mg}$ prednisolone per day with piroxicam in CRPS following stroke and found significant improvement after one month of prednisolone treatment. ${ }^{32}$ However since the use of corticosteroids may lead to potential serious complications long-term use of corticosteroids is not recommended. 


\section{Analgesic therapies}

There are no studies on the analgesic action of acetaminophen (paracetamol) in CRPS. As such the usefulness of acetaminophen and NSAID's is questionable. Slow release morphine $(90 \mathrm{mg} / \mathrm{d})$ was not effective in a double blind placebo controlled trial, so opioids are not likely to be of any benefit. The pain in CRPS is of neuropathic nature. First line therapy of neuropathic pain consists of tricyclic antidepressants like amitriptyline, the most frequently investigated drug for neuropathic pain. It improves pain and sleep impairment and can be given in CRPS although there are no trials that evaluate TCA's in CRPS. ${ }^{33}$ Carbamazepine in a dose of $600 \mathrm{mg} / \mathrm{d}$ significantly reduced pain in a placebo controlled RCT. ${ }^{34}$ Gabapentin has a mild effect on pain in a subpopulation of CRPS patients and is therefore worth trying. ${ }^{35}$ The NMDA blocker, ketamine, administered intravenously in subanesthetic dosages of maximal 20-25 mg/h/70 kg has been shown to be effective in relieving CRPS-associated pain in one retrospective case series report and two randomized double blind placebo controlled trials. $^{36-38}$

\section{Vasodilatory therapy}

Patients with hyperactive vasomotor symptoms leading to (intermittent) cold extremity CRPS may respond to alpha 1 adrenergic blockers like phenoxybenzamine and torazosin or calcium channel blockers like nifedipine. ${ }^{39,40}$

\section{Spasmolytic therapy}

Oral spasmolytic therapy with oral benzodiazepines or oral baclofen may be used in CRPS related dystonia, tremor or myoclonus. ${ }^{16}$

In conclusion: Physical therapy with active mobilization and graded motor imagery treatment together with a symptom oriented pharmacological treatment is the best initial approach of CRPS. 


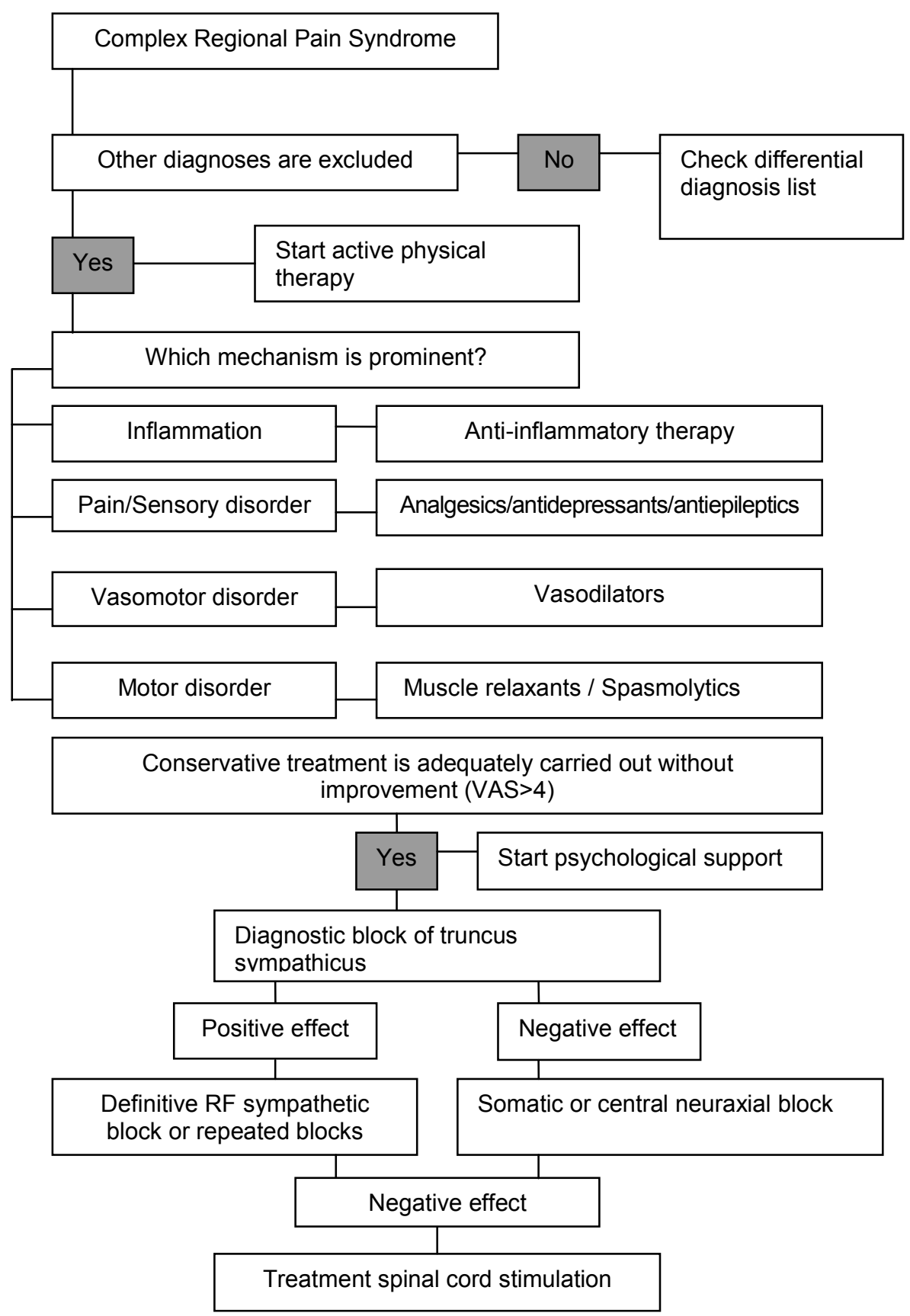

Figure 1: Clinical practice algorithm for the treatment of CRPS 


\section{II.B Interventional management}

If conventional therapy fails to give adequate relief of symptoms (e.g. pain score more than 4), interventional pain management techniques may be considered. These techniques are: intravenous regional blocks, sympathetic blocks of the ganglion stellatum for CRPS in the arm, and of the lumbar truncus sympathicus for CRPS in the leg. Peripheral and spinal cord stimulation and epidural or intrathecal drug administration may also be considered. Somatic and central neuraxial blocks for the management of CRPS have also been described.

\section{Intravenous regional blocks}

Intravenous regional blocks (IVRB's) with guanethidine for the treatment of CRPS-1 were first described by Hannington - Kiff. ${ }^{41}$ The technique consists of the intravenous administration of $10-20 \mathrm{mg}$ of guanethidine in a heparinized, isotonic saline solution of $25 \mathrm{ml}$, after elevating the arm for one minute and inflating a tourniquet at $50 \mathrm{~mm} \mathrm{Hg}$ above the patient's systolic blood pressure. The tourniquet is maintained for 15 -30 minutes after which it is let down slowly. This technique causes displacement of noradrenalin (NA) from presynaptic vesicles and prevents the reuptake of NA leading to an increase in skin blood flow during several days.

\section{Intravenous regional blocks with guanethidine}

The effect of IVRG with guanethidine for CRPS was studied in several case series, ${ }^{42-44}$ prospective trials ${ }^{45}$ and 3 RCT's. ${ }^{46-48}$ The outcome of case series is variable.

One study of 17 patients treated with a series of IVRB guanethidine and lidocaine found successful outcome in all patients. The authors claimed their success to the number of blocks provided: 25 in an 11 week period instead of the usual 1-6 blocks. $^{43}$

In a prospective case controlled study of 26 patients with CRPS of the hand significant better pain reduction and improvement of function was observed after treatment with DMSO-50\% ointment four times daily during three weeks when compared to treatment with IVRB guanethidine twice a week during three weeks. ${ }^{45}$ In a double blind cross over study with saline, high dose guanethidine and low dose guanethidine, no significant difference between groups was found. All groups reported less than $30 \%$ pain reduction, there was no evidence of a dose response for guanethidine. The trial was stopped prematurely after serious adverse events in two patients with the high dose of guanethidine. ${ }^{46} \mathrm{~A}$ double blind controlled multicenter RCT comparing IVRB with guanethidine or placebo in a group of 60 CRPS patients found no differences in long term outcome. ${ }^{47}$ In another RCT in a group of 57 CRPS patients, comparing IVRB with guanethidine to saline, again no significant long term differences were found. ${ }^{48}$ 


\section{Intravenous regional blocks with other medications}

IVRB with lidocaine and methylprednisolone was not effective when compared to saline in a RCT in 22 CRPS-1 patients. ${ }^{49}$ In a retrospective case series of 61 patients treated with IVRB containing lidocaine and ketorolac, $26 \%$ of patients had complete resolution of pain, $43 \%$ had partial response and $31 \%$ had no response to this therapy. ${ }^{50}$ In one double blind placebo controlled study, the use of intravenous regional ketanserine, a potent vasodilator, had a pain relieving effect. ${ }^{51}$

In conclusion, there is evidence that IVRB with guanethidine is not effective for the management of CRPS. The use of ketanserine was only studied in an earlier small trial.

Sympathetic blocks: Ganglion stellatum (stellate ganglion) and lumbar block The sympathetic nervous system has been implicated in numerous pain syndromes ranging from neuropathic pain to vascular pain to visceral pain. A role for sympathetic block (SB) is presumed. Recently this was extensively reviewed by Day. ${ }^{52} \mathrm{He}$ concludes that despite frequent use of minimally invasive sympathetic blocks and neurolysis their efficacy for providing analgesia has been sparsely reported in the literature. Focusing on sympathetic block for CRPS we could identify thirteen articles: two on SB (Ganglion stellatum, stellate ganglion block [SGB] and lumbar sympathetic block [LSB]), six on SGB and five on LSB.

Ganglion stellatum (stellate ganglion) block

Ganglion stellatum (stellate ganglion) block (SGB) is commonly performed for CRPS of the upper extremity. This cervicothoracic ganglion sends sympathetic afferents to the truncus cervicalis of the plexus brachialis and is located anterolaterally to the head of the first rib, lateral to the musculus longus colli and posteromedial to the arteria vertebralis. ${ }^{53}$ (see figure 2 ) 


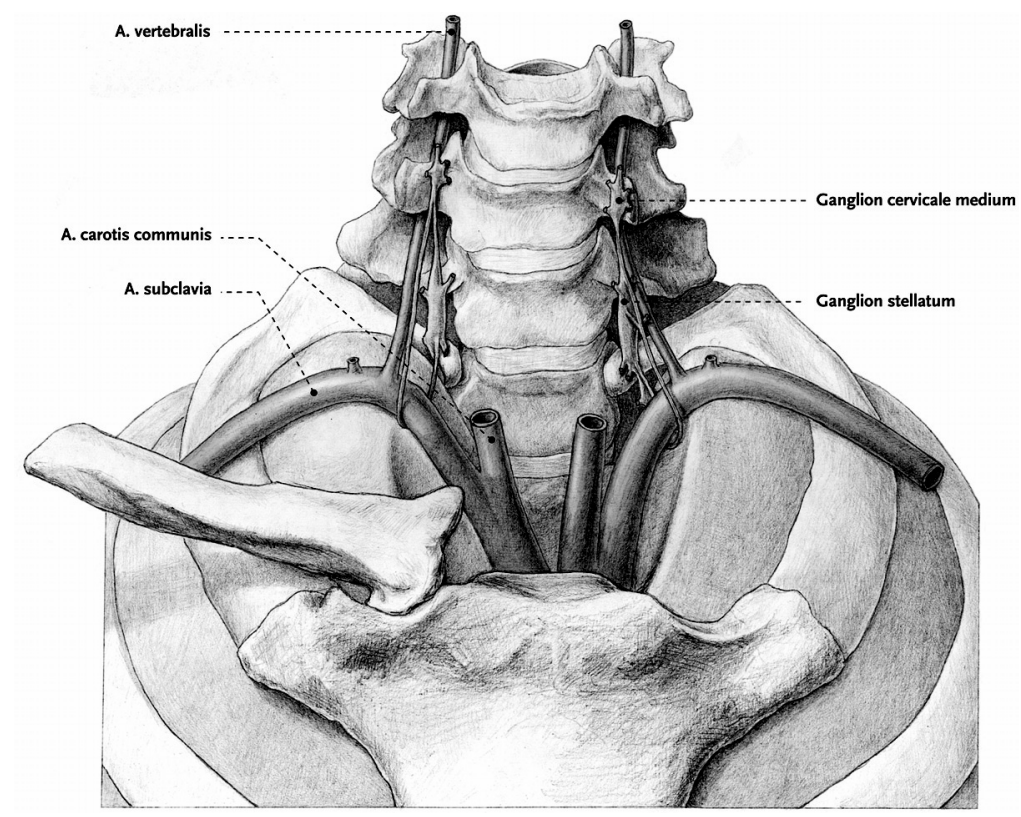

Figure 2: Anatomic illustration of the ganglion stellatum“

Illustration: Rogier Trompert Medical Art. www.medical-art.nl "

Linson et al ${ }^{54}$ described the use of SGB for patients with CRPS in the upper arm. Twenty-eight patients were all treated with indwelling-catheter injections of bupivacaine $0.5 \%$, four times a day during a mean of seven days (range 1-14 days). Short term outcomes were good: $90 \%$ of patients improved during treatment. In the long term, at six months to six years, two patients were lost to follow up. Of the remaining 26 patients, 19 felt that their pain had remained improved. Seven patients however, judged the pain improvement in the long term as minimal. Another study also found prolonged SGB with bupivacaine useful if intermittent SGB's plus conservative treatment with analgesics, tranquilizers and physical therapy failed. After an average of three years follow up there was $25 \%$ relapse rate and $75 \%$ marked to complete improvement in a group of 26 post-traumatic CRPS patients. ${ }^{55}$ The combination therapy of daily SGB with up to 10-15 injections, together with oral amitriptyline up to $100 \mathrm{mg}$ per day was found to give significant improvements in both VAS pain ratings and grip force strength. ${ }^{56}$ In another study SGB performed within 16 weeks after onset of symptoms gave significantly better pain relief than if performed later than 16 weeks after symptom onset. Moreover, it was found that a decrease in skin perfusion of the CRPS extremity as compared to the normal side, adversely affected the efficacy of the SGB. ${ }^{57}$

In a small case series of six patients the effect of opioid infiltration for CRPS-1 was examined; the data showed no efficacy of morphine when injected around the ganglion stellatum. ${ }^{58}$ 
Radiofrequency (RF) denervation of the ganglion stellatum was found comparably effective to other methods of SGB blockade with $40.7 \%$ of patients having more than $50 \%$ pain relief, in a selected group of patients who responded positively to a diagnostic block with 4-6 ml lidocaine $1 \% .{ }^{59}$

\section{Lumbar sympathetic block}

Lumbar sympathetic block (LSB) is frequently performed at the L2 to L4 lumbar levels for complex regional pain syndrome of the lower extremity. Pre- and postganglionic fibers form a synapse in the sympathetic ganglia. These ganglia are located at the anterolateral side of the lumbar vertebrae (see figure 3 ).

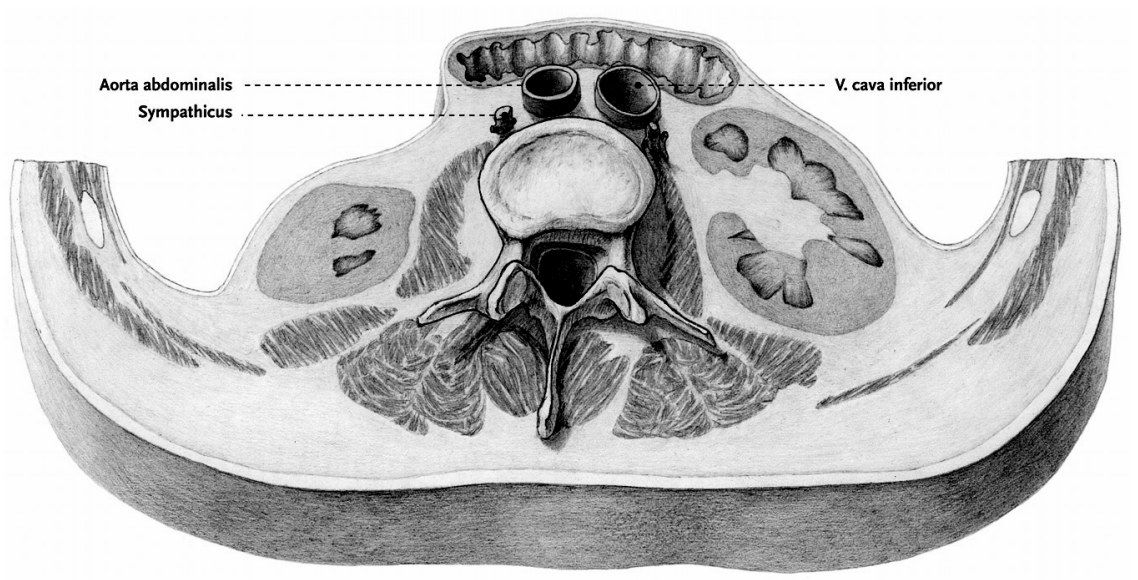

Figure 3: Anatomic illustration of the lumbar truncus sympathicus

"Illustration: Rogier Trompert Medical Art. www.medical-art.nl"

Unlike the SGB's image-guided techniques are mandatory. Under fluoroscopic guidance the technique has been demonstrated to be easy to perform. ${ }^{60}$ Computerized tomography (CT), ${ }^{61}$ magnetic resonance imaging (MRI) ${ }^{62}$ and ultrasound based techniques have also been described and their reliability demonstrated. ${ }^{63}$ However since CT and MRI are time consuming and less suitable for daily practice, fluoroscopy remains the method of choice. Ultrasound based techniques however may become more important in the near future.

LSB's can be performed by repeated injections of local anesthetic. In order to achieve longer lasting results neurolysis with for example phenol has been used. Radiofrequency treatment of the lumbar sympathetic chain is the third method for performing LSB.

In 29 patients with CRPS of the lower limb following total knee replacement LSB was performed with intermittent injections of $20 \mathrm{ml}$ bupivacaine $0.375 \%$. Complete pain relief was found in $13(45 \%)$ patients, partial pain relief in 12 (41\%) patients and no pain relief in $3(10 \%)$ patients. One patient dropped out due to technical 
failure. ${ }^{64}$ Iohexol, a regularly used water-soluble contrast dye was found not to alter the effect of LSB and even improved pain relief. In a subset of 11 patients, who agreed to report some aspects of pain in more detail, it was noted that the increase in skin temperature correlated significantly with the relief of allodynia. ${ }^{65}$

RF LSB at the L2-L4 sympathetic ganglia was documented in a case series of 20 patients with CRPS, $5(25 \%)$ became pain free and 9 (45\%) had temporary pain relief. ${ }^{66}$ RF LSB was compared with phenol neurolysis. It was found that phenol retained sympatholytic effects in $89 \%$ of patients after 8 weeks as compared to only $12 \%$ in the RF group. ${ }^{67}$ In a RCT performed in 20 CRPS- 1 patients it was found that $\mathrm{RF}$ treatment of $80^{\circ} \mathrm{C}$ for $90 \mathrm{sec}$ at the $\mathrm{L} 2-\mathrm{L} 4$ sympathetic ganglia was as effective as phenol neurolysis at the same ganglia ( $3 \mathrm{ml}$ phenol $7 \%$ at each lumbar level). All patients had statistically significant levels of reduction from baseline of various pain scores at 4 months follow up, however, phenol caused neuropathic pain symptoms in one patient $(10 \%) .{ }^{68}$

\section{Sympathetic blocks}

In a double blind, placebo controlled cross over study it was found that the duration of pain relief by SB with local anesthetics was reliably longer ( 90 hours) as compared to saline (20 hours). ${ }^{69}$ Sympathetic blocks were examined (SGB and LSB) with weekly injections of $14-16 \mathrm{ml}$ bupivacaine $0.25 \%$ or continuous bupivacaine $0.25 \%$ infusions of $5 \mathrm{ml}$ per hour for 5 days if pain relief was limited to the duration of the local anesthetic. Significant long-term improvement of pain (47\% reduction in VAS pain score) and functionality was found in all patients at a mean follow-up of 9.4 months. If patients responded by $50 \%$ or greater pain relief after diagnostic block this improvement was highly correlated with improvement at long term follow up. Mechanical and thermal allodynia predicted a positive response to initial sympathetic block. Anxiety negatively influenced pain relief and functional outcome. ${ }^{70}$

In a recent trial in 9 patients with CRPS-1 of more than six months duration, comparing the analgesic action of LSB with bupivacaine to LSB with bupivacaine mixed with botulinum toxin $A$ (BTA) it was found that BTA significantly increased the analgesic action of the LSB. Analgesia duration prolonged from fewer than 10 days (95\% $\mathrm{Cl} 0-12)$ to 71 days ( $95 \% \mathrm{Cl} 12-253)$. The mechanism of action being explained by the BTA preventing the release of acetylcholine from the preganglionic sympathetic nerves and thus inducing long-lasting but not permanent sympathetic block. $^{71}$

In conclusion: SGB by means of intermittent injections of local anesthetic for the management of CRPS of the upper limb was documented in retrospective and prospective studies. RF SGB was evaluated in a retrospective study.

LSB with local anesthetic was demonstrated to be superior to placebo injection. RF LSB yields comparable results to phenol neurolysis. The latter may produce a 
longer effect but the risk for deafferentation pain is higher. Therefore RF treatment is preferred.

\section{Neurostimulation}

\section{Transcutaneous electrical stimulation}

Transcutaneous electrical nerve stimulation (TENS) may give pain relief in a subgroup of patients with CRPS. ${ }^{72}$ Although there is no conclusive evidence for the use and effectiveness of TENS, this therapy is non-invasive with only minimal adverse events, the most common being a contact allergy for the skin electrodes. ${ }^{73}$ This makes TENS suitable as a preliminary or add-on therapy. ${ }^{74}$

\section{Spinal cord stimulation}

For patients with chronic CRPS who do not respond to conservative medical and rehabilitation therapy or sympathetic blocks, Spinal Cord Stimulation (SCS) may be considered. The short-term effect of this therapy in patients with CRPS has been demonstrated in a randomized study. ${ }^{75}$ In this study 54 patients with CRPS were included and randomized 2:1 to receive SCS and physical therapy or a standard regimen of physical therapy alone. Thirty-six patients were assigned to and treated with a test SCS. Twenty-four of those reported a reduction in pain and in these patients a definitive system was implanted. Eighteen patients only received physical therapy. Six months post treatment, the intention to treat analysis showed a clear reduction in pain intensity in the group with stimulated patients despite the fact that only 24 of the 36 patients were actually treated with SCS. The positive effects on pain and global perceived effect remained in an intention to treat analysis two years after implantation. ${ }^{76}$ Pain reduction was identical in patients treated with a cervical lead compared to a lumbar lead. ${ }^{77}$ Five years after the start of treatment the differences are smaller, but the patients who were treated with SCS are still doing better than the patients who had a negative test SCS or those who were in the control group. At the end of the follow-up period, despite the diminishing effect, $95 \%$ of the patients treated with the SCS indicated that they were prepared to undergo the treatment again for the same result. ${ }^{78}$ The evidence of a recent review on the clinical and cost-effectiveness of SCS in the management of chronic neuropathic or ischemic pain suggests that this treatment is effective in reducing the chronic neuropathic pain of CRPS type $1 .{ }^{79}$

\section{Peripheral nerve stimulation}

In a prospective case series, peripheral nerve stimulation (PNS) with surgically placed plate type electrodes connected with an implantable pulse generator reduced allodynic and spontaneous pain in 19 (63\%) out of 30 implanted patients with CRPS and symptoms in the distribution of one major peripheral nerve. ${ }^{80}$ In a retro- 
spective study with 52 patients (48 CRPS-2 patients and 4 phantom limb patients) 47 patients were implanted after a positive trial stimulation. Of these patients 43 (91\%) had lasting excellent to good success with marked pain reduction and reduction of pain related disability. ${ }^{81}$ In another retrospective study 41 PNS devices were implanted in 38 patients with pain in a peripheral nerve distribution. Over $60 \%$ of patients had significant improvement of their pain of more than $50 \%$ following implantation of the peripheral nerve stimulator. ${ }^{82}$ The technique can only be applied if the pain is in the distribution of a peripheral nerve and is thus less suitable for most CRPS-1 patients.

\section{Somatic and central neuraxial blocks}

\section{Plexus brachialis block}

Somatic nerve block of the plexus brachialis also blocks the efferent sympathetic nerves around it. Theoretically somatic blockade increases the ability to tolerate physical therapy, especially if the shoulder is also affected. In a retrospective case series 25 patients of which 17 CRPS patients, improvement in pain and range of motion was found after interscalene block with $30-40 \mathrm{ml}$ bupivacaine $0.125 \%$ injected every other day up to a total of 10 injections. This approach was suggested if sympathetic blockade failed. ${ }^{83}$

In a small case series of 6 CRPS patients treated with continuous or daily axillary injections with bupivacaine together with physical and occupational therapy, three out of six patients responded well to this therapy, another patient also responded well initially but the catheter had to be removed due to infection at the insertion site. The two poor responders were chronic CRPS patients. ${ }^{84}$

\section{Epidural administration of drugs}

The epidural administration of opioids and other drugs is increasingly being offered for non-malignant pain. Epidural bupivacaine in high anesthetic doses for 2-3 days followed by epidural infusion of opioids during maximal 7 days together with continuous passive motion, allowed for recovery of the knee function in patients with CRPS of the knee. ${ }^{85}$ Epidural clonidine has been demonstrated to give short term pain relief in chronic CRPS and to be possibly effective in the long term with small VAS reductions from $7.0 \pm 0.4$ to $5.1 \pm 0.6(p<0.05)^{86}$

Unilateral cervical epidural analgesia with low dose bupivacaine and clonidine continuous infusions for CRPS may be an interesting approach. The low bupivacaine dose gives only minimal limb muscle weakness and allows for active rehabilitation therapy. ${ }^{87}$ In a retrospective study 37 CRPS-1 patients were treated with this unilateral epidural catheter technique with continuous bupivacaine and fentanyl infusions. Of these patients almost $90 \%$ improved significantly when treated within one year after onset of symptoms. If treatment was initiated more than one year after 
onset and if more than one limb was involved, the success rate decreased dramatically. $^{88}$

\section{Intrathecal administration of drugs}

The intrathecal administration of drugs has been utilized increasingly in the last 30 years. Intrathecal administration of morphine with a totally implantable drug delivery system gave $>50 \%$ pain relief in a case series of 5 patients with chronic CRPS. ${ }^{89}$ Intrathecal treatment of CRPS pain with bupivacaine in high anesthetic doses up to $90 \mathrm{mg}$ per day was studied in a small series of three patients. The infusion improved pain but did not prevent the syndrome from becoming chronic and was therefore not recommended. ${ }^{90}$

Intrathecal baclofen improves dystonia, pain, disability and quality of life in patients with CRPS-1 associated dystonia but is associated with a high complication rate as described below. ${ }^{91}$

Intrathecal ziconotide (a non-opioid analgesic) may be a promising drug for the treatment of refractory CRPS pain but requires more research. ${ }^{92}$

\section{II.C Complications of interventional management}

\section{Complications of the intravenous regional blocks}

The IVRB technique is a relatively safe procedure to perform but with frequent minor side effects like dizziness (41\% of patients) after release of the tourniquet. ${ }^{50}$ Sometimes serious orthostatic hypotension may occur. ${ }^{46}$

\section{Complications of the ganglion stellatum (stellate ganglion) block}

The incidence of severe complications is 1.7 in 1000 patients. Potentially lifethreatening complications usually arise from inadvertent subarachnoid injection or injection in the arteria vertebralis. This makes ECG monitoring and placement of an intravenous line prior to performing the procedure mandatory. ${ }^{93}$ Actually the autonomic innervation of the arm occurs via Th1. However puncture at this level gives a small chance of injecting into the thoracic pleural cavity. To prevent this it is possible to first inject towards $\mathrm{C7}$ and then adjust the needle in the direction of Th1. A side effect can be the occurrence of Horner's syndrome caused by the local anesthetic spreading to the cervical truncus sympathicus. Hoarseness can also occur via the nervus laryngeus recurrens.

\section{Complications of the lumbar sympathetic block}

Blocking the sympathetic nervous system causes vasodilatation in the extremity which may lead to (orthostatic) hypotension. Therefore patients should receive intravenous fluid infusion prior to treatment. During recovery blood pressure should be measured intermittently over a period of 45 minutes. After the recovery period 
sufficient fluid intake during the first 24 hours is advised. Patients can sometimes develop a warm and edematous leg that can possibly be interpreted as an overshoot. These symptoms usually disappear spontaneously after about 6 weeks. Another possible complication is damage to the nervus ilioinguinalis or more frequently $(5-10 \%)$ the nervus genitofemoralis. This can give a neuropathic deafferentation pain. An alternative approach, the transdiscal technique has been demonstrated to lower the risk of nervus genitofemoralis neuritis. ${ }^{94}$ Similarly, this risk is reduced if RF denervation of the lumbar truncus sympathicus is used instead of injecting a neurolytic agent. ${ }^{67}$ With double-sided chemical LSB men can become impotent.

\section{Complications of spinal cord stimulation}

Possible complications which require reoperation include electrode dislocation or pain from the implanted pulse generator pocket. ${ }^{76}$ Life-threatening complications like meningitis are rare but other adverse events like infection, dural puncture, pain in the region of a stimulator component, equipment failure, revision procedures other than battery change and removal operations occur in $34 \%$ of the patients. ${ }^{95}$

\section{Complications of peripheral nerve stimulation}

Possible complications requiring reoperation are related to the surgical technique or PNS equipment design and include migration of the electrode in $33 \%$, infection in $15 \%$ and the need for placement in an alternative location in $11 \%$ of patients. ${ }^{96}$

\section{Complications of plexus brachialis block}

Plexus brachialis block is a relatively safe procedure with the most common complication being infection of the catheter skin insertion site

\section{Complications of epidural and intrathecal drug administration}

Frequent complications of epidural drug administration include infections and catheter or pump failure. ${ }^{97}$ Adverse effects of intrathecal drug administration include infections, catheter and pump system failures, post dural puncture headache and the formation of intrathecal granulomas, carrying the potential to produce spinal cord compression.

\section{II.D Evidence for interventional management}

A summary of the available evidence is given in table 6 
Table 6: Summary of evidence for interventional pain management of CRPS

\begin{tabular}{ll}
\hline Technique & Score \\
\hline Intravenous regional block guanethidine & $2 \mathrm{~A}-$ \\
Ganglion stellatum (stellate ganglion) block & $2 \mathrm{~B}+$ \\
Lumbar sympathetic block & $2 \mathrm{~B}+$ \\
Plexus brachialis block & $2 \mathrm{C}+$ \\
Epidural infusion analgesia & $2 \mathrm{C}+$ \\
Spinal cord stimulation & $2 \mathrm{~B}+$ \\
Peripheral nerve stimulation & $2 \mathrm{C}+$ \\
\hline
\end{tabular}

\section{Recommendations}

Based upon the available evidence with regard to effect and complications we recommend the following interventional techniques for the treatment of CRPS:

For patients with CRPS with severe pain, allodynia or with a clear skin temperature difference as opposed to the non-affected extremity which do not respond to medication and physical therapy, a diagnostic block of the ganglion stellatum or the lumbar sympathetic nervous system can be performed. If this block provides at least $50 \%$ pain reduction, this procedure can be repeated a few times with local anesthetic. Radiofrequency therapy of the ganglion stellatum or the lumbar sympathetic ganglia is a suitable alternative. In the case of persistent symptoms SCS can be recommended after multidisciplinary evaluation. Somatic plexus brachialis block, epidural analgesia and PNS can be considered, preferentially in a study design.

\section{III.A Clinical practice algorithm}

The practice algorithm is illustrated in Figure 1

\section{III.B Technique(s)}

\section{Ganglion stellatum (stellate ganglion) block}

Injections have traditionally been guided by palpable anatomical landmarks. ${ }^{98}$ Supportive technology such as fluoroscopy, ${ }^{99}$ computed tomography ${ }^{100}$ and ultrasound ${ }^{101}$ have been demonstrated to make the procedure technically more reliable. SGB's may be performed by injection of local anesthetics or by RF denervation.

The patient is placed in a supine position with the head slightly hyperextended. The height of C6-C7 is determined by fluoroscopy with the C-arm in anteroposterior position. The $\mathrm{C}$-arm is adjusted until the vertebral end plates are viewed perpendicular. After local disinfection the skin is anesthetized using $1 \%$ lidocaine and a needle is inserted at the junction of the processus transversus and the corresponding C6- or C7 corporus vertebralis. After contact with the bone, oblique pro- 
jection is used to check if the needle is anterior to the foramen intervertebrale. If the needle is past this level no contact has been made with the base of the processus transversus and the needle needs to be repositioned. Once the needle is in the correct position a small amount $(0.5-1 \mathrm{ml})$ of contrast dye is injected in order to prevent intravascular injection. The contrast dye must spread craniocaudally. (see figures 4 and 5 )

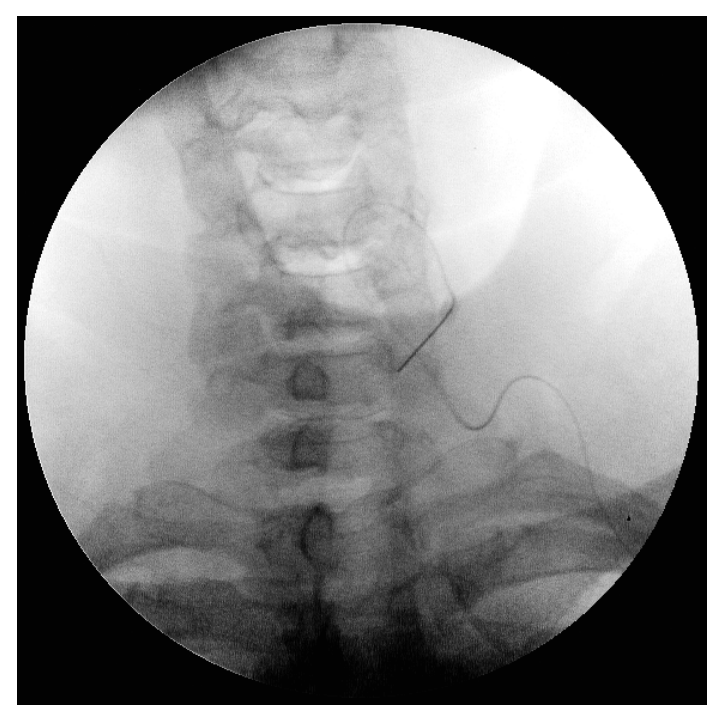

Figure 4: Ganglion stellatum (stellate ganglion) diagnostic block AP view needle position

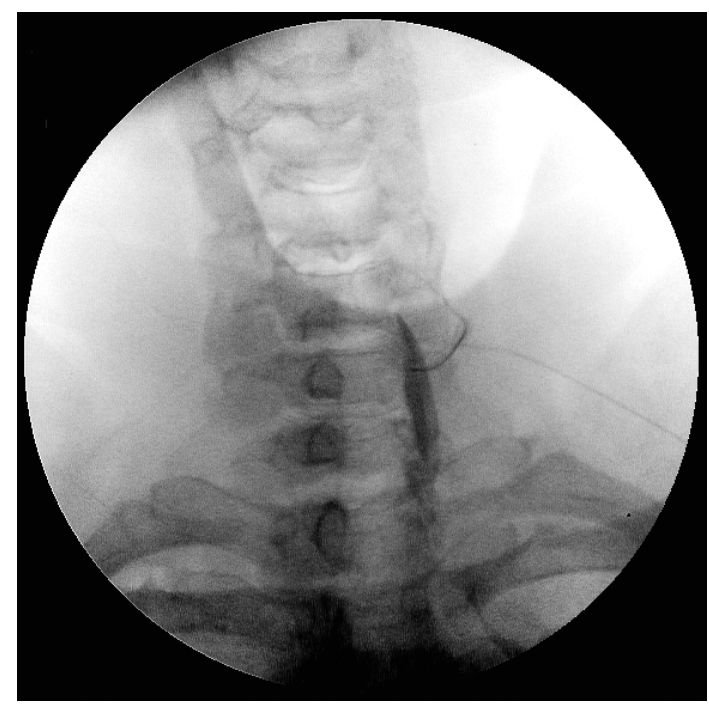

Figure 5 : Ganglion stellatum (stellate ganglion) block antero posterior view, contrast dye outline 
For a test block, the injection is given using a $60 \mathrm{~mm}, 20$ gauge radiocontrast needle. After C-arm fluoroscopy confirmation of the correct position $5 \mathrm{ml} 1 \%$ lidocaine or $0.25 \%$ bupivacaine is injected depending on the spread of the contrast dye.

For a definitive block using RF, a $60 \mathrm{~mm}, 20$ gauge RF needle is combined with a thermocouple probe for thermometry and thermal lesioning. After confirmation of the correct needle position with fluoroscopy, electrical stimulation is performed at $50 \mathrm{~Hz}$ (sensory stimulation) and $2 \mathrm{~Hz}$ (motor stimulation) to $1 \mathrm{~mA}$, to ensure that there is no contact with a segmental nerve root (patient should not feel anything apart from a faint feeling in the shoulder and/or arm). Then $0.7 \mathrm{ml} 1 \%$ lidocaine in injected after which a thermal lesion is carried out for 1 minute at $80^{\circ} \mathrm{C}$. This procedure can be repeated if necessary.

\section{Lumbar sympathetic block}

The patient is placed in prone position on the treatment table, a cushion can be placed under the abdomen in order to prevent too much lumbar lordosis. The C-arm fluoroscope is used to identify the level L2-L4. The C-arm is adjusted in the craniocaudal direction until the vertebral end plates are viewed perpendicular. Then the $\mathrm{C}$-arm, is turned laterally until the distal end of the processus transversus projects in line with the lateral edge of the corresponding L2-L4 corpora vertebrae. (see figure 7)

After local disinfection the skin is anesthetized using $1 \%$ lidocaine and a needle is inserted using tunnel view until the front of the vertebra has been reached. Use lateral projection to check that the needle does not pass the anterior side of the corpus vertebrae. Also use AP projection to check that the needlepoint projects over the facet joint of the spinal column. The truncus sympathicus can be reached by a single needle approach at the $\mathrm{L} 3$ corpus vertebrae ${ }^{102}$ or by a multiple needle approach at the L2-L4 corpora vertebrae. If there is a good contrast outline of the dye when starting with the single needle approach at $L 3$ there is no more need for the multiple needle approach. At all times a small amount $(0.5-1 \mathrm{ml})$ of contrast dye should be injected (injection of too much contrast dye makes repositioning of the needle more difficult). In the AP-projection the contrast dye should be visible as a cloud in front of the corpus vertebrae, but not laterally. In the case of a streaky lateral spread the needle could be in the musculus psoas compartment. In this case the needle needs to be inserted more deeply. Using lateral projection a string will be seen running along the anterolateral aspect of the corpus vertebrae (Figure 6). A 20 gauge, $150 \mathrm{~mm}$ canula at the level of $\mathrm{L} 3$ is used for a test block. After confirmation of the correct needle positioning by radiocontrast dye, $5-10 \mathrm{ml}$ of $1 \%$ lidocaine or $0.25 \%$ bupivacaine is injected. 


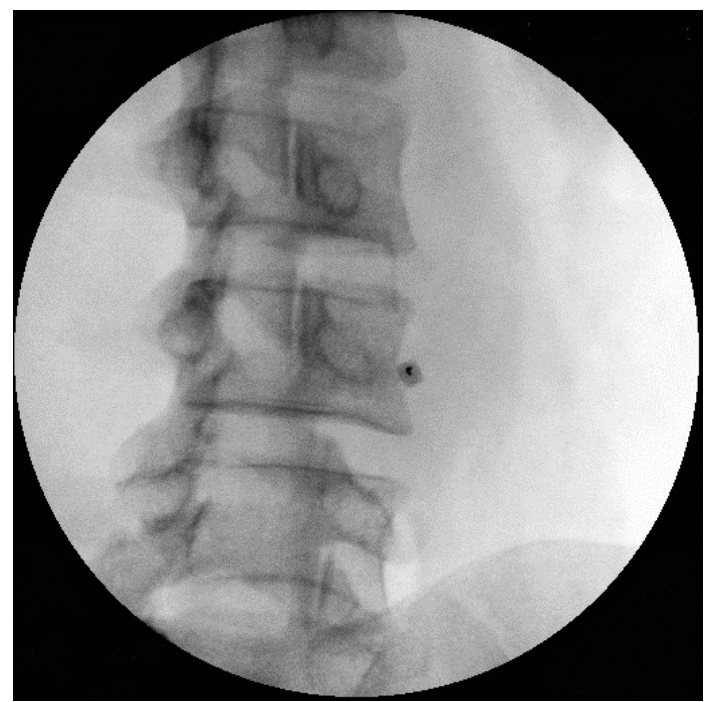

Figure 6: Lumbar sympathetic nervous system: diagnostic block injection point with oblique projection of needle using tunnel view

For a definitive block using RF a 20 gauge, $150 \mathrm{~mm}$ long RF needle with a $10 \mathrm{~mm}$ non-insulated tip is used combined with a thermocouple probe for thermometry and thermal lesioning. Consideration can be given to only blocking at two levels, L3 and L4. After confirmation of the correct position with the fluoroscope, electrical stimulation is carried out, using consecutively $50 \mathrm{~Hz}$ (sensory stimulation) and $2 \mathrm{~Hz}$ (motor stimulation) to $1 \mathrm{~mA}$, to ensure that there is no contact with a segmental nerve root (patient should not feel anything apart from a faint feeling in the abdomen). At each level $0.7 \mathrm{ml} 1 \%$ lidocaine is injected after which a thermal lesion is carried out for 1 minute at $80^{\circ} \mathrm{C}$. This procedure can be repeated if necessary. 


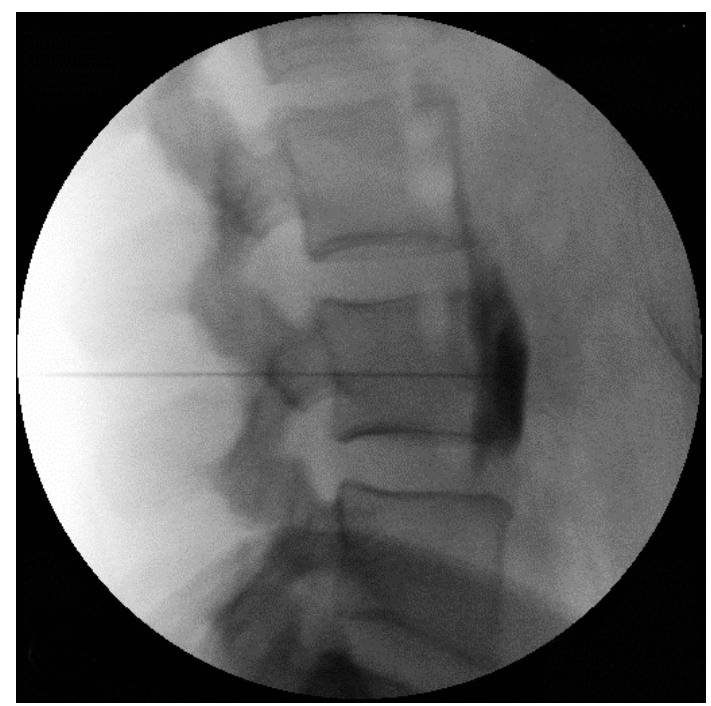

Figure 7: Lumbar sympathetic nervous system: diagnostic block injection point with lateral projection.

\section{Spinal cord stimulation}

All patients in the discussed studies received trial SCS with a temporary electrode after the prophylactic administration of $1500 \mathrm{mg}$ of cefuroxim intravenously. With the patient in prone position, under direct fluoroscopy a Tuohy needle was introduced in the epidural space. The electrode was advanced until the tip was at C4 in the case of upper extremity CRPS and at T12 in the case of lower extremity CRPS. The electrode was positioned so that there was adequate stimulation as reported by the patient as paresthesias covering the area of pain. The needle was then withdrawn and the electrode connected to an external stimulator. The trial SCS was carried out at home for at least one week. Meanwhile patients were encouraged to perform their normal daily activities. A permanent implant was performed if there was a $50 \%$ pain reduction score or if there was a score of at least six (meaning much improvement) on a seven point scale for global perceived effect of treatment. The permanent implantation technique used consisted of the introduction of an epidural stimulation electrode via a $5-\mathrm{cm}$ midline incision with the patient in prone position after prophylactic administration of $1500 \mathrm{mg}$ of cefuroxim intravenously. The electrode was fixed with special clips. After placing the patient in a lateral position the electrode was connected with an internal pulse generator in the left lower anterior abdominal wall by a tunneled extension lead. The patient remained in the hospital for 24 hours after implantation and was given two additional doses of $750 \mathrm{mg}$ cefuroxim. Stimulation parameters used consisted of high frequency stimulation (rate $85 \mathrm{~Hz}$ ) with a pulse width of 210 microseconds. The pulse intensity was con- 
trolled by means of a patient programmer which allowed the patient to adjust the amplitude of stimulation from 0 to 10 Volts.

\section{Summary}

There is no gold standard for diagnosis of CRPS. Clinical history and physical examination form the cornerstones of the diagnostic process.

When conservative treatment with physical and medical treatment fails, multidisciplinary evaluation should follow. If there is no improvement in pain and dysfunction, sympathetic blockade should be performed. If this block is effective, it may be followed by repeated injections or RF treatment. If symptoms persist, a continuous epidural infusion, intermittent or continuous plexus brachialis block in combination with exercise therapy may be useful. If symptoms persist SCS after a successful trial stimulation period may yield positive results.

\section{Acknowledgements}

This review was performed within a knowledge consortium that integrates research on complex regional pain syndrome type 1; Trauma Related Neuronal Dysfunction (TREND). The project is supported by a Dutch Government grant (BSIK03016). This review was initially based on practice guidelines, written by Dutch and Flemish (Belgian) experts that are assembled in a handbook for the Dutch-speaking pain physicians. After translation, the manuscript was updated and edited in cooperation with U.S./International pain specialists.

The authors thank A. Lataster and the department of Anatomy and Embryology of the University Maastricht for the support and the supervision on the correct use of the nomina as well as the control of the anatomic illustrations. The help of José Geurts and Nicole Van den Hecke in coordinating the different versions of this manuscript was valuable. 


\section{References}

1. Guyatt G, Gutterman D, Baumann MH, Addrizzo-Harris D, Hylek EM, Phillips B, Raskob G, Lewis SZ, Schunemann $\mathrm{H}$ : Grading strength of recommendations and quality of evidence in clinical guidelines: report from an american college of chest physicians task force. Chest 2006; 129, 1: 174-81

2. van Kleef $M$, Mekhail $\mathrm{N}$, van Zundert J: Evidence-based guidelines for interventional pain medicine according to clinical diagnoses. Pain Pract 2009; 9, 4: 247-51

3. Veldman PH, Reynen HM, Arntz IE, Goris RJ: Signs and symptoms of reflex sympathetic dystrophy: prospective study of 829 patients. Lancet 1993; 342, 8878: 1012-6

4. Stanton-Hicks M, Janig W, Hassenbusch S, Haddox JD, Boas R, Wilson P: Reflex sympathetic dystrophy: changing concepts and taxonomy. Pain 1995; 63, 1: 127-33

5. Bruehl S, Harden RN, Galer BS, Saltz S, Backonja M, Stanton-Hicks M: Complex regional pain syndrome: are there distinct subtypes and sequential stages of the syndrome? Pain 2002; 95, 1-2: 11924

6. de Mos M, de Bruijn AG, Huygen FJ, Dieleman JP, Stricker BH, Sturkenboom MC: The incidence of complex regional pain syndrome: a population-based study. Pain 2007; 129, 1-2: 12-20

7. Sandroni $P$, Benrud-Larson LM, McClelland RL, Low PA: Complex regional pain syndrome type I: incidence and prevalence in Olmsted county, a population-based study. Pain 2003; 103, 1-2: 199207

8. Groeneweg JG, Huygen FJ, Heijmans-Antonissen C, Niehof S, Zijlstra FJ: Increased endothelin-1 and diminished nitric oxide levels in blister fluids of patients with intermediate cold type complex regional pain syndrome type 1. BMC Musculoskelet Disord 2006; 791

9. Birklein F, Schmelz M: Neuropeptides, neurogenic inflammation and complex regional pain syndrome (CRPS). Neurosci Lett 2008; 437, 3: 199-202

10. Oaklander AL, Fields $\mathrm{HL}$ : Is reflex sympathetic dystrophy/complex regional pain syndrome type I a small-fiber neuropathy? Ann Neurol 2009; 65, 6: 629-638

11. Gibbs GF, Drummond PD, Finch PM, Phillips JK: Unravelling the pathophysiology of complex regional pain syndrome: focus on sympathetically maintained pain. Clin Exp Pharmacol Physiol 2008; 35, 7: 717-24

12. de Mos M, Sturkenboom MC, Huygen FJ: Current understandings on complex regional pain syndrome. Pain Pract 2009; 9, 2: 86-99

13. Schurmann M, Zaspel J, Lohr P, Wizgall I, Tutic M, Manthey N, Steinborn M, Gradl G: Imaging in early posttraumatic complex regional pain syndrome: a comparison of diagnostic methods. Clin J Pain 2007; 23, 5: 449-57

14. Zyluk A: The usefulness of quantitative evaluation of three-phase scintigraphy in the diagnosis of post-traumatic reflex sympathetic dystrophy. J Hand Surg Br 1999; 24, 1: 16-21

15. Krumova EK, Frettloh J, Klauenberg S, Richter H, Wasner G, Maier C: Long-term skin temperature measurements - a practical diagnostic tool in complex regional pain syndrome. Pain 2008; 140, 1: 822

16. Perez RS, Zollinger PE, Dijkstra PU, Thomassen-Hilgersom IL, Zuurmond WW, Rosenbrand CJ, Geertzen JH: [Clinical practice guideline 'Complex regional pain syndrome type I']. Ned Tijdschr Geneeskd 2007; 151, 30: 1674-9

17. Merskey H, Bogduk N: Radicular Pain - Radicular Pain and Radiculopathy, Classification of chronic pain, 2 Edition. Seattle, Washington, IASP Press, 1994, pp 13-16

18. Harden RN, Bruehl S, Stanton-Hicks M, Wilson PR: Proposed new diagnostic criteria for complex regional pain syndrome. Pain Med 2007; 8, 4: 326-31

19. Bruehl S, Harden RN, Galer BS, Saltz S, Bertram M, Backonja M, Gayles R, Rudin N, Bhugra MK, Stanton-Hicks M: External validation of IASP diagnostic criteria for Complex Regional Pain Syndrome and proposed research diagnostic criteria. International Association for the Study of Pain. Pain 1999; 81, 1-2: 147-54 
20. Oerlemans HM, Oostendorp RA, de Boo T, Goris RJ: Pain and reduced mobility in complex regional pain syndrome I: outcome of a prospective randomised controlled clinical trial of adjuvant physical therapy versus occupational therapy. Pain 1999; 83, 1: 77-83

21. Moseley GL: Graded motor imagery is effective for long-standing complex regional pain syndrome: a randomised controlled trial. Pain 2004; 108, 1-2: 192-8

22. Daly $A E$, Bialocerkowski $A E$ : Does evidence support physiotherapy management of adult Complex Regional Pain Syndrome Type One? A systematic review. Eur J Pain 2009; 13, 4: 339-53

23. Ezendam D, Bongers RM, Jannink MJ: Systematic review of the effectiveness of mirror therapy in upper extremity function. Disabil Rehabil 20091-15

24. Rico H, Merono E, Gomez-Castresana F, Torrubiano J, Espinos D, Diaz P: Scintigraphic evaluation of reflex sympathetic dystrophy: comparative study of the course of the disease under two therapeutic regimens. Clin Rheumatol 1987; 6, 2: 233-7

25. Zuurmond WW, Langendijk PN, Bezemer PD, Brink HE, de Lange JJ, van loenen AC: Treatment of acute reflex sympathetic dystrophy with DMSO 50\% in a fatty cream. Acta Anaesthesiol Scand 1996; 40, 3: 364-7

26. Perez RS, Zuurmond WW, Bezemer PD, Kuik DJ, van Loenen AC, de Lange JJ, Zuidhof AJ: The treatment of complex regional pain syndrome type I with free radical scavengers: a randomized controlled study. Pain 2003; 102, 3: 297-307

27. Perez RS, Pragt E, Geurts J, Zuurmond WW, Patijn J, van Kleef M: Treatment of patients with complex regional pain syndrome type I with mannitol: a prospective, randomized, placebo-controlled, double-blinded study. J Pain 2008; 9, 8: 678-86

28. Manicourt DH, Brasseur JP, Boutsen Y, Depreseux G, Devogelaer JP: Role of alendronate in therapy for posttraumatic complex regional pain syndrome type I of the lower extremity. Arthritis Rheum 2004; 50, 11: 3690-7

29. Robinson JN, Sandom J, Chapman PT: Efficacy of pamidronate in complex regional pain syndrome type I. Pain Med 2004; 5, 3: 276-80

30. Kingery WS: A critical review of controlled clinical trials for peripheral neuropathic pain and complex regional pain syndromes. Pain 1997; 73, 2: 123-39

31. Christensen K, Jensen EM, Noer I: The reflex dystrophy syndrome response to treatment with systemic corticosteroids. Acta Chir Scand 1982; 148, 8: 653-5

32. Kalita J, Vajpayee A, Misra UK: Comparison of prednisolone with piroxicam in complex regional pain syndrome following stroke: a randomized controlled trial. Qjm 2006; 99, 2: 89-95

33. Rowbotham MC: Pharmacologic management of complex regional pain syndrome. Clin J Pain 2006; 22, 5: 425-9

34. Harke H, Gretenkort P, Ladleif HU, Rahman S, Harke O: The response of neuropathic pain and pain in complex regional pain syndrome I to carbamazepine and sustained-release morphine in patients pretreated with spinal cord stimulation: a double-blinded randomized study. Anesth Analg 2001; 92, 2: 488-95

35. van de Vusse AC, Stomp-van den Berg SG, Kessels AH, Weber WE: Randomised controlled trial of gabapentin in Complex Regional Pain Syndrome type 1 [ISRCTN84121379]. BMC Neurol 2004; 413

36. Correll GE, Maleki J, Gracely EJ, Muir JJ, Harbut RE: Subanesthetic ketamine infusion therapy: a retrospective analysis of a novel therapeutic approach to complex regional pain syndrome. Pain Med 2004; 5, 3: 263-75

37. Sigtermans MJ, van Hilten JJ, Bauer MC, Arbous MS, Marinus J, Sarton EY, Dahan A: Ketamine produces effective and long-term pain relief in patients with Complex Regional Pain Syndrome Type 1. Pain 2009; 145, 3: 304-11

38. Schwartzman RJ, Alexander GM, Grothusen JR, Paylor T, Reichenberger E, Perreault M: Outpatient intravenous ketamine for the treatment of complex regional pain syndrome: a double-blind placebo controlled study. Pain 2009; 147, 1-3: 107-15 
39. Muizelaar JP, Kleyer M, Hertogs IA, DeLange DC: Complex regional pain syndrome (reflex sympathetic dystrophy and causalgia): management with the calcium channel blocker nifedipine and/or the alpha-sympathetic blocker phenoxybenzamine in 59 patients. Clin Neurol Neurosurg 1997; 99, 1: 26-30

40. Inchiosa MA, Jr., Kizelshteyn G: Treatment of complex regional pain syndrome type I with oral phenoxybenzamine: rationale and case reports. Pain Pract 2008; 8, 2: 125-32

41. Hannington-Kiff JG: Intravenous regional sympathetic block with guanethidine. Lancet 1974; 1, 7865: 1019-20

42. Field J, Monk C, Atkins RM: Objective improvements in algodystrophy following regional intravenous guanethidine. J Hand Surg Br 1993; 18, 3: 339-42

43. Paraskevas KI, Michaloglou AA, Briana DD, Samara M: Treatment of complex regional pain syndrome type I of the hand with a series of intravenous regional sympathetic blocks with guanethidine and lidocaine. Clin Rheumatol 2006; 25, 5: 687-93

44. Kaplan R, Claudio M, Kepes E, Gu XF: Intravenous guanethidine in patients with reflex sympathetic dystrophy. Acta Anaesthesiol Scand 1996; 40, 10: 1216-22

45. Geertzen JH, de Bruijn H, de Bruijn-Kofman AT, Arendzen JH: Reflex sympathetic dystrophy: early treatment and psychological aspects. Arch Phys Med Rehabil 1994; 75, 4: 442-6

46. Jadad AR, Carroll D, Glynn CJ, McQuay HJ: Intravenous regional sympathetic blockade for pain relief in reflex sympathetic dystrophy: a systematic review and a randomized, double-blind crossover study. J Pain Symptom Manage 1995; 10, 1: 13-20

47. Ramamurthy S, Hoffman J: Intravenous regional guanethidine in the treatment of reflex sympathetic dystrophy/causalgia: a randomized, double-blind study. Guanethidine Study Group. Anesth Analg 1995; 81, 4: 718-23

48. Livingstone JA, Atkins RM: Intravenous regional guanethidine blockade in the treatment of posttraumatic complex regional pain syndrome type 1 (algodystrophy) of the hand. $J$ Bone Joint Surg $\mathrm{Br}$ 2002; 84, 3: 380-6

49. Taskaynatan MA, Ozgul A, Tan AK, Dincer K, Kalyon TA: Bier block with methylprednisolone and lidocaine in CRPS type I: a randomized, double-blinded, placebo-controlled study. Reg Anesth Pain Med 2004; 29, 5: 408-12

50. Connelly NR, Reuben S, Brull SJ: Intravenous regional anesthesia with ketorolac-lidocaine for the management of sympathetically-mediated pain. Yale J Biol Med 1995; 68, 3-4: 95-9

51. Hanna MH, Peat SJ: Ketanserin in reflex sympathetic dystrophy. A double-blind placebo controlled cross-over trial. Pain 1989; 38, 2: 145-50

52. Day M: Sympathetic blocks: the evidence. Pain Pract 2008; 8, 2: 98-109

53. Hogan $\mathrm{QH}$, Erickson SJ: MR imaging of the stellate ganglion: normal appearance. AJR Am J Roentgenol 1992; 158, 3: 655-9

54. Linson MA, Leffert R, Todd DP: The treatment of upper extremity reflex sympathetic dystrophy with prolonged continuous stellate ganglion blockade. J Hand Surg Am 1983; 8, 2: 153-9

55. Todd DP: Prolonged stellate block in treatment of reflex sympathetic dystrophy. Agressologie 1991; 32, 5 Spec No: 281-2

56. Karakurum G, Pirbudak L, Oner U, Gulec A, Karadasli H, Satana T: Sympathetic blockade and amitriptyline in the treatment of reflex sympathetic dystrophy. Int J Clin Pract 2003; 57, 7: 585-7

57. Ackerman WE, Zhang JM: Efficacy of stellate ganglion blockade for the management of type $1 \mathrm{com}$ plex regional pain syndrome. South Med J 2006; 99, 10: 1084-8

58. Glynn C, Casale R: Morphine injected around the stellate ganglion does not modulate the sympathetic nervous system nor does it provide pain relief. Pain 1993; 53, 1: 33-7

59. Forouzanfar $T$, van Kleef $M$, Weber WE: Radiofrequency lesions of the stellate ganglion in chronic pain syndromes: retrospective analysis of clinical efficacy in 86 patients. Clin J Pain 2000; 16, 2: 1648

60. Sprague RS, Ramamurthy S: Identification of the anterior psoas sheath as a landmark for lumbar sympathetic block. Reg Anesth 1990; 15, 5: 253-5 
61. Redman DR, Robinson PN, Al-Kutoubi MA: Computerised tomography guided lumbar sympathectomy. Anaesthesia 1986; 41, 1: 39-41

62. Konig CW, Schott UG, Pereira PL, Trubenbach J, Schneider W, Claussen CD, Duda SH: MR-guided lumbar sympathicolysis. Eur Radiol 2002; 12, 6: 1388-93

63. Kirvela O, Svedstrom E, Lundbom N: Ultrasonic guidance of lumbar sympathetic and celiac plexus block: a new technique. Reg Anesth 1992; 17, 1: 43-6

64. Cameron HU, Park YS, Krestow M: Reflex sympathetic dystrophy following total knee replacement. Contemp Orthop 1994; 29, 4: 279-81

65. Tran KM, Frank SM, Raja SN, El-Rahmany HK, Kim L, Vu B: Lumbar sympathetic block for sympathetically maintained pain: changes in cutaneous temperatures and pain perception. Anesth Analg 2000; 90, 6: 1396-401

66. Rocco AG: Radiofrequency lumbar sympatholysis. The evolution of a technique for managing sympathetically maintained pain. Reg Anesth 1995; 20, 1: 3-12

67. Haynsworth RF, Jr., Noe CE: Percutaneous lumbar sympathectomy: a comparison of radiofrequency denervation versus phenol neurolysis. Anesthesiology 1991; 74, 3: 459-63

68. Manjunath PS, Jayalakshmi TS, Dureja GP, Prevost AT: Management of lower limb complex regional pain syndrome type 1: an evaluation of percutaneous radiofrequency thermal lumbar sympathectomy versus phenol lumbar sympathetic neurolysis--a pilot study. Anesth Analg 2008; 106, 2: 647-9, table of contents

69. Price DD, Long S, Wilsey B, Rafii A: Analysis of peak magnitude and duration of analgesia produced by local anesthetics injected into sympathetic ganglia of complex regional pain syndrome patients. Clin $\mathrm{J}$ Pain 1998; 14, 3: 216-26

70. Hartrick CT, Kovan JP, Naismith P: Outcome prediction following sympathetic block for complex regional pain syndrome. Pain Pract 2004; 4, 3: 222-8

71. Carroll I, Clark JD, Mackey S: Sympathetic block with botulinum toxin to treat complex regional pain syndrome. Ann Neurol 2009; 65, 3: 348-51

72. Robaina FJ, Rodriguez JL, de Vera JA, Martin MA: Transcutaneous electrical nerve stimulation and spinal cord stimulation for pain relief in reflex sympathetic dystrophy. Stereotact Funct Neurosurg 1989; 52, 1: 53-62

73. Nnoaham KE, Kumbang J: Transcutaneous electrical nerve stimulation (TENS) for chronic pain. Cochrane Database Syst Rev 2008, 3: CD003222

74. Cruccu G, Aziz TZ, Garcia-Larrea L, Hansson P, Jensen TS, Lefaucheur JP, Simpson BA, Taylor RS: EFNS guidelines on neurostimulation therapy for neuropathic pain. Eur J Neurol 2007; 14, 9: 952-70

75. Kemler MA, Barendse GA, van Kleef M, de Vet HC, Rijks CP, Furnee CA, van den Wildenberg FA: Spinal cord stimulation in patients with chronic reflex sympathetic dystrophy. N Engl J Med 2000; 343, 9: 618-24

76. Kemler MA, De Vet HC, Barendse GA, Van Den Wildenberg FA, Van Kleef M: The effect of spinal cord stimulation in patients with chronic reflex sympathetic dystrophy: two years' follow-up of the randomized controlled trial. Ann Neurol 2004; 55, 1: 13-8

77. Forouzanfar T, Kemler MA, Weber WE, Kessels AG, van Kleef M: Spinal cord stimulation in complex regional pain syndrome: cervical and lumbar devices are comparably effective. Br J Anaesth 2004; 92, 3: 348-53

78. Kemler MA, de Vet HC, Barendse GA, van den Wildenberg FA, van Kleef M: Effect of spinal cord stimulation for chronic complex regional pain syndrome Type I: five-year final follow-up of patients in a randomized controlled trial. J Neurosurg 2008; 108, 2: 292-8

79. Simpson EL, Duenas A, Holmes MW, Papaioannou D, Chilcott J: Spinal cord stimulation for chronic pain of neuropathic or ischaemic origin: systematic review and economic evaluation. Health Technol Assess 2009; 13, 17: iii, ix-x, 1-154

80. Hassenbusch SJ, Stanton-Hicks M, Schoppa D, Walsh JG, Covington EC: Long-term results of peripheral nerve stimulation for reflex sympathetic dystrophy. J Neurosurg 1996; 84, 3: 415-23 
81. Buschmann D, Oppel F: [Peripheral nerve stimulation for pain relief in CRPS II and phantom-limb pain]. Schmerz 1999; 13, 2: 113-20

82. Mobbs RJ, Nair S, Blum P: Peripheral nerve stimulation for the treatment of chronic pain. J Clin Neurosci 2007; 14, 3: 216-21; discussion 222-3

83. Gibbons JJ, Wilson PR, Lamer TJ, Elliott BA: Interscalene blocks for chronic upper extremity pain. Clin J Pain 1992; 8, 3: 264-9

84. Ribbers GM, Geurts AC, Rijken RA, Kerkkamp HE: Axillary brachial plexus blockade for the reflex sympathetic dystrophy syndrome. Int J Rehabil Res 1997; 20, 4: 371-80

85. Cooper DE, DeLee JC, Ramamurthy S: Reflex sympathetic dystrophy of the knee. Treatment using continuous epidural anesthesia. J Bone Joint Surg Am 1989; 71, 3: 365-9

86. Rauck RL, Eisenach JC, Jackson K, Young LD, Southern J: Epidural clonidine treatment for refractory reflex sympathetic dystrophy. Anesthesiology 1993; 79, 6: 1163-9; discussion 27A

87. Buchheit T, Crews JC: Lateral cervical epidural catheter placement for continuous unilateral upper extremity analgesia and sympathetic block. Reg Anesth Pain Med 2000; 25, 3: 313-7

88. Moufawad S, Malak O, Mekhail NA: Epidural infusion of opiates and local anesthetics for Complex Regional Pain Syndrome. Pain Pract 2002; 2, 2: 81-6

89. Kanoff RB: Intraspinal delivery of opiates by an implantable, programmable pump in patients with chronic, intractable pain of nonmalignant origin. J Am Osteopath Assoc 1994; 94, 6: 487-93

90. Lundborg C, Dahm P, Nitescu P, Appelgren L, Curelaru I: Clinical experience using intrathecal (IT) bupivacaine infusion in three patients with complex regional pain syndrome type I (CRPS-I). Acta Anaesthesiol Scand 1999; 43, 6: 667-78

91. van Rijn MA, Munts AG, Marinus J, Voormolen JH, de Boer KS, Teepe-Twiss IM, van Dasselaar NT, Delhaas EM, van Hilten JJ: Intrathecal baclofen for dystonia of complex regional pain syndrome. Pain 2009; 143, 1-2: 41-7

92. Kapural L, Lokey K, Leong MS, Fiekowsky S, Stanton-Hicks M, Sapienza-Crawford AJ, Webster LR: Intrathecal ziconotide for complex regional pain syndrome: seven case reports. Pain Pract 2009; 9, 4: 296-303

93. Wulf H, Maier C: [Complications and side effects of stellate ganglion blockade. Results of a questionnaire survey]. Anaesthesist 1992; 41, 3: 146-51

94. Ohno K, Oshita S: Transdiscal lumbar sympathetic block: a new technique for a chemical sympathectomy. Anesth Analg 1997; 85, 6: 1312-6

95. Turner JA, Loeser JD, Deyo RA, Sanders SB: Spinal cord stimulation for patients with failed back surgery syndrome or complex regional pain syndrome: a systematic review of effectiveness and complications. Pain 2004; 108, 1-2: 137-47

96. Ishizuka $\mathrm{K}$, Oaklander $\mathrm{AL}$, Chiocca EA: A retrospective analysis of reasons for reoperation following initially successful peripheral nerve stimulation. J Neurosurg 2007; 106, 3: 388-90

97. Hassenbusch SJ: Epidural and subarachnoid administration of opioids for nonmalignant pain: technical issues, current approaches and novel treatments. J Pain Symptom Manage 1996; 11, 6: 357-62

98. Carron H, Litwiller R: Stellate ganglion block. Anesth Analg 1975; 54, 5: 567-70

99. Abdi S, Zhou Y, Patel N, Saini B, Nelson J: A new and easy technique to block the stellate ganglion. Pain Physician 2004; 7, 3: 327-31

100.Erickson SJ, Hogan QH: CT-guided injection of the stellate ganglion: description of technique and efficacy of sympathetic blockade. Radiology 1993; 188, 3: 707-9

101.Narouze S, Vydyanathan A, Patel N: Ultrasound-guided stellate ganglion block successfully prevented esophageal puncture. Pain Physician 2007; 10, 6: 747-52

102. Hatangdi VS, Boas RA: Lumbar sympathectomy: a single needle technique. Br J Anaesth 1985; 57, 3: 285-9 


\section{CHAPTER III}

\section{Predictors of Pain Relieving Response to Sympathetic Blockade in Complex Regional Pain Syndrome type 1}

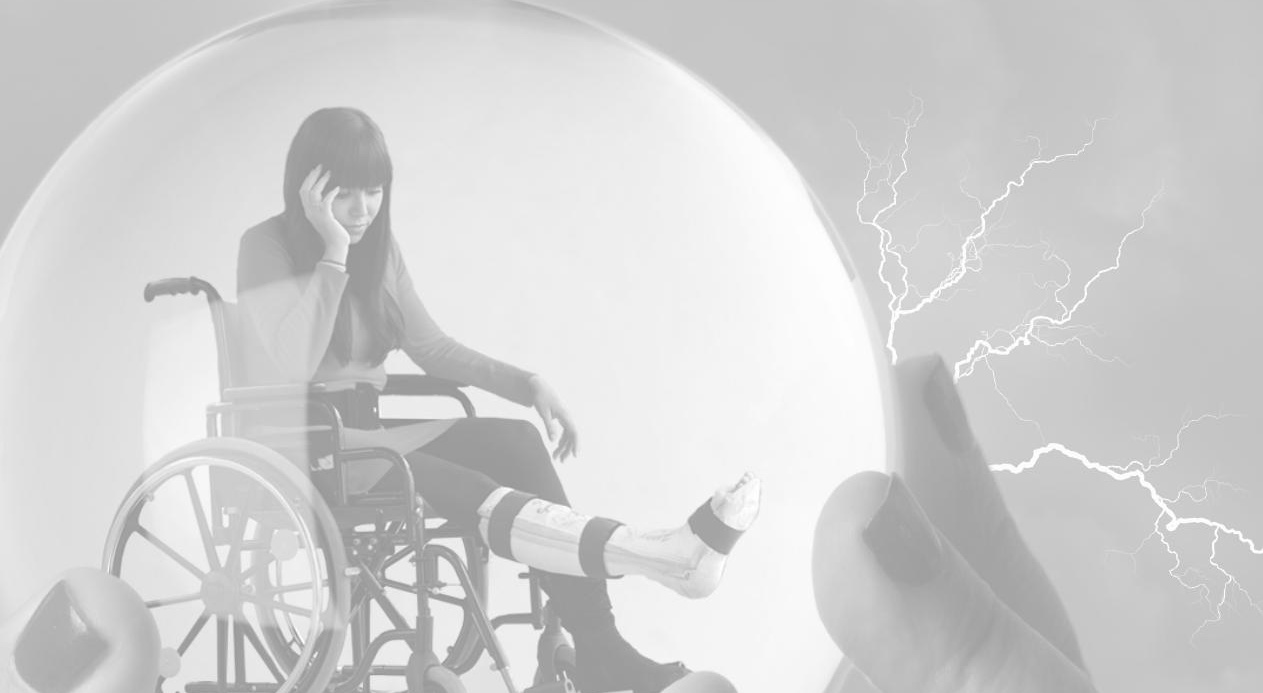

Frank van Eijs MD, José Geurts MSc, Maarten van Kleef MD, PhD, Catharina G Faber MD, PhD, Roberto S Perez, PhD, Alfons G.H. Kessels MD, MSc, Jan Van Zundert MD, $\mathrm{PhD}$

Anesthesiology: in press 


\begin{abstract}
Background: Sympathetic blockade with local anesthetics is frequently used in the management of complex regional pain syndrome type 1(CRPS-1), with variable degree of success in pain relief. The current study investigated which signs or symptoms of CRPS-1 could be predictive for the outcome. The incidence of side effects and complications of sympathetic blockade was also prospectively determined.
\end{abstract}

Methods: Prospective observational study in 49 patients with CRPS-1 in one extremity only and of less than one year duration with severe pain and persistent functional impairment, not responding to standard treatment with medication and physical therapy.

Results: Fifteen patients (31\%) were good or moderate responders. Response rate was not different in patient groups with cold or warm type CRPS-1, or in those with more or less than $1.5^{\circ} \mathrm{C}$ differential increase in skin temperature after sympathetic blockade. Allodynia and hypoesthesia were negative predictors for treatment success in CRPS-1. There were no symptoms or signs of CRPS-1 that positively predicted treatment success. A majority of patients (84\%) suffered transient side effects such as headache, dysphagia, increased pain, backache, nausea, blurred vision, groin pain, hoarseness and hematoma at the puncture site. No major complications were reported.

Conclusions: The presence of allodynia and hypoesthesia are negative predictors for treatment success. The selection of sympathetic blockade as treatment for CRPS-1 should be carefully balanced between potential success and side effect ratio. The procedure is as likely to cause a transient increase in pain as there is the likelihood of pain decrease. Patients should be informed accordingly. 


\section{Introduction}

The use of a sympathetic block (SB) for diagnostic and therapeutic purposes in the management of complex regional pain syndrome type one (CRPS-1) is based on earlier hypotheses concerning the involvement of the sympathetic nervous system in the pathophysiological mechanism of this disease. ${ }^{1}$ The nociceptive afferent input was believed to cause hyperactive spinal neuron activity, which stimulated the sympathetic neurons to induce arterial spasms, ischemia and edema. ${ }^{2}$

In certain cases of CRPS-1, the pain may be due to a sympathetically maintained form of pain which is classically defined as pain relieved by SB with local anesthetics $^{3,4}$ Consequently, SB is frequently performed for the management of CRPS. Current treatment guidelines for CRPS-1 limit the role of SB to selected cases, which are refractory to conservative treatment with pharmacological therapy and physical rehabilitation. ${ }^{5,6}$ When a single sympathetic block with a local anesthetic (diagnostic block) proves successful (50\% or more pain reduction for the duration of action of the local anesthetic), repeated blocks or a more definitive sympathetic blockade using radiofrequency lesions may be considered. ${ }^{6,7}$ A review of the literature shows that SB with a local anesthetic in patients with CRPS resulted in pain relief in about one third of the patients. ${ }^{8}$ If one could predict which patients would benefit from $\mathrm{SB}$, this would assist physicians in patient selection and reduce the number of unsuccessful invasive sympathetic block procedures along with their potential complications and side effects. Signs such as mechanical allodynia, temperature asymmetry and color changes have been related to a positive response to sympathetic blockade. ${ }^{7,9}$ Dynamic mechanical allodynia predicted a pain relieving response to SB in one study, ${ }^{9}$ but failed to predict pain relief in another study. ${ }^{10}$ Some authors believe that patients with primarily cold CRPS-I, who do not respond adequately to vasodilating medication, may be good candidates for percutaneous sympathetic blockade using local anesthetics, although this was never proven in a prospective study $^{11}$ In order to investigate possible predictors of successful sympathetic blockade in CRPS-1, we conducted a prospective observational study in which we investigated if easily obtainable signs and symptoms like hyperalgesia and allodynia, hypoesthesia and hyperesthesia, warm or cold subtype, abnormal skin coloring, abnormal extremity sweating, edema, and abnormal motor signs and symptoms could predict the pain reducing effect of SB in patients with CRPS-1 of less than one year duration. Although serious complications such as pneumothorax, convulsions and severe hypotension and hypoventilation due to subarachnoid block are known to occur occasionally, ${ }^{12}$ there is a lack of studies assessing possible side effects. ${ }^{8}$ Therefore, the second aim of the study was to determine the number and type of adverse events following sympathetic blocks with local anesthetics. 


\section{Materials and methods}

\section{Patients}

In this prospective observational study we screened all consecutive patients with a possible diagnosis of CRPS, referred to the pain management centers of Maastricht and Tilburg in the Netherlands. Patients were eligible for participation in the study if they had CRPS-1 according to the criteria established by the International Association for the Study of Pain (IASP) which are: ${ }^{13}$ (1) The presence of continuous pain, allodynia or hyperalgesia disproportional to the inciting event; (2) evidence at some time of edema, abnormal skin blood flow and sudomotor abnormalities in the region of pain; (3) other causes of pain or dysfunction are excluded.

Other inclusion criteria were: disease duration less than one year after the initiating trauma; signs and symptoms in one extremity only; age 18 years or older; able to follow written and verbal instructions; no pain reduction with persistent functional impairment after initial standard therapy (see below); mean Numerical pain Rating Score of five or more on a scale from 0 to 10 (with 0 meaning no pain at all and 10 meaning the worst imaginable pain) assessed according to Jensen. ${ }^{14}$ Exclusion criteria were: pregnancy, coagulation disorders, general infection, fever or local infection at the puncture site, drug or alcohol abuse, diabetic polyneuropathy or any other disease that may account for signs and symptoms mimicking CRPS. The study was approved by the medical ethics committees of the Maastricht University Medical Centre and the St. Elisabeth Hospital in Tilburg, the Netherlands. All patients gave written informed consent.

\section{Standard therapy}

According to CRPS treatment guidelines ${ }^{15}$ and before offering SB as treatment, all patients received physical therapy aimed at active mobilization, according to a fixed protocol which consisted of graded exercises aimed at restoring strength, mobility and function of the affected extremity. Physical therapy was applied twice a week with a minimum duration of 30 minutes. Exercises were adjusted so that an increase of pain during and after exercise returned to pre-session levels within 24 hours. ${ }^{16}$ Topical application of the free radical scavenger dimethyl sulfoxide $50 \%$ three to five times daily was given as anti-inflammatory therapy. The physical therapy was supplemented with oral analgesic medication such as non-steroidal anti-inflammatory agents, acetaminophen and tramadol. If insufficient pain relief was obtained after at least three weeks of the analgesic medication, gabapentin was given in doses up to $1800 \mathrm{mg}$ daily. Insufficient pain relief was defined as an unchanged Numerical pain Rating Score or maximal one point Numerical pain Rating Score improvement. If insufficient pain relief was obtained after at least three weeks of gabapentin, 
transcutaneous electrical nerve stimulation therapy was applied for at least two weeks. After this, if there still was insufficient pain relief a sympathetic blockade, i.e. stellate ganglion block for the upper extremity and lumbar sympathetic block for the lower extremity, was proposed.

\section{Sympathetic blocks}

During the procedure and for a period of at least 30 minutes after the procedure, patients were continuously monitored by pulse oximetry and an automated noninvasive blood pressure monitor. Just before performing the SB an intravenous line was placed for safety reasons. All SB's were performed by staff anesthesiologists with at least ten years' experience in interventional pain management. A gold standard for defining an adequate block remains undefined. Therefore we considered the SB's correctly performed if there was radioscopically confirmed adequate craniocaudal contrast dye outline over the prevertebral sympathetic chain at the C6C7-Th1 level for the upper limb and over the prevertebral sympathetic chain at the L3-L4-L5 level for the lower limb. Injection of local anesthetic was given only after radiological confirmation of this adequate craniocaudal contrast dye outline.

Stellate ganglion block on the cervical sympathetic chain was performed at the vertebral level $66-7$, using the anterior paratracheal approach with fluoroscopic guidance. ${ }^{6}$ The patient was placed in supine position with the head slightly hyperextended. The height of C6-7 was determined by fluoroscopy with the C-arm in antero-posterior position and adjusted until the vertebral end plates were viewed perpendicular. After local disinfection the skin was anesthetized using $1 \%$ lidocaine and a $60 \mathrm{~mm}, 20$ gauge radiocontrast needle was inserted the junction of the processus transversus and the corresponding $\mathrm{C} 6$ or $\mathrm{C} 7$ corpus vertebralis. After contact with the bone, oblique projection is used to check if the needle is anterior to the foramen intervertebrale. If the needle was past this level, no contact was made with the base of the processus transversus and the needle was repositioned. Once the needle was in the correct position a small amount $(0.5-1 \mathrm{ml})$ of contrast dye was injected to visualize and prevent potential intravascular injection. After obtaining adequate craniocaudal contrast dye spread, an injection of $10 \mathrm{ml}$ of bupivacaïne $0.25 \%$ was given. This volume of local anesthetic was chosen because the objective was to test the standard SB technique and this amount generally reflects common clinical practice.

Lumbar sympathetic block was performed with the patient placed in prone posi-

tion. ${ }^{6}$ The C-arm fluoroscope was used to identify the level L2-L4 and adjusted until the vertebral end plates are viewed perpendicular. Then the $\mathrm{C}$-arm was turned laterally until the distal end of the processus transversus projects in line with the lateral edge of the corresponding L2-L4 corpora vertebrae. After local disinfection the skin was anesthetized using $1 \%$ lidocaine and a $15 \mathrm{~cm}, 20$ gauge needle was inserted 
using tunnel view until the front of the vertebra was reached. The lateral projection was used to check if the needle did not pass the anterior side of the corpus vertebrae. The anterior posterior projection was used to check if the needle point projected over the facet joint of the spinal column. The truncus sympathicus was reached by a single needle approach at the L3 corpus vertebrae. After obtaining adequate craniocaudal contrast dye outline, $10 \mathrm{ml}$ of bupivacaine $0.25 \%$ was injected.

\section{Variables}

Average week spontaneous pain scores were derived from a numerical rating scale from 0 to 10, assessed three times daily on 5 consecutive days, at home at baseline, immediately prior to SB and at 30 minutes, 2, 4, 6 and 8 hours after the SB and three times daily for a period of one week after SB.

Skin temperature was measured in degrees Celsius (으) using a Genius First Temp infrared thermometer set on "surface" in a room maintained at $20-22{ }^{\circ} \mathrm{C}$ and after an adjustment period of 10 minutes. Measurements were made at the affected and the contra lateral extremity. The dorsal aspects of the hands or feet were assessed at five standardized points. The mean temperature was calculated of these five measurements. Temperature measurements were performed at the outpatient clinic, at baseline before the SB and at 30 minutes after the SB. This allowed us to measure the relative increase in skin temperature as a measure of completeness of the SB. ${ }^{17}$

Treatment success was defined as pain relief of $\geq 50 \%$ for at least 6 hours. Patients who had pain reduction of $50 \%$ for at least 6 hours or more were considered moderate responders. Patients who had pain relief of at least $50 \%$ for $2-7$ days were considered good responders.

To make subgroup phenotype analysis possible, evaluations were performed according to a strict measurement protocol, distinguishing symptoms reported by patients and signs established by the investigators. Assessment of signs was performed in a clinical fashion (i.e., left-right comparisons, palpation, provocation tests. The features were registered as dichotomous variables (present-absent). ${ }^{18}$ A standardized symptom checklist was used at the outpatient clinic to register relevant signs and symptoms associated with CRPS-1 within one of the four different categories according to the factor structure proposed by Harden and Bruehl. Patients with CRPS-1 may report symptoms or display signs in four different categories: sensory, vasomotor, sudomotor/edema and motor/trophic. ${ }^{19,20}$

The symptoms were assessed by history taking and the signs were objectively measured and observed by the physician. In the sensory category hypoesthesia and hyperesthesia signs and allodynia were assessed by gently stroking the skin with a cotton swab. If this caused pain the patient was considered to have allodynia. Hy- 
peralgesia sign was assessed by means of blunt pinprick. If this caused more pain compared to the contralateral side hyperalgesia was considered present. In the vasomotor category, skin color asymmetry existence (blue or red discoloration) was observed and skin temperature asymmetry was assessed by infrared thermometry. In the edema/sudomotor category, the edema and sweating asymmetry were assessed by history taking and observation. In the motor/trophic category, the reduced range of motion, muscle weakness of the involved limb, tremor, myoclonus, bradykinesia and trophic abnormalities (i.e. of hair, skin and nails) were also assessed by history taking and observation.

\section{Statistical analysis}

The frequency of occurrence at baseline of the different possible predictors of outcome was determined in the successfully (50\% pain relief) and in the nonsuccessfully treated group. We performed an intention to treat analysis based on technically correctly performed SB as confirmed by C-arm radioscopy. We also did a subgroup analysis of patients that experienced a relative increase in skin temperature of at least $1.5^{\circ}$ Celsius over the contralateral side since some authors consider this amount of temperature increase sufficient evidence of a blockade of the sympathetic nervous system, even though not all sympathetic function may be abolished. ${ }^{17,21,22}$ Additionally, we examined if a moderately important pain decrease of $30 \%$ or more for minimally 2 days after the intervention, would influence the predictor finding in subgroup analysis. ${ }^{23}$ Change in skin temperature versus change in pain intensity was visualized with a scatter plot, using different symbols to indicate the responder and non-responder patients.

For each patient in the current study, the number of CRPS characteristics present was calculated within four sign and four symptom categories (sensory, vasomotor, sudomotor, mototrophic). ${ }^{24}$ The frequency and duration (in days) of side effects was established and tabulated for stellate ganglion and lumbar sympathetic blockade separately.

Because of different total numbers of signs and symptoms in each category, standardized scores ( $Z$ scores) for each of these eight categories were derived. These Z-scores were used in the univariate logistic regression analysis. The predictive performance of the four symptom and signs categories, age, gender, localization of the disease, precipitating event, disease duration, and all assessed symptoms and signs of CRPS-I individually, were evaluated with an univariate regression analysis or Chi Square analysis. Two-tailed $p$ values of less than 0.05 were considered significant.

The model building was done according to Hosmer and Lemeshow. ${ }^{25}$ To judge the importance of the variables in the model, variables with a $p$ value of $<0.10$ were considered as a candidate in a multivariate logistic regression model with a forward 
stepwise procedure. Compared with Hosmer and Lemeshow's suggestion ( $p$ value < $0.25)$, this P-value was more conservatively chosen because of the relative small sample size of responder patients. The multivariate logistic regression with forward stepwise procedure entered only variables with $\mathrm{p}$ values of $<0.05$.

The predicted probability of the multivariate regression analysis was used to construct a receiver operating characteristic curve and calculate the area under the curve. The area under the curve is indicative for the discriminative ability where 0.5 indicates no discrimination and an area under the curve of 1.0 indicates perfect discrimination. ${ }^{26}$ We used a bootstrapping procedure to adjust for over optimism in model performance. ${ }^{26-28}$ Bootstrap samples were drawn with replacement $(n=200)$ from the full data set and the area under the curve of these data sets were averaged. Analyses were performed with the Statistical Package for the Social Sciences, version 15 (SPSS Inc., Chicago, II). The bootstrap procedure and univariate regression analysis was performed with STATA/SE version 11.1 (StataCorp LP, College Station, Texas).

\section{Results}

\section{Study population}

The source population comprised of 147 patients with presumed CRPS, referred between June 2005 and October 2008 to the pain management centers of Maastricht and Tilburg in the Netherlands. One hundred and two patients fulfilled the inclusion criteria for this study. These 102 patients had CRPS-I in one extremity with disease duration of less than 12 months (mean duration 17 weeks, range 2-50 weeks). Of these 102 patients, 49 improved with medication and physical therapy and 49 patients provided informed consent for the SB and completed the study. The 49 patients, improved with conservative treatment, and four patients who refused SB were excluded from this study (Figure 1). 


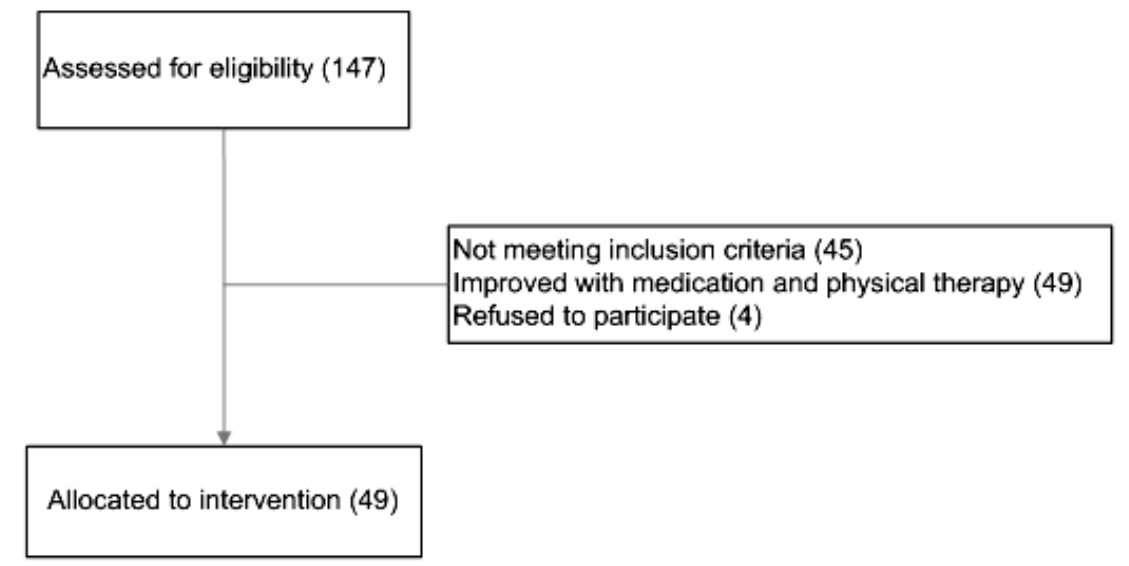

Figure 1: Flow chart of patient flow through the study

Table 1 shows the baseline variables of SB treated patients. Mean age of the participants was 44.9 (SD 12.1) years range 18-71, and $76 \%$ was female. The mean time since CRPS onset (initial injury) and the SB treatment was 233 (SD 84) days.

\section{Symptoms and signs of CRPS-I}

All patients fulfilled the IASP criteria, 90\% the Budapest clinical and $76 \%$ fulfilled the Budapest research criteria. $^{19,20,29}$

Table 1: Baseline demographics and characteristics

\begin{tabular}{|c|c|c|c|}
\hline Characteristics & & $\mathrm{N}$ & $\%$ \\
\hline Total & & 49 & \\
\hline Age & Mean (SD) 44.9(12.1) & & \\
\hline Disease duration in days & Mean (SD) 233 (84) & & \\
\hline Male gender & & 12 & 24 \\
\hline \multicolumn{4}{|l|}{ CRPS-1 location: } \\
\hline Lower extremity & & 27 & 55 \\
\hline Upper extremity & & 22 & 45 \\
\hline Left side & & 26 & 53 \\
\hline Right side & & 23 & 47 \\
\hline \multicolumn{4}{|l|}{ Precipitating event } \\
\hline None & & 13 & 26 \\
\hline Fracture, sprain & & 19 & 39 \\
\hline Surgery & & 14 & 29 \\
\hline Other & & 3 & 6 \\
\hline \multicolumn{4}{|l|}{ CRPS- 1 criteria } \\
\hline IASP & & 49 & 100 \\
\hline Budapest clinical I & & 44 & 90 \\
\hline Budapest research & & 37 & 76 \\
\hline
\end{tabular}

CRPS-1: complex regional pain syndrome type 1, IASP: International association for the study of pain 


\section{Outcome}

The 49 evaluated patients had radioscopically confirmed adequate craniocaudal contrast dye spread over the prevertebral sympathetic chain. All these SB were considered to be technically correctly performed. As shown in table 2 fifteen patients $(15 / 49,31 \%)$ were successfully treated with SB. Of these, ten patients were good responders and five were moderate responders. In 34 patients the SB did not result in pain relief. Table 3 shows that thirty-three $(33 / 49,67 \%)$ patients had a relative skin temperature increase of at least 1.5 ㅇ C after SB. Among the 33\% that did not show a temperature increase, there were still $37 \%$ responders. The scatter plot which visualizes change in skin temperature versus pain relief shows that skin temperature increase after SB did not correlate with pain decrease in our study (Figure 2).

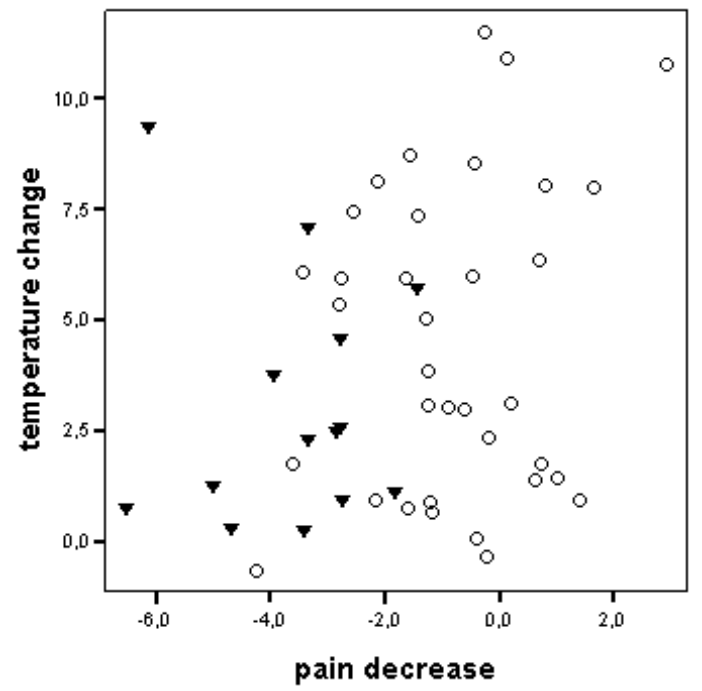

Figure 2: Scatter plot of mean pain change versus skin temperature change after sympathetic blockade treatment in responder $(\boldsymbol{\nabla})$ and non-responder (o) patients to sympathetic block

Table 2: Mean numerical pain rating scores NRS (SD) in responders and non-responders to sympathetic blockade before and after the treatment

\begin{tabular}{llll}
\hline Outcome & $\begin{array}{l}0-7 \text { days before SB } \\
\text { NRS(SD) }\end{array}$ & $\begin{array}{l}2-48 \text { hours } \\
\text { NRS(SD) }\end{array}$ & $\begin{array}{l}0-7 \text { days } \\
\text { NRS(SD) }\end{array}$ \\
\hline Responders $(\mathrm{N}=15)$ & $5.8(1.2)$ & $2.7(1.1)$ & $2.9(1.2)$ \\
Good $(\mathrm{N}=10)$ & $5.9(1.3)$ & $2.5(1.2)$ & $2.5(1.0)$ \\
Moderate $(\mathrm{N}=5)$ & $5.6(1.1)$ & $2.9(0.9)$ & $3.7(1.1)$ \\
Non responders $(\mathrm{N}=34)$ & $6.8(1.4)$ & $5.9(1.8)$ & $6.1(1.7)$ \\
\hline
\end{tabular}

NRS: numerical pain rating score, SD: standard deviation 
Table 3: Responders after sympathetic block according to relative skin temperature increase

\begin{tabular}{lccc}
\hline & SB $>1.5^{\circ} \mathrm{C}$ & & Total \\
& No & Yes & \\
\hline Non-responders & 10 & 24 & 34 \\
Good\&moderate responders & 6 & 9 & 15 \\
Total & 16 & 33 & 49 \\
\hline
\end{tabular}

SB: sympathetic block

\section{Intention to treat analysis, univariate analysis and logistic regression}

Table 4 shows the results of the baseline symptom and sign assessment. These variables together with the baseline demographics and characteristics as shown in table 1 were used in an univariate logistic analysis to explore correlations between patient characteristics and success of SB treatment.

Baseline demographics and characteristics, e.g. disease duration ( $P$ 0.44; Table 1 ) did not predict pain relief after SB in univariate analysis. The univariate analysis indicates that the absence or presence of cold asymmetries in the affected extremities did not predict SB outcome in our study (objectively measured cold asymmetry $P 0.87$; warm asymmetry $P 0.63$ ).

For model-building the symptoms allodynia ( $P 0.03)$, hypoesthesia ( $P 0.04)$, bradykinesia $(P 0.04)$, tremor and or myoclonus ( $P$ 0.06), the sign bradykinesia $(P 0.06)$, and the motor/trophic subgroup $(P 0.04)$ were considered as potential predictors and were entered in a stepwise multivariate logistic regression model. The variable bradykinesia was measured as a sign and as a symptom and these proved to be collinear. Therefore, we performed the modeling procedure upon two models.

In both procedures allodynia $(P 0.02)$ and hypoesthesia $(P 0.02)$ were included in the final model.

\section{Performance of the model}

Figure 3 shows the Receiver Operating Characteristic curve with the area under the curve. The area under the curve was $0.82(\mathrm{Cl} 0.70$ to 0.95$)$. In the models as generated by the bootstrap procedure the rate of occurrence of hypoesthesia in the model was $84 \%$, allodynia $75 \%$, bradykinesia (sign as well symptom) $37 \%$ and motor/trophic subgroup $22 \%$. The average of the area under the curves of the receiver operating characteristic curves was 0.78 ( $\mathrm{Cl} 0.61$ to 0.95 ). 


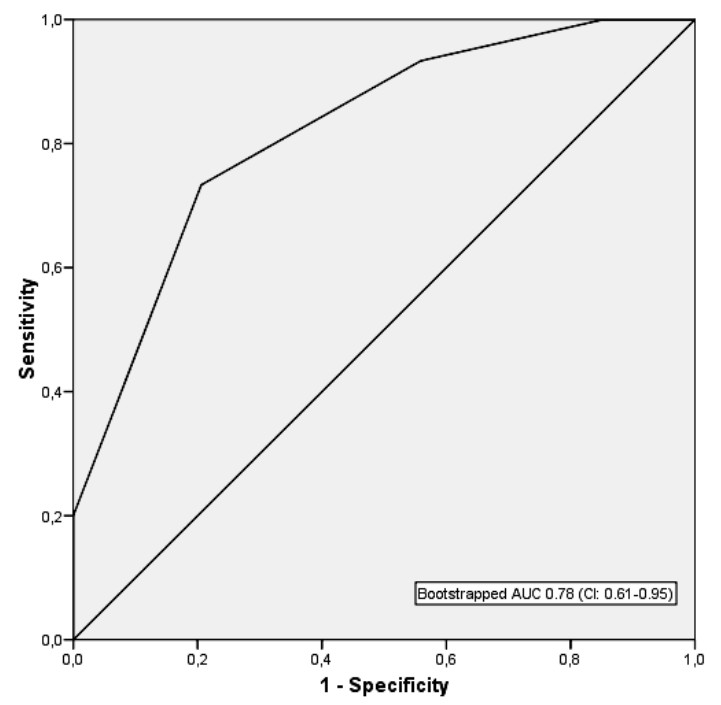

Figure 3: Performance of the predictive model with allodynia and hypoesthesia as negative predictive value. Receiver operating characteristic curve and bootstrapped mean Area Under the Curve

\section{Subgroup analysis}

As shown in table 3 the percentage of responders in our study was not significantly different in patients with or without a skin temperature increase of more than 1.5 ${ }^{\circ} \mathrm{C}$ after SB: $9 / 33(27 \%)$ in the group with $>1.5^{\circ} \mathrm{C}$ increase; $6 / 16(37 \%)$ in the group < $1.5^{\circ} \mathrm{C}$ increase; Chi-square $P$ 0.52. In the subgroup of CRPS-1 patients with more than $1.5^{\circ} \mathrm{C}$ skin temperature increase, we found no predictors of a positive pain relieving response to SB. Allodynia and hypoesthesia in this analysis also were predictors of a negative pain relieving response after the intervention.

We repeated the analysis with patients, who had $30 \%$ or more pain decrease for minimally 2 days after the intervention ( $n=21 / 49 ; 43 \%)$. In univariate analysis we only found predictors for a negative response to SB i.e. allodynia for pressure $(P$ $0.04)$, decreased range of motion ( $P 0.05)$, allodynia for movement $(P 0.03)$, and bradykinesia sign ( $P$ 0.03).

\section{Side effects}

In 41 patients (84\%) transient side effects of the SB treatment were reported, 8 patients had no side effects. In the stellate ganglion block treated patients $76 \%$ of patients had difficulty in swallowing (dysphagia). In the lumbar sympathetic block treated patients $61 \%$ of patients reported back pain that lasted for a median of 2 days with a maximum of 7 days. The pain was reported to be increased by $33-36 \%$ 
of the patients for a median of 3 days (0-11 days), the numerical pain rating scale scores however did not support this increase. This pain aggravation also occurred in two patients successfully treated with SB but this episode lasted for maximal 2 days (Table 5).

Table 4: Results of Chi-square and univariate regression analysis in symptoms and signs for unsuccessful Sympathetic Blockade treatment.

\begin{tabular}{|c|c|c|c|c|c|c|c|c|}
\hline \multicolumn{9}{|c|}{ Dependent variable: unsuccessful Sympathetic Blockade } \\
\hline \multirow{2}{*}{$\begin{array}{l}\text { Classes of symptoms } \\
\text { Sensory }\end{array}$} & \multicolumn{4}{|c|}{ Symptom } & \multicolumn{4}{|c|}{ Sign } \\
\hline & $\mathrm{N}$ & $\mathrm{P}$ & OR & $\mathrm{Cl}$ & $\mathrm{N}$ & $\mathrm{P}$ & OR & $\mathrm{Cl}$ \\
\hline Allodynia & 17 & 0.03 & 5.13 & $1.0,26.3$ & 12 & 0.21 & & \\
\hline Hyperesthesia & 10 & 0.25 & 0.46 & $0.12,1.69$ & 10 & 0.48 & 0.59 & $0.14,2.50$ \\
\hline Hypoesthesia & 20 & 0.04 & 2.92 & $0.96,16.8$ & 18 & 0.10 & 3.16 & $0.75,13.26$ \\
\hline Hyperalgesia & 29 & 0.30 & 1.41 & $0.41,4.82$ & 27 & 0.86 & 1.11 & $0.33,3.75$ \\
\hline Hypoalgesia & 14 & 0.63 & 0.72 & $0.19,2.69$ & 14 & 0.63 & 0.72 & $0.19,2.69$ \\
\hline \multicolumn{9}{|l|}{ Vasomotor } \\
\hline Asymmetry in skin color & 48 & NE & & & 22 & 0.65 & 1.33 & $0.39,4.58$ \\
\hline Asymmetry in temperature & 46 & 0.92 & 1.14 & $0.10,13.66$ & 22 & 0.87 & 0.90 & $0.27,3.05$ \\
\hline Cold & 26 & 0.97 & 0.98 & $0.29,3.33$ & 35 & 0.63 & 1.39 & $0.37,5.18$ \\
\hline Warm & 16 & 0.47 & 0.63 & $0.18,2.22$ & 14 & 0.63 & 0.72 & $0.19,2.69$ \\
\hline \multicolumn{9}{|l|}{ Sudomotor } \\
\hline Edema & 44 & 0.64 & 1.59 & $0.24,10.66$ & 18 & 0.33 & 1.93 & $0.51,7.30$ \\
\hline Asymmetry in sweating & 22 & 0.87 & 0.90 & $0.27,3.05$ & 5 & 0.15 & 0.25 & $0.04,1.69$ \\
\hline \multicolumn{9}{|l|}{ Mototrophic } \\
\hline Decreased range of motion & 39 & 0.15 & 2.9 & $0.69,12.15$ & 33 & 0.17 & 2.43 & $0.68,8.64$ \\
\hline Weakness & 46 & 0.92 & 1.14 & $0.09,13.66$ & 31 & 0.34 & 1.83 & $0.53,6.34$ \\
\hline Dystonia & 20 & 0.58 & 0.71 & $0.21,2.42$ & 3 & NE & & \\
\hline Tremor/myoclonus & 29 & 0.06 & 3.5 & $0.92,13.2$ & 3 & NE & & \\
\hline Trophic disturbances & 15 & 0.79 & 0.83 & $0.23,3.07$ & 9 & 0.54 & 1.69 & $0.31,9.27$ \\
\hline Bradykinesia & 24 & 0.04 & 3.93 & $1.04,14.9$ & 23 & 0.06 & 3.48 & $0.92,13.2$ \\
\hline
\end{tabular}

\begin{tabular}{ll}
\hline Subgroup of symptoms \& signs for Budapest variables \\
Z-scores & $\mathrm{P}$ \\
\hline Sensory & 0.12 \\
Vasomotor & 0.86 \\
Sudomotor & 0.98 \\
Motortrophic & 0.04 \\
\hline
\end{tabular}

P Probability, OR Odds Ratio, CI 95\% Confidence Intervals NE Not Estimable due to cell with zero counts 
Table 5: Side effects in days following sympathetic blockade.

\begin{tabular}{|c|c|c|c|c|c|}
\hline \multirow[b]{2}{*}{ Side effects } & \multicolumn{2}{|c|}{ Stellatum blockade( $N 21)$} & \multicolumn{2}{|c|}{ Lumbar blockade( $N 28)$} & \multirow{2}{*}{$\begin{array}{l}\text { Total } \\
\mathrm{N}(\%)\end{array}$} \\
\hline & $\mathrm{N}(\%)$ & $\begin{array}{l}\text { Median (min-max) } \\
\text { in days }\end{array}$ & $N(\%)$ & $\begin{array}{l}\text { Median (min-max) } \\
\text { in days }\end{array}$ & \\
\hline No side effects & $2(9.5)$ & & $6(21.4)$ & & $8(16)$ \\
\hline Horner & $11(52.4)$ & 0 & & & \\
\hline Blurred vision & $4(19.1)$ & 0 & & & \\
\hline Increased pain & $7(33.3)$ & $4(1-7)$ & $10(35.7)$ & $3(0-11)$ & $17(34.7)$ \\
\hline Headache & $13(61.9)$ & $2(1-6)$ & $8(28.6)$ & $2(0-3)$ & $21(42.9)$ \\
\hline Nausea/vomiting & $5(23.8)$ & $2(2-5)$ & 5 (17.9) & $2(1-3)$ & $10(20.4)$ \\
\hline Dysphagia & $16(76.2)$ & $3(1-7)$ & $1(3.6)$ & $1(0-1)$ & $17(34.7)$ \\
\hline Hoarseness & $7(33.3)$ & $1.5(1-6)$ & $2(7.1)$ & $3(2-4)$ & $9(18.4)$ \\
\hline Hematoma & $3(14.3)$ & $4(4-6)$ & $2(7.1)$ & $3(2-4)$ & $5(10.2)$ \\
\hline Back pain & $5(23.8)$ & $3(2-7)$ & $17(60.7)$ & $2(0-7)$ & $22(44.9)$ \\
\hline Groin pain & & & $5(17.9)$ & $2.5(0-3)$ & $6(10.2)$ \\
\hline
\end{tabular}

Min Minimum, Max Maximum, 0 day of intervention

\section{Discussion}

In our study we found that 15 out of 49 (31\%) patients were good or moderate responders to SB. Secondly, allodynia and hypoesthesia are predictors of a negative response to SB in CRPS-1. Thirdly, the presence of cold type or warm type CRPS-1 in our study made no difference in the response to SB. Fourthly, the patient subgroup with skin temperature increase of more than 1.5 degrees Celsius after SB did not show more responders. Finally, a majority of patients $(41 / 49 ; 84 \%)$ suffer from (transient) side effects.

This prospective study on the initial outcome of SB contains the largest amount of CRPS-1 patients $(n=49)$ having undergone SB. Other outcome studies on SB have included relatively small numbers, varying from 1 to 33 patients. ${ }^{9}, 10,22,30-32$ Moreover, our study is the first which has systematically reported on the incidence of side effects following sympathetic blockade with local anesthetics.

Fifteen out of 49 (31\%) patients were good or moderate responders to SB. This is equal to the results in other studies although these studies usually included populations with both acute and chronic CRPS. ${ }^{30,33}$ Our group consisted of CRPS-1 patients with disease duration of less than one year. The prognosis is typically better in early CRPS-1. Since we only included patients who had no pain relief after a standard conservative therapy protocol of at least 8 weeks, our patient group did have therapy resistant pain, with a poorer prognosis, qualifying them for SB.

In contrast to prior opinion, ${ }^{11}$ in our study cold type CRPS-1 patients did not show more pain relieve after SB compared with warm type CRPS-1 patients. The Odds Ratio's show that the temperature difference or initial temperature did not 
prove to be a predictor of success, there was equal chance of achieving pain relief or not after SB. This is in contrast to a previous study where the magnitude of temperature increase after SB predicted relief of spontaneous pain and allodynia. ${ }^{34}$ This observation of Trann et al however was made in a small subset of 11 patients and more than one SB per patient was allowed to be performed, which may have introduced bias. Furthermore, in contrast with our study, skin temperature measurements were made on the ipsilateral side only, therefore correction for a possible skin temperature increase due to the environment of the examination room was not possible. In another study skin temperature and asymmetries in skin temperature also did not predict pain relief to SB. ${ }^{10}$

An interesting observation is the existence of responders in the group that showed less than 1.5 o C skin temperature increase $(6 / 16=37 \%)$. There was no increase in responders in the group with a relative skin temperature increase of $1.5^{\circ} \mathrm{C}$ or more as opposed to the group that did not show this increase. This indicates that the relative increase in skin temperature after the SB was not a predictive factor for its pain relieving effect. Possible explanations for the phenomenon of responder patients in the absence of an adequate skin temperature rise may include spillover of the local anesthetic to somatic nerves, systemic action of absorbed local anesthetic fluid or placebo response.

Allodynia and hypoesthesia symptoms proved to be statistically significant predictors of a negative response to SB. In the subgroup of CRPS-1 patients with more than the $1.5^{\circ} \mathrm{C}$ skin temperature increase after $\mathrm{SB}$, we also found allodynia and hypoesthesia to be predictors for a negative pain relieving response. Allodynia is a well-known sign of central sensitization in the central nervous system at the level of the medullary cord or higher. ${ }^{35}$ Hypoesthesia may be related to impairment of central processing of large caliber peripheral $A ß$ fiber input. In an earlier report, peripheral $A ß$ fibers were found to be intact in CRPS forearm skin in contrast to peripheral nociceptive small diameter fibers (A delta and C-fibers) which were degenerated. ${ }^{36}$ The central sensitization and altered sensory transmission may alter sensorimotor processing, associated with central disinhibition, leading to signs and symptoms like tremor, myoclonus and bradykinesia. ${ }^{37,38}$ With the presence of signs and symptoms of central dysfunction at the level of the spinal cord or higher, it is understandable why a peripheral intervention like SB is not likely to benefit the patient.

In our study not all SB were followed by an $1.5^{\circ} \mathrm{C}$ increase in relative temperature. Despite a radioscopically confirmed, correctly performed SB, 16 of the 49 patients (37\%) did not show this reaction. This might suggest that the technical procedure was suboptimal causing misdistribution of the local anesthetic drug. The insufficient temperature increase after SB is, however, a common occurrence in studies concerning SB. ${ }^{21,39}$ In another study, the number of patients $(10 / 33 ; 30 \%)$ that did not show the expected skin temperature rise after SB was comparable with our study. ${ }^{22}$ Furthermore, the number of responder patients in this study corresponds 
to the number of responder patients in other studies. ${ }^{30,33}$ We therefore suggest that the technique used as described in the methods section was in fact optimally performed. This justifies the intention to treat analysis as performed in our study.

Although all patients met the IASP criteria, not all patients met the Budapest clinical criteria (90\%) or the Budapest research criteria (76\%), implying a possible lack of specificity in a small part of the patient sample. However, the Budapest criteria for CRPS were only recently validated in 2010, ${ }^{19,20}$ and at the time of inclusion of our study in 2005 and up till now the IASP criteria are considered valid diagnostic criteria. Since our objective was to identify factors that could predict a positive response to SB, patient inclusion according to the IASP criteria seemed justified.

A potential limitation of this study involves the patient sample. The sample was based on available new CRPS-1 patients. Therefore, we chose conservative $P$-values to build the model and performed a bootstrap procedure to check for overoptimism in the model performance. This procedure showed that the performance of the model remained good. It must be stressed that this study did not assess the long term outcome of CRPS-1 after SB. We therefore cannot make a statement on the long term efficacy of SB in CRPS-1. We focused on the search for predictors of a positive response to SB in order to improve the selection of patients with CRPS-1 likely to benefit from this treatment.

When considering an invasive procedure such as SB one should be aware of the possible side effects and complications of the procedure. We know the possibility of potentially life-threatening complications (1.7/1000) which may arise from inadvertent subarachnoid injection or injection in the arteria vertebralis. ${ }^{12}$ The existence of other less severe side effects did not receive much attention in the literature. Although we had no major complications, side effects seem to be considerable as shown by our study. A majority of patients showed temporary side effects like headache, backache, nausea, blurred vision, groin pain, dysphagia, hoarseness and hematoma at the puncture site. Temporary Horner syndrome is often considered a normal phenomenon after stellate ganglion block. The target when blocking this cervicothoracic sympathetic ganglion however is its thoracic part, since innervation of the arm is mediated via Th1 and Th2. As such the accompanying Horner syndrome is an inconvenient aspect of the treatment, but unpreventable when performed at the safer C6 or C7 level. Puncture at lower levels would increase the risk of pneumothorax. Seventeen out of 49 patients (35\%) had increased transient pain after SB which returned to baseline one week after SB. Whether or not SB is an effective treatment for CRPS-1 cannot be answered from our results. Only good quality randomized controlled trials with appropriate sample sizes and robust outcome measures could prove if SB really is indicated in CRPS-1. In clinical practice, indications for SB in CRPS-1 should be carefully balanced against possible complications or side effects. As for the effect of SB on pain in early CRPS-1 (less than one year after initiating event): allodynia and hypoesthesia predicted a negative re- 
sponse to SB. The procedure is as likely to cause a transient increase in pain as there is the likelihood of pain decrease. Patients should be informed accordingly.

\section{References}

1. Bonica JJ. Causalgia and other reflex sympathetic dystrophies. In: Bonica JJ, Loeser JD, Chapman C, eds. The management of pain 2nd ed, Vol. 1. ed. Philadelphia: Lea and Febiger; 1990. 220-243.

2. Evans JA. Reflex sympathetic dystrophy. Surg Clin North Am. 1946;26:780-790.

3. Raja SN, Treede RD, Davis KD, Campbell JN. Systemic alpha-adrenergic blockade with phentolamine: a diagnostic test for sympathetically maintained pain. Anesthesiology. 1991;74:691-698.

4. Jorum E, Orstavik K, Schmidt R, Namer B, Carr RW, Kvarstein G, et al. Catecholamine-induced excitation of nociceptors in sympathetically maintained pain. Pain. 2007;127:296-301.

5. Perez RS, Zollinger PE, Dijkstra PU, Thomassen-Hilgersom IL, Zuurmond WW, Rosenbrand KC, et al. Evidence based guidelines for complex regional pain syndrome type 1. BMC Neurol. 2010;10:20.

6. van Eijs F, Stanton-Hicks M, Van Zundert J, Faber CG, Lubenow TR, Mekhail N, et al. Evidence-based interventional pain medicine according to clinical diagnoses. 16. Complex regional pain syndrome. Pain Pract. 2011;11:70-87.

7. Nelson DV, Stacey BR. Interventional therapies in the management of complex regional pain syndrome. Clin J Pain. 2006;22:438-442.

8. Cepeda MS, Lau J, Carr DB. Defining the therapeutic role of local anesthetic sympathetic blockade in complex regional pain syndrome: a narrative and systematic review. Clin J Pain. 2002;18:216-233.

9. Hartrick CT, Kovan JP, Naismith P. Outcome prediction following sympathetic block for complex regional pain syndrome. Pain Pract. 2004;4:222-228.

10. Dellemijn PL, Fields HL, Allen RR, McKay WR, Rowbotham MC. The interpretation of pain relief and sensory changes following sympathetic blockade. Brain. 1994;117 ( Pt 6):1475-1487.

11. Geertzen J, Perez R, Dijkstra P, Kemler M, Rosenbrand C. Complex Regional Pain Syndrome type 1 Guidelines. Alphen aan den Rijn, the Netherlands: van Zuiden Communications B.V. ; 2006.

12. Wulf $\mathrm{H}$, Maier $\mathrm{C}$. [Complications and side effects of stellate ganglion blockade. Results of a questionnaire survey]. Anaesthesist. 1992;41:146-151.

13. Merskey H, Bogduk N. Classification of Chronic Pain: Descriptions of Chronic Pain Syndromes and Definitions of Pain Terms., 2 ed. Seattle: Wash: IASP Press; 1994.

14. Jensen MP, McFarland CA. Increasing the reliability and validity of pain intensity measurement in chronic pain patients. Pain. 1993;55:195-203.

15. Stanton-Hicks M, Baron R, Boas R, Gordh T, Harden N, Hendler N, et al. Complex Regional Pain Syndromes: guidelines for therapy. Clin J Pain. 1998;14:155-166.

16. Oerlemans HM, Oostendorp RA, de Boo T, Goris RJ. Pain and reduced mobility in complex regional pain syndrome I: outcome of a prospective randomised controlled clinical trial of adjuvant physical therapy versus occupational therapy. Pain. 1999;83:77-83.

17. Stevens RA, Stotz A, Kao TC, Powar M, Burgess S, Kleinman B. The relative increase in skin temperature after stellate ganglion block is predictive of a complete sympathectomy of the hand. Reg Anesth Pain Med. 1998;23:266-270.

18. Perez RS, Collins S, Marinus J, Zuurmond WW, de Lange JJ. Diagnostic criteria for CRPS I: differences between patient profiles using three different diagnostic sets. Eur J Pain. 2007;11:895-902.

19. Harden RN, Bruehl S, Perez RS, Birklein F, Marinus J, Maihofner C, et al. Validation of proposed diagnostic criteria (the "Budapest Criteria") for Complex Regional Pain Syndrome. Pain. 2010;150:268-274.

20. Harden RN, Bruehl S, Stanton-Hicks M, Wilson PR. Proposed new diagnostic criteria for complex regional pain syndrome. Pain Med. 2007;8:326-331. 
21. Hogan QH, Taylor ML, Goldstein M, Stevens R, Kettler R. Success rates in producing sympathetic blockade by paratracheal injection. Clin J Pain. 1994;10:139-145.

22. Schurmann M, Gradl G, Wizgal I, Tutic M, Moser C, Azad S, et al. Clinical and physiologic evaluation of stellate ganglion blockade for complex regional pain syndrome type I. Clin J Pain. 2001;17:94-100.

23. Dworkin RH, Turk DC, Wyrwich KW, Beaton D, Cleeland CS, Farrar JT, et al. Interpreting the clinical importance of treatment outcomes in chronic pain clinical trials: IMMPACT recommendations. $J$ Pain. 2008;9:105-121.

24. Bruehl S, Harden RN, Galer BS, Saltz S, Backonja M, Stanton-Hicks M. Complex regional pain syndrome: are there distinct subtypes and sequential stages of the syndrome? Pain. 2002;95:119-124.

25. Hosmer D, Lemeshow S. hoofdstuk titel. In: Applied Logistic Regression, Vol. ed. New York: John Wiley \& Sons; 1989. 135-175.

26. Harrell FE, Jr., Lee KL, Mark DB. Multivariable prognostic models: issues in developing models, evaluating assumptions and adequacy, and measuring and reducing errors. Stat Med. 1996;15:361-387.

27. Efron B, Tibshirani R. Hoofdstuk titel. In: An introduction to the bootstrap, Vol. ed. New York: Chapman \& Hall; 1993. 105-123.

28. Steyerberg EW, Bleeker SE, Moll HA, Grobbee DE, Moons KG. Internal and external validation of predictive models: a simulation study of bias and precision in small samples. J Clin Epidemiol. 2003;56:441-447.

29. Bruehl S, Harden RN, Galer BS, Saltz S, Bertram M, Backonja M, et al. External validation of IASP diagnostic criteria for Complex Regional Pain Syndrome and proposed research diagnostic criteria. International Association for the Study of Pain. Pain. 1999;81:147-154.

30. Ackerman WE, Zhang JM. Efficacy of stellate ganglion blockade for the management of type 1 complex regional pain syndrome. South Med J. 2006;99:1084-1088.

31. Price DD, Long S, Wilsey B, Rafii A. Analysis of peak magnitude and duration of analgesia produced by local anesthetics injected into sympathetic ganglia of complex regional pain syndrome patients. Clin $J$ Pain. 1998;14:216-226.

32. Yucel I, Demiraran Y, Ozturan K, Degirmenci E. Complex regional pain syndrome type I: efficacy of stellate ganglion blockade. J Orthop Traumatol. 2009;10:179-183.

33. Meier PM, Zurakowski D, Berde CB, Sethna NF. Lumbar sympathetic blockade in children with complex regional pain syndromes: a double blind placebo-controlled crossover trial. Anesthesiology. 2009;111:372-380.

34. Tran KM, Frank SM, Raja SN, El-Rahmany HK, Kim LJ, Vu B. Lumbar sympathetic block for sympathetically maintained pain: changes in cutaneous temperatures and pain perception. Anesth Analg. 2000;90:1396-1401.

35. Bruehl S. An update on the pathophysiology of complex regional pain syndrome. Anesthesiology. 2010;113:713-725.

36. Oaklander AL, Rissmiller JG, Gelman LB, Zheng L, Chang Y, Gott R. Evidence of focal small-fiber axonal degeneration in complex regional pain syndrome-I (reflex sympathetic dystrophy). Pain. 2006;120:235-243.

37. van Rijn MA, Marinus J, Putter $\mathrm{H}$, van Hilten JJ. Onset and progression of dystonia in complex regional pain syndrome. Pain. 2007;130:287-293.

38. van Hilten JJ. Movement disorders in complex regional pain syndrome. Pain Med. 2010;11:12741277.

39. Baron R, Levine JD, Fields HL. Causalgia and reflex sympathetic dystrophy: does the sympathetic nervous system contribute to the generation of pain? Muscle Nerve. 1999;22:678-695. 
CHAPTER IV

\section{Brush evoked allodynia predicts outcome of Spinal Cord Stimulation in Complex Regional Pain Syndrome - Type 1}

Frank van Eijs MD, Helwin Smits MD, José W. Geurts MSc, Alfons G.H. Kessels MD MSc, Marius A. Kemler MD PhD, Maarten van Kleef MD PhD, Elbert A.J. Joosten PhD, Catharina G.Faber MD PhD

European Journal of Pain. 2010; 14 (2): 164-9 


\begin{abstract}
Background: Spinal Cord Stimulation (SCS) has proven to be an effective however an invasive and relatively expensive treatment of chronic Complex Regional Pain Syndrome type 1(CRPS-1). Furthermore, in one third of CRPS-1 patients, SCS treatment fails to give significant pain relief and $32-38 \%$ of treated patients experience complications. The aim of the current study was to develop effective prognostic factors for prediction of successful outcome of SCS.

Methods and Results: The study population consisted of 36 chronic CRPS patients enrolled in a randomized controlled trial of SCS efficacy. We analyzed various prognostic factors in the group of patients treated with SCS and compared baseline values of possible predictors of outcome in the successfully treated and the not successfully treated group. Success was defined as Patient Global Perceived Impression of Change score of at least "much improved" and pain reduction of at least 2.5 on a visual analogue scale (VAS score $0-10$ ). Univariate analyses showed that patient age, duration of the disease, localization of the disease, intensity of the pain, and the presence of mechanical hypoesthesia did not predict SCS success. The mean and maximum value of brush-evoked allodynia proved to be statistically significant predictors of outcome. Using Receiver-Operating Characteristic (ROC) curve analyses of maximum allodynia values, the diagnostic sensitivity for successful SCS was 0.75 and the specificity 0.81 .
\end{abstract}

Conclusion: Brush evoked allodynia may be a significant negative prognostic factor of SCS treatment outcome after one year in chronic CRPS-1. 


\section{Introduction}

CRPS-1 is a syndrome that describes an array of painful conditions that are characterized by a continuing regional pain which is seemingly disproportionate in time or degree to the usual course of any known trauma or other lesion, as defined by the clinical diagnostic criteria of the International Association for the Study of Pain(IASP). ${ }^{1}$ Common symptoms in CRPS-1 patients are the presence of pain, edema, trophic changes and sensory disturbances, with mechanical hypoesthesia being present in $74 \%$ and mechanical allodynia in $85 \%$ of cases ${ }^{2-4}$.

Spinal cord stimulation (SCS) is an accepted, effective therapy for chronic pain in Complex regional Pain syndrome (CRPS) patients who fail to improve with medication, physical therapy or less invasive procedures and who require additional or more aggressive pain therapy ${ }^{5,6}$. It is considered general practice in SCS treatment to begin with a test stimulation period of about one week with an external stimulating device before a permanent SCS device is implanted. Both test stimulation and subsequent implantation of a SCS device are invasive procedures, with common complications such as electrode displacement and pain from the pulse generator pocket, requiring reoperation. These complications are reported in 31-38\% of patients within the first two years of stimulation ${ }^{7,8}$.

About two thirds of CRPS-1 patients undergo implantation of a permanent spinal cord stimulating system ${ }^{9-11}$. The effect of the permanent SCS on pain may gradually decline over time ${ }^{12-14}$.

There have been few reports on the prognostic factors in successful stimulation in CRPS-1 ${ }^{6,15,16}$. Absent or significantly altered neural conductivity in the dorsal column-lemniscal system as measured by somatosensory evoked potentials (SSEPs) was a negative predictor of SCS success in patients with intractable chronic neuropathic pain ${ }^{15}$. A differential effect of SCS related to the severity of the allodynia was reported in an experimental neuropathic pain model in rats. ${ }^{16}$ In this model SCS led to a better and faster pain relief in mildly allodynic rats than in those with severe allodynia.

The present study is part of our participation in a randomized controlled trial of SCS efficacy for CRPS patients out of which demographic criteria and a variety of reliable and validated pain and sensory measurement were used to asses changes in outcome in the SCS treated group ${ }^{9}$.

For identification of predictors for successful pain relief after SCS treatment, we analyzed pretreatment responses to the above mentioned criteria and correlated each with the reported pain status after trial stimulation and after one year of SCS treatment. Special attention was paid to two clinically useful and common sensory characteristics in CRPS-1, namely mechanical hypoesthesia and brush evoked allodynia. 


\section{Methods}

\section{Patients}

The study population was drawn from a series of 54 consecutive CRPS- 1 patients who underwent a randomized trial of SCS at the University Medical Centre of Maastricht, The Netherlands ${ }^{17}$. Of these trial patients only the 36 patients treated with SCS were considered for this study.

Patients were eligible for the study if they were between 18 and 65 years old and met the diagnostic criteria for CRPS-1 established by the IASP with impaired function and symptoms beyond the area of trauma (Table 1$)^{1}$. Additional criteria for enrolment included disease which was clinically restricted to one hand or foot and affected the entire hand or foot, and which had lasted for at least six months. Furthermore, patients should not have a sustained response to standard therapy (six months of physical therapy, sympathetic blockade, transcutaneous electrical nerve stimulation, and pain medication), and suffer a mean pain intensity of at least $5 \mathrm{~cm}$ on a visual-analogue scale from 0 (no pain) to $10 \mathrm{~cm}$ (worst imaginable pain).

Exclusion criteria were the presence of Raynaud's disease, current or previous neurologic abnormalities unrelated to reflex sympathetic dystrophy, another condition affecting the function of the diseased or contra lateral extremity, a bloodclotting disorder, or use of an anticoagulant drug, and implanted cardiac pacemaker. The study was approved by the Medical Ethics Committee of Maastricht University Medical Centre, Maastricht, the Netherlands. All patients gave written informed consent prior to inclusion in the study.

Of the 36 patients, 24 patients were responders to SCS trial therapy and subsequently underwent implantation of a permanent SCS device. In 12 patients the trial stimulation was unsuccessful and the percutaneous trial electrode was removed. All 36 patients received a standardized physical therapy program.

\section{Materials}

All 36 patients considered for this study had a trial stimulation period of at least one week of home-testing during which pain had to be scored in a pain diary, three times a day ${ }^{18}$. If there was less than $50 \%$ pain reduction, patients were considered non-responders, and subsequently the test electrode was removed. A spinal cord stimulator was implanted permanently if the visual-analogue score for the intensity of pain during the last four days of the testing period was at least 50 percent lower than the baseline score, or if there was a score of at least 6 ("much improved") on a seven-point scale for patients global impression of change (PGIC). PGIC is a sevenpoint ordinal scale, used after treatment, as an external criterion of clinically important change. A score of 4 means no change in the condition, and scores $>4$ denotes 
an improvement indicating "improved", "much improved" and "very much improved", and a score of 3 or less means a worsening, " minimally worse", "much worse", "very much worse" ${ }^{19}$. PGIC measures are valid indicators of important change in CRPS patients ${ }^{12,19}$.

\section{Implantation of the Spinal Cord Stimulator System}

After the prophylactic administration of cefuroxime (1500 mg given intravenously), the patient was placed in the prone position and a $5-\mathrm{cm}$ vertical midline incision was made in the skin overlying the thoracic spine (if the hand was affected) or the lumbar spine (if the foot was affected). An electrode (model 3487A, Medtronic) was implanted in a fashion similar to the implantation of the temporary lead and was fixed with special clips. The patient was then placed in a lateral position, and a sedative was administered ( $1 \mathrm{mg}$ of propofol per kilogram of body weight). A pulse generator (Itrel III, model 7425, Medtronic) was implanted subcutaneously in the left lower anterior abdominal wall and connected to the electrode by a tunnelled extension lead (model 7495-51/66, Medtronic). After the skin had been closed, the pulse generator was activated (rate, $85 \mathrm{~Hz}$; pulse width, $210 \mu \mathrm{sec}$ ) with the use of a console programmer (model 7432, Medtronic). The patient could control the intensity of stimulation by adjusting the amplitude from 0 to $10 \mathrm{~V}$ with a programmer (model 7434-NL, Medtronic). The patient remained in the hospital for 24 hours after the implantation, during which time two doses of cefuroxime (750 mg each) were given intravenously. If no change in the position of the electrode was evident on an x-ray film obtained the following day, the patient was discharged.

\section{Physical Therapy}

Physical therapy, which both groups of patients received, consisted of a standardized program of graded exercises designed to improve the strength, mobility, and function of the affected hand or foot. Pain during the exercises was considered acceptable, but if it had not returned to the pre-session level within 24 hours, the intensity of the exercises was reduced. Physical therapy was administered for 30 minutes twice a week, with a minimum of two days between sessions. The total duration of the physical therapy was six months, starting after the second assessment. To ensure standardization, selected physical therapists were trained to provide the program of exercises. The coordinating physical therapist from our institution visited the other therapists regularly to make sure the treatment was uniform. 


\section{Data collection and follow up}

Outcome measures were assessed at baseline. The effect of SCS on pain intensity VAS and PGIC was measured at 1, 3, 6, and 12 months after implantation.

\section{Methods}

Semmes-Weinstein pressure filaments (Smith \& Nephew Rolyan Inc, Germantown, WI) were used to measure mechanical detection thresholds (i.e. mechanical hypoesthesia). Measurements at hands and feet were done at nine standardized sites. This procedure has been described earlier ${ }^{9}$. Hands were examined in sitting position, while the feet were examined in the supine position. Subjects were required to keep their eyes closed while being tested.

We classified the amount of mechanical hypoesthesia into four categories of intensity according to the Semmes Weinstein conversion tables. These categories are: normal sensibility, diminished sensibility to light touch, diminished protective sensation and loss of protective sensation.

Brush evoked allodynia was assessed by transiently stroking the skin of subject's hands and feet with a soft standardized brush at nine sites ${ }^{9}$. This procedure is not painful in normal subjects. If the procedure was perceived as painful, this signifies the presence of allodynia and subjects were asked to verbally rate the evoked pain on a numerical rating scale (NRS) from 0 to $10(0=$ no pain and $10=$ worst imaginable pain). The mean brush evoked allodynia was then calculated by dividing the total score by nine.

Demographic characteristics, spontaneous pain VAS, localization of the CRPS-1, duration of the disease, medication use, Semmes Weinstein QST measurements and brush evoked allodynia were all measured before implantation as baseline values. Subjects were tested in a quiet room maintained at $21-23^{\circ} \mathrm{C}$ and after having received explanation of the procedure.

\section{Statistical analysis}

Patients who in the first year of their treatment with SCS had a sustained effect on their pain reduction, as defined by pain reduction of at least 2.5 on their VAS score and/or a PGIC score of "much improved" or "very much improved" in at least 3 out of the 4 follow up assessments are considered to be successfully treated ${ }^{19}$. Implanted patients with significant decline in pain reduction during the evaluation period as defined by not meeting the above mentioned criteria for successful treatment are considered to be unsuccessfully treated with SCS.

The frequency of occurrence at baseline of the different possible predictors of SCS outcome were determined in the successful and in the non-successful group. The predictive performance of allodynia (maximum value and average of nine meas- 
urements), hypoesthesia, age, gender, localization of the disease, duration of the disease, and baseline intensity of the pain was investigated. Due to the limited number of patients this analysis was done with a univariate logistic regression analysis. This way only two statistically significant predictors $(p<0.10)$ remained and these were entered in a multivariate logistic regression model with a forward stepwise procedure. The results of this regression analysis were used to construct a ROC curve and calculate an Area Under the Curve (AUC). Non parametric testing i.e. Mann-Whitney, was used for the hypoesthesia and allodynia parameters due to the non-symmetrical distribution of results. Analysis were performed with the Statistical Package for the Social Sciences, version 16.0 (SPSS Inc., Chicago, II). Two-tailed p values of less than 0.05 were considered statistically significant.

\section{Results}

Thirty-six patients, aged 40-65 yr, 22 women and 14 men, with chronic CRPS-1 in one extremity, who had been referred to our department and took part in the previously described randomized clinical trial and who subsequently underwent SCS trial stimulation were part of this predictor study.

All 36 chronic CRPS-1 patients underwent SCS trial stimulation with a screening electrode. Following the trial period 12 patients did not receive a permanent implant due to insufficient pain reduction. Twenty-four patients received an implant after a positive trial.

Table 1 shows the diagnostic criteria for CRPS- 1 as assessed in this study in relation to implant effect. There are no differences between the separate groups in all aspects of the absolute and relative criteria for CRPS- 1 .

Baseline characteristics and the distribution of patients in relation to treatment effect are shown in Table 2. Furthermore, it shows the results of the chi square tests for patient age, gender, disease duration, localization of the disease, allodynia, hypoesthesia and pain intensity measured by the success rate of SCS after trial stimulation and one year of SCS treatment. The average age of patients included in this study was 40, SD 11.7, range 21- 65 years. The lower limb was affected in 14 patients and 22 patients had upper limb involvement. The mean duration of the disease was 40 months, SD 27.5, range 9 - 120. The mean patient baseline pain intensity VAS score was 71 millimeters, SD 15, range $50-90$. Chi square analysis showed no significant correlation between age, location of the affection, baseline pain intensity VAS score, gender, and success of SCS. Medication use included peripheral analgesics like non steroidal anti-inflammatory drugs and acetaminophen, antidepressants and antiepileptic drugs and weak opioids like tramadol or buprenorphin. Thirteen out of twenty allodynia patients used one or more of these drugs and ten out of sixteen patients in the non allodynia group. Only one patient used 
oral morphine sulfate and two used an antidepressant or antiepileptic. So there was no clinical relevant difference in the use of medication between the groups. Our data indicate that the absence or presence of hypoesthesia, light or severe, does not predict SCS outcome (P 0.55). In our patient sample, only allodynia was significantly correlated with success of treatment after one year. A trend could be seen after the trial period towards the negative association of allodynia and treatment success (P 0.06). The difference in success rate after one year (Mann Whitney test) is statistically significant ( $P$ 0.017) between the groups with and without allodynia. In the successfully treated group 5 patients had severe allodynia $(5 / 20 ; 25 \%)$ compared to 11 patients in the not successfully treated group $(11 / 16 ; 69 \%)$.

After one year, 20 out of the 24 (83\%) SCS-implanted patients maintained their significant pain reduction.

Of the 24 patients who underwent definitive implantation, four showed a significant loss of pain reduction after one year. These four patients together with the 12 patients not receiving a permanent implant were considered to be unsuccessfully treated after one year (16/36 patients; $41 \%$ ). Table 3 shows the baseline characteristics of the unsuccessfully treated group in separate categories and combined. Of the 4 patients implanted but longer term non-responding to SCS treatment, 3 patients suffered severe allodynia. In all other aspects the baseline variables did not differ. The univariate logistic regression analysis shows that the maximum value as well as the mean value of brush evoked allodynia are statistically significant predictors of outcome after SCS trial and even more significant after one year of SCS treatment. These two predictors were entered in a multivariate logistic regression model with a forward stepwise procedure. The result of this regression analysis was used to construct a ROC curve and calculate an Area Under the Curve (AUC) and is displayed in figure 1 . The corresponding tables belonging to figure 1 show that the cutoff point can be set at a brush evoked allodynia pain intensity NRS score of 2.5 with a sensitivity of 0.75 and a specificity of 0.81 . 
Table 1: Diagnostic Criteria for CRPS-1 in the Study Related to Implant Effect *

\begin{tabular}{lrrrr}
\hline & $\begin{array}{r}{ }^{ \pm} \mathrm{R} . \mathrm{I} . \\
\mathrm{N}=20(\%)\end{array}$ & $\begin{array}{r}\mathrm{N} . \mathrm{N} . \\
\mathrm{N}=12(\%)\end{array}$ & $\begin{array}{r}\mathrm{N} . \mathrm{I} . \\
\mathrm{N}=4(\%)\end{array}$ & $\begin{array}{r}\text { TOTAL } \\
36(\%)\end{array}$ \\
\hline Absolute criteria & & & & \\
Pain & 20 & 12 & 4 & 4 \\
Impaired function & 20 & 12 & 4 & \\
Symptoms beyond the area of trauma & 20 & 12 & & \\
Relative criteria & & & & \\
Cold, warm, or intermittently cold/warm & $15(75)$ & $8(67)$ & $4(100)$ & $27(75)$ \\
Edema & $16(80)$ & $10(83)$ & $4(100)$ & $30(83)$ \\
Increased nail growth & $8(40)$ & $8(67)$ & $3(75)$ & $19(53)$ \\
Increased hair growth & $4(20)$ & $2(17)$ & $2(50)$ & $8(22)$ \\
Hyperhidrosis & $15(75)$ & $10(83)$ & $2(50)$ & $27(75)$ \\
Abnormal skin color & $18(90)$ & $11(92)$ & $4(100)$ & $33(92)$ \\
Hypoesthesia & $14(70)$ & $6(50)$ & $1(25)$ & $21(58)$ \\
Hyperalgesia & $15(75)$ & $11(92)$ & $4(100)$ & $30(83)$ \\
Mechanical or thermal allodynia or both & $15(75)$ & $11(92)$ & $4(100)$ & $30(83)$ \\
\hline
\end{tabular}

* All the absolute criteria, together with at least three of the relative criteria, were required for this study

${ }^{ \pm}$R.I. Responders implanted: N.N. Non-responders not implanted; N.I. Non-responders implanted

Table 2: Baseline Characteristics of 36 CRPS-1 Patients in Relation to Implant Effect

\begin{tabular}{|c|c|c|c|c|c|c|c|}
\hline \multicolumn{2}{|l|}{ Characteristic } & \multicolumn{4}{|c|}{ Implant Effect } & \multicolumn{2}{|c|}{$P$ Values } \\
\hline & & \multicolumn{2}{|c|}{ Trial Effect (N\%) } & \multicolumn{2}{|c|}{1 Year Effect (N\%) } & \multirow[t]{3}{*}{ Trial } & \multirow[t]{3}{*}{ 1Year } \\
\hline & & Successful & Unsuccessful & Successful & Unsuccessful & & \\
\hline & & $\mathrm{N}=24$ & $\mathrm{~N}=12$ & $N=20$ & $\mathrm{~N}=16$ & & \\
\hline \multirow[t]{2}{*}{ Age } & $\leq 40$ & $15(65 \%)$ & $8(35 \%)$ & $13(65 \%)$ & $7(35 \%)$ & \multirow{3}{*}{0.81} & \multirow[b]{2}{*}{0.20} \\
\hline & $>40$ & $9(69 \%)$ & $4(31 \%)$ & 7 (44\%) & $9(56 \%)$ & & \\
\hline \multirow[t]{3}{*}{ Gender } & Male $\mathrm{N}=14$ & $9(64 \%)$ & $5(36 \%)$ & $6(43 \%)$ & $8(57 \%)$ & & \\
\hline & Female $\mathrm{N}=22$ & $15(68 \%)$ & & $14(64 \%)$ & & \multirow[t]{2}{*}{0.81} & \multirow[t]{2}{*}{0.22} \\
\hline & & & $7(32 \%)$ & & $8(36 \%)$ & & \\
\hline \multirow[t]{2}{*}{ Localization } & Arm & $15(68 \%)$ & $7(32 \%)$ & $12(55 \%)$ & $10(45 \%)$ & \multirow{2}{*}{0.81} & \multirow{2}{*}{0.88} \\
\hline & Leg & $9(64 \%)$ & $5(36 \%)$ & $8(57 \%)$ & $6(43 \%)$ & & \\
\hline \multicolumn{2}{|c|}{ Disease duration $<40$} & $15(68 \%)$ & $7(32 \%)$ & $13(62 \%)$ & $8(38 \%)$ & \multirow{2}{*}{0.45} & \multirow{2}{*}{0.36} \\
\hline in months & $\geq 40$ & $9(64 \%)$ & $5(36 \%)$ & 7 (47\%) & $8(53 \%)$ & & \\
\hline \multirow[t]{2}{*}{ Pain intensity } & VAS $\leq 7.1$ & $12(75 \%)$ & $4(25 \%)$ & $12(57 \%)$ & $9(43 \%)$ & \multirow{2}{*}{0.34} & \multirow{2}{*}{0.20} \\
\hline & VAS $>7.1$ & $12(60 \%)$ & $8(40 \%)$ & $8(53 \%)$ & $7(47 \%)$ & & \\
\hline \multirow[t]{3}{*}{ Allodynia } & Absent & $14(88 \%)$ & $2(12 \%)$ & $13(81 \%)$ & $3(19 \%)$ & & \\
\hline & Moderate & $2(50 \%)$ & $2(50 \%)$ & $2(50 \%)$ & 2 (50\%) & \multirow[t]{2}{*}{0.06} & \multirow[t]{2}{*}{0.017} \\
\hline & Severe & $8(50 \%)$ & $8(50 \%)$ & 5 (31\%) & 11 (69\%) & & \\
\hline \multirow[t]{2}{*}{ Hypoesthesia } & Absent/light* & 11 (69\%) & $5(31 \%)$ & $8(50 \%)$ & $8(50 \%)$ & \multirow{2}{*}{0.81} & \multirow{2}{*}{0.55} \\
\hline & Severe** & $13(65 \%)$ & $7(35 \%)$ & $12(60 \%)$ & $8(40 \%)$ & & \\
\hline
\end{tabular}

*Normal sensibility or diminished sensibility to light touch

**Diminished sensibility or loss of protective sensation 
Table 3: Baseline characteristics of CRPS-1 Patients Non-responding to SCS Therapy

\begin{tabular}{|c|c|c|c|c|}
\hline & & Non-responde & ter one year of $t$ & tment \\
\hline & & $\mathrm{N}$ I. & ${ }^{\mathrm{N}} \mathrm{N}$ & ${ }^{\mathrm{N}} \mathrm{C}$ \\
\hline Characteristic & & $\mathrm{N}=4$ & $\mathrm{~N}=12$ & $\mathrm{~N}=16$ \\
\hline Age - Mean (SD) - R & nge & $46(9) 33-55$ & $41(14) 21-65$ & $42(13) 21-65$ \\
\hline Disease duration in & nonths - Mean (SD) -Range & 39(29) $11-76$ & $43(24) 14-99$ & $42(24) 11-99$ \\
\hline Pain intensity VAS in & mm - Mean (SD) - Range & $75(11) 60-85$ & $72(12) 54-95$ & $73(12) 54-95$ \\
\hline Gender N (\%) & Male & $3(75 \%)$ & $5(42 \%)$ & $8(50 \%)$ \\
\hline & Female & $1(25 \%)$ & $7(58 \%)$ & $8(50 \%)$ \\
\hline Localization N (\%) & Arm & $3(75 \%)$ & $7(58 \%)$ & $10(63 \%)$ \\
\hline & Leg & $1(25 \%)$ & $5(42 \%)$ & $6(37 \%)$ \\
\hline Allodynia N (\%) & Absent & $1(25 \%)$ & $2(17 \%)$ & $3(19 \%)$ \\
\hline & Moderate & $0(0 \%)$ & $2(17 \%)$ & $2(12 \%)$ \\
\hline & Severe & $3(75 \%)$ & $8(66 \%)$ & $11(69 \%)$ \\
\hline Hypoesthesia N(\%) & Absent/light* & $3(75 \%)$ & $5(42 \%)$ & $8(50 \%)$ \\
\hline & Severe** & $1(25 \%)$ & $7(58 \%)$ & $8(50 \%)$ \\
\hline
\end{tabular}

${ }^{\mathrm{N}}$ I. Non-responders implanted ${ }^{\mathrm{N}} \mathrm{N}$. Non-responders not implanted ${ }^{\mathrm{N}} \mathrm{C}$. Combined group of non-responders *Normal sensibility or diminished sensibility to light touch ${ }^{* *}$ Diminished sensibility or loss of protective sensation

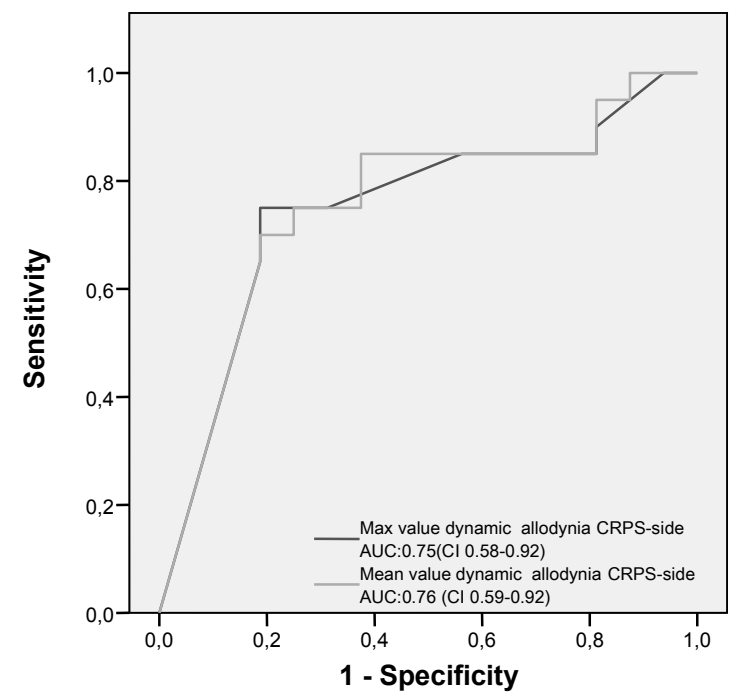

Figure 1: ROC Curve and Area Under the Curve. ROC Curve and Area Under the Curve of the Maximal and Mean Value of the Brush Evoked Allodynia Measurements on the CRPS-1 Affected Limb in Patients after 1 Year of SCS Treatment 


\section{Discussion}

Spinal cord stimulation is an established and effective treatment option for controlling chronic pain in CRPS-1 patients, but it is also an invasive and expensive therapy. The selection of optimal candidates is a very important factor for increasing SCS treatment success rates. In this study we showed that the presence of brush evoked allodynia may be a negative predictor for successful SCS treatment.

Not every patient achieves an acceptable reduction of pain following treatment with SCS. Patients with paraplegic pain, stump pain, and phantom limb pain do not respond to SCS, whereas patients having pain attributable to failed back syndrome, ischemic lower limb pain, painful peripheral neuropathy or CRPS-1 in general do. ${ }^{14}$ In patients with failed back syndrome who have undergone surgical procedures it has been demonstrated that, with a shorter duration of the pain syndrome, greater rates of success could be achieved ${ }^{14}$. In the present study with chronic CRPS-1 patients, we could not confirm this correlation between disease duration and SCS success. Others found that increased patient age was inversely correlated with SCS success, in a patient population consisting mainly of failed back surgery syndrome; however, in our population of CRPS-1 patients we observed no effect of patient age on outcome ${ }^{20}$.

SCS has evolved as a clinical application of Melzack and Wall's gate-control theory $^{21}$. The general mechanism of pain relief by SCS is still understood in these gating terms. The pain alleviating effect is generally seen to be caused by activation of large-diameter afferents in the dorsal columns. The fact that chronic neuropathic pain patients, even those with severe hypoesthesia, can still show a successful response to SCS might be explained by the presence of remaining intact large fibers in the dorsal column which can be recruited for stimulation.

Pain in an affected extremity provoked by the normally non painful stimulus of a brush is regarded as a sign of central sensitization ${ }^{22}$. Our results show that brush evoked allodynia seems to be associated with a lower chance of achieving long-term pain reduction with SCS treatment. This phenomenon is probably due to central sensitization which makes it difficult to suppress the total experienced pain, both spontaneous and evoked, even when stimulating the spinal cord dorsal columns. Central sensitization on spinal level occurs in the dorsal horn and is probably caused by repetitive high frequency stimulation of peripheral C-fibres leading to an amplification and prolongation of the response of the dorsal horn neurons, a phenomenon called 'wind up'. This process may be linked to increased release of substance $P$ and the excitatory neurotransmitter glutamate, mediated through voltage gated $\mathrm{N}$ calcium channels, leading to postsynaptic N-methyl-D-aspartate (NMDA) receptor interaction and hyperexcitability. Furthermore the amount of inhibitory neurotransmitter Gamma-aminobutyric acid (GABA) and GABAergic interneurones within the spinal cord may increase or decrease the output of the dorsal horn. These 
mechanisms cause increased sensitivity to pain (hyperalgesia) and input from nonnociceptive Aß-fibres to be perceived as pain (allodynia) ${ }^{23,24}$

So far, neurochemical and electrophysiological evidence from experimental studies has suggested that the effects of SCS on the dorsal columns are mediated centrally in the dorsal horns of the spinal cord, by altering the release of neurotransmitters (e.g. increased release of GABA) and suppression of hyperexcitable WDR (Wide Dynamic Range neurons) ${ }^{25}$. In experimental SCS the amount of pain relief is related to the severity of allodynia ${ }^{16,26}$. The non-response to SCS in animals with severe allodynia may well relate to a severe form of central neuropathic derangement and may imply a disability to produce appropriate amounts of GABA, either alone or accompanied by the increased loss of inhibitory interneurons. In this scenario modulation of dorsal horn neurons by SCS could have either little or no effect. Other animal studies showed that the combination of SCS with pharmacological therapy, in rats not responsive to SCS, can become effective when combined with intrathecal or intravenous medication like baclofen, adenosine, gabapentin and pregabalin. ${ }^{27}$.

Non of these medications were being used by the described patients. CRPS patients who fulfil the criteria for SCS are rather scarce and, although the sample sizes of our study are small, we consider the present study of interest because it can provide new insights into pain mechanism and treatment in CRPS-1 patients. Because of these small sample sizes we adjusted our statistical tests for small and nonparametric data.

In the most ideal situation, when comparing different possible predictors, all patients in one group should have undergone exactly the same treatment. In this study 12 patients who did not show pain reduction after one week of trial stimulation and the 4 patients who did receive an implant but showed significant loss of pain reduction after one year were both considered non responders. These 16 patients were compared to the responder group where all patients received an SCS implant. Because both groups did not receive exactly the same treatment which is preferable in predictor studies, we analyzed the groups according to success of the trial versus failure of the trial and the association with allodynia. This reflects widely accepted routine clinical practice where patients indeed have the device removed, or permanent stimulating treatment is not considered, if they do not have significant pain reduction after the trial period.

To our knowledge the predictive effect of mechanical allodynia on the outcome of SCS therapy in neuropathic pain syndromes such as CRPS-1 has never been investigated. We tested for brush evoked allodynia in nine standardized places of the hand or foot and calculated the mean. However, the ROC curve shows that brush evoked allodynia at the area of maximal pain is an equally effective indicator as the average of nine individual allodynia measurements. This has clinical relevance since the attention of clinician and patient in routine clinical assessment of CRPS-1 pa- 
tients is typically directed towards the area of maximal pain and allodynia. As in diabetic neuropathy, severe hypoesthesia of the plantar aspect of the foot can easily be detected by bed side testing using the 10 grams filament and severe hypoesthesia of the hand and dorsal aspect of the foot can easily be detected using the 4 grams filament ${ }^{28}$. We showed that there was no correlation between the severity of hypoesthesia and the success of SCS. Hence testing for the presence of hypoesthesia, despite its importance in the diagnosis of CRPS-1, seems to be of no value in predicting SCS success.

In conclusion, there seems to be a good chance (81\%) of achieving and maintaining successful pain reduction for more than one year with SCS if allodynia is absent before stimulation is started. If brush evoked allodynia is shown with a minimal intensity of 2.5 on a NRS scale, the chance of achieving successful stimulation is significantly lower (31\%). This does not necessarily mean that patients with allodynia should be denied a test spinal cord stimulation since there still is a $31 \%$ chance of achieving successful pain reduction. However, if there is any doubt about satisfactory pain reduction in a patient with allodynia after the trial phase, it is probably better not to proceed with a definitive implant.

\section{References}

1. Merskey H, Bogduk N. Classification of Chronic Pain: Descriptions of Chronic Pain Syndromes and Definitions of Pain Terms., 2 ed. Seattle: Wash: IASP Press; 1994.

2. Kemler MA, Schouten HJ, Gracely RH. Diagnosing sensory abnormalities with either normal values or values from contralateral skin: comparison of two approaches in complex regional pain syndrome I. Anesthesiology. 2000;93:718-727.

3. Maihofner C, Handwerker HO, Birklein F. Functional imaging of allodynia in complex regional pain syndrome. Neurology. 2006;66:711-717.

4. Maihofner C, Birklein F. [Complex regional pain syndromes: new aspects on pathophysiology and therapy]. Fortschr Neurol Psychiatr. 2007;75:331-342.

5. Grabow TS, Tella PK, Raja SN. Spinal cord stimulation for complex regional pain syndrome: an evidence-based medicine review of the literature. Clin J Pain. 2003;19:371-383.

6. Taylor RS, Van Buyten JP, Buchser E. Spinal cord stimulation for complex regional pain syndrome: a systematic review of the clinical and cost-effectiveness literature and assessment of prognostic factors. Eur J Pain. 2006;10:91-101.

7. Kemler MA, De Vet HC, Barendse GA, Van Den Wildenberg FA, Van Kleef M. The effect of spinal cord stimulation in patients with chronic reflex sympathetic dystrophy: two years' follow-up of the randomized controlled trial. Ann Neurol. 2004;55:13-18.

8. Kumar K, Wilson JR, Taylor RS, Gupta S. Complications of spinal cord stimulation, suggestions to improve outcome, and financial impact. J Neurosurg Spine. 2006;5:191-203.

9. Kemler MA, Reulen JP, Barendse GA, van Kleef M, de Vet HC, van den Wildenberg FA. Impact of spinal cord stimulation on sensory characteristics in complex regional pain syndrome type I: a randomized trial. Anesthesiology. 2001;95:72-80.

10. North RB. Spinal cord stimulation for chronic, intractable pain: superiority of "multichannel" devices. Pain. 1991;44:119-130. 
11. Spiegelmann R, Friedman WA. Spinal cord stimulation: a contemporary series. Neurosurgery. 1991;28:65-70; discussion 70-61.

12. Farrar JT, Jr. JPY, LaMoreaux L, Werth JL, Poole RM. Clinical importance of changes in chronic pain intensity measured on an 11-point numerical scale. Pain. 2001;94:149-158.

13. Kemler MA, de Vet HC, Barendse GA, van den Wildenberg FA, van Kleef M. Effect of spinal cord stimulation for chronic complex regional pain syndrome Type I: five-year final follow-up of patients in a randomized controlled trial. J Neurosurg. 2008;108:292-298.

14. Kumar K, Toth C, Nath RK, Laing P. Epidural spinal cord stimulation for treatment of chronic pain-some predictors of success. A 15-year experience. Surg Neurol. 1998;50:110-120; discussion 120111.

15. Sindou MP, Mertens P, Bendavid U, Garcia-Larrea L, Mauguiere F. Predictive value of somatosensory evoked potentials for long-lasting pain relief after spinal cord stimulation: practical use for patient selection. Neurosurgery. 2003;52:1374-1383; discussion 1383-1374.

16. Smits $H$, Ultenius $C$, Deumens R, Koopmans GC, Honig WM, van Kleef M, et al. Effect of spinal cord stimulation in an animal model of neuropathic pain relates to degree of tactile "allodynia". Neuroscience. 2006;143:541-546.

17. Kemler MA, Barendse GA, van Kleef $M$, de Vet HC, Rijks CP, Furnee CA, et al. Spinal cord stimulation in patients with chronic reflex sympathetic dystrophy. N Engl J Med. 2000;343:618-624.

18. Jensen MP, McFarland CA. Increasing the reliability and validity of pain intensity measurement in chronic pain patients. Pain. 1993;55:195-203.

19. Forouzanfar $T$, Weber WE, Kemler M, van Kleef $M$. What is a meaningful pain reduction in patients with complex regional pain syndrome type 1? Clin J Pain. 2003;19:281-285.

20. Burchiel KJ, Anderson VC, Wilson BJ, Denison DB, Olson KA, Shatin D. Prognostic factors of spinal cord stimulation for chronic back and leg pain. Neurosurgery. 1995;36:1101-1110; discussion 11101101.

21. Melzack R, Wall PD. Pain mechanisms: a new theory. Science. 1965;150:971-979.

22. Vaneker $M$, Wilder-Smith $O H$, Schrombges $P$, de Man-Hermsen I, Oerlemans HM. Patients initially diagnosed as 'warm' or 'cold' CRPS 1 show differences in central sensory processing some eight years after diagnosis: a quantitative sensory testing study. Pain. 2005;115:204-211.

23. Baron R. Neuropathic pain: a clinical perspective. In: Hofmann FB, Ganten D, Page CP, Rosenthal W, Michel MC, Beavo JA, et al., eds. Handbook of experimental pharmacology, Vol. ed. Berlin: Springer; 2009. 3-30.

24. D'Mello R, Dickenson AH. Spinal cord mechanisms of pain. Br J Anaesth. 2008;101:8-16.

25. Cui JG, Linderoth B, Meyerson BA. Effects of spinal cord stimulation on touch-evoked allodynia involve GABAergic mechanisms. An experimental study in the mononeuropathic rat. Pain. 1996;66:287-295.

26. Yakhnitsa V, Linderoth B, Meyerson BA. Spinal cord stimulation attenuates dorsal horn neuronal hyperexcitability in a rat model of mononeuropathy. Pain. 1999;79:223-233.

27. Wallin J, Cui JG, Yakhnitsa V, Schechtmann G, Meyerson BA, Linderoth B. Gabapentin and pregabalin suppress tactile allodynia and potentiate spinal cord stimulation in a model of neuropathy. Eur J Pain. 2002;6:261-272.

28. Perkins BA, Olaleye D, Zinman B, Bril V. Simple screening tests for peripheral neuropathy in the diabetes clinic. Diabetes Care. 2001;24:250-256. 
CHAPTER V

\section{Spinal Cord Stimulation in Complex Regional}

\section{Pain Syndrome type 1 of less than twelve} months duration.

\section{A prospective observational study}

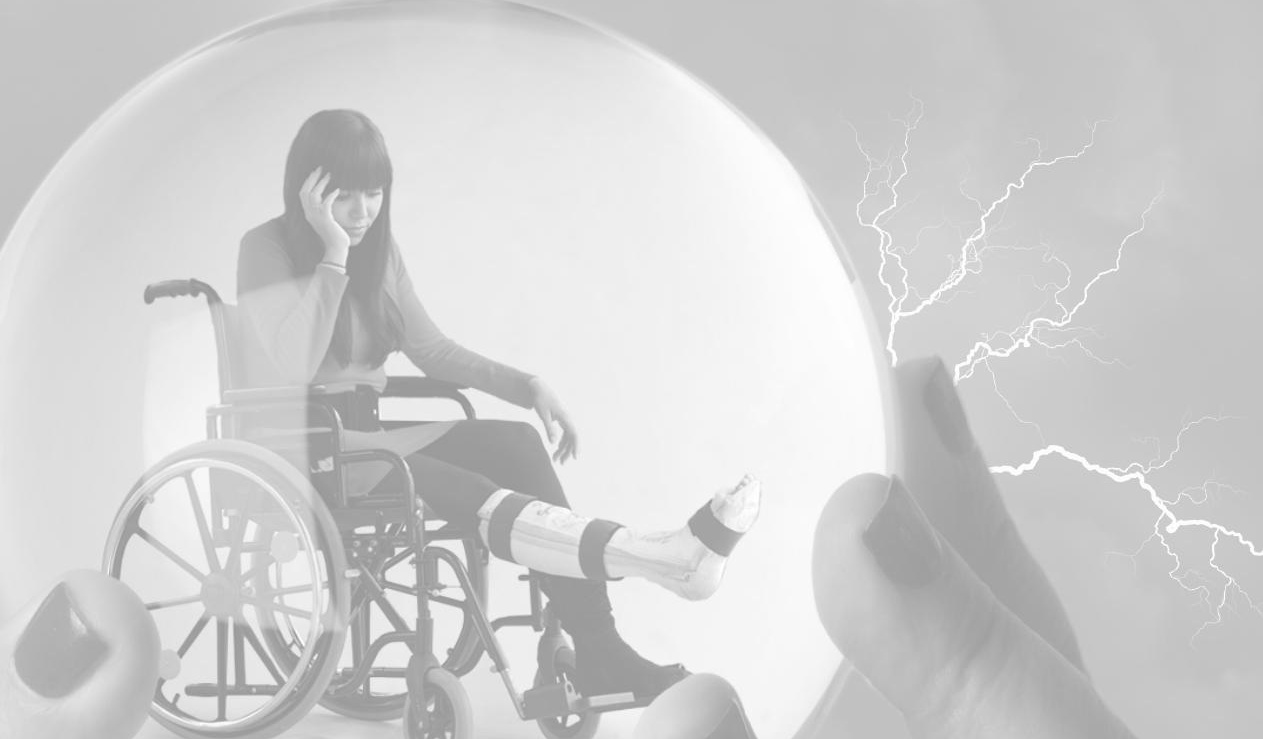

Frank van Eijs MD, José Geurts MSc, Jan Van Zundert MD, PhD, FIPP, Catharina G Faber MD, PhD, Alfons G.H. Kessels PhD, Elbert A.J. Joosten PhD, Maarten van Kleef $\mathrm{MD}, \mathrm{PhD}, \mathrm{FIPP}$

Neuromodulation: in press 


\begin{abstract}
Introduction: Complex regional pain syndrome type 1 (CRPS-1) has a high probability of becoming chronic. The early use of spinal cord stimulation (SCS) has been recommended as a strategy to prevent chronicity.

Methods: In a prospective study we treated 74 CRPS-1 patients with a mean disease duration of 17 weeks with standard therapy consisting of physical therapy, topical dimethyl sulfoxide, analgesics, transcutaneous stimulation and sympathetic blockade. Patients who did not respond to standard therapy were offered treatment with SCS. In these patients we investigated the impact on pain, quality of life (SF36) and functional outcome.

Results: Out of 74 patients treated with standard therapy, 55 (74\%) improved. Twelve patients were eligible for early SCS treatment. Six patients refused and six patients received SCS. In these six patients included for early SCS, the overall mean pain relief after one year was 35\%. The mental component of the SF36 improved, however, there was no effect on the physical component. None of the patients showed a clear improvement in functional outcome. This is comparable to chronic, sympathetically independent, CRPS-1 patients treated with SCS.

Conclusion: We conclude that the feasibility of doing a study on early SCS therapy in CRPS-1 is low because of the good improvement of the disease with standard therapy in the first year after onset. This study raises questions about the need to use SCS early in the course of CRPS-1 because of the probable lack of additional benefit compared to SCS in chronic, sympathetically independent, CRPS-1.
\end{abstract}




\section{Introduction}

Complex regional pain syndrome type 1 (CRPS-1) is a severe chronic pain condition characterized by sensory, autonomic, motor, and dystrophic signs and symptoms. It usually occurs after trauma and is characterized by spontaneous and evoked pain which is disproportionate in severity and duration to the expected course of the initiating trauma. ${ }^{1}$ The reported incidence varies from 5.46 to 26.2 per 100,000 person years. Women are affected 3.4 to 4 times more often than men. ${ }^{2,3}$ In general, the outcome of chronic CRPS is not favorable. After one year, signs and symptoms in patients with CRPS are well developed and pain is refractory, with the majority of patients demonstrating only moderate increase in symptoms over the following years. ${ }^{4}$ In a population based cohort study of 102 CRPS patients, $31 \%$ remained incapable to work after two or more years. ${ }^{5}$ Of these patients, $64 \%$ still showed persistent signs and symptoms 5.8 years after onset of the syndrome (range 2.1 to 10.8 years). CRPS therefore is a serious condition with a high probability of chronicity and residual impairment. Recommendations from an expert panel suggest concomitant use of psychological, rehabilitation and interventional pain management techniques. ${ }^{6}$ Therapy aimed at restoring function should be started as soon as possible, as any delay in treatment is likely to worsen outcome. Spinal cord stimulation (SCS) is a more invasive technique to be considered when other treatments fail. A systematic review reports spinal cord stimulation (SCS) to be a (cost)effective therapy in the management of patients with chronic CRPS-1. ${ }^{7}$ However, despite its efficacy in the treatment of pain, SCS performed in chronic CRPS-1 showed no important improvement in functional outcome. ${ }^{8}$ Therefore the early use of SCS for the management of CRPS was recommended as a strategy to prevent chronicity and possible central sensitization in order to improve pain, functional status and outcome. ${ }^{9}$ A favorable outcome of CRPS is reported in some case studies where SCS was used in the first year of the syndrome. ${ }^{10,11}$ In a retrospective case series describing early SCS intervention in ten consecutive military personnel patients with CRPS of 5-12 months duration, significant reduction of pain and daily morphine requirements was reported. All patients became compliant with physical therapy and six returned to active duty. These initial findings suggested that early use of SCS, i.e. less than one year after the inciting event, improves functional outcome. ${ }^{12}$ We report a prospective observational study where we investigated the feasibility of treating patients with SCS within one year after the onset of CRPS, and studied the attributed beneficial effect of SCS on pain and functional outcome if applied early in the course of the disease. 


\section{Patients and Methods}

\section{Patients}

In this prospective observational study, we screened all consecutive patients referred to our pain management center with a possible diagnosis of CRPS. Medical specialists and family physicians were informed by mail of the intention to start a study investigating the effect of SCS applied early in the course of CRPS-1, if patients did not obtain satisfactory pain reduction after standard therapy. They were asked to refer patients with severely painful CRPS-1 limited to one extremity, upper or lower, and in an early stage of the disease. Patients were eligible for the study if they had CRPS-1 according to the criteria established by the International Association for the Study of Pain (IASP). ${ }^{1}$ Other inclusion criteria were: disease duration less than one year; signs/symptoms in one extremity only; no treatable underlying cause of the pain; age 18 years or older; able to follow written and verbal instructions; mean Numerical pain Rating Score (NRS) according to Jensen ${ }^{13}$ of five or more on a scale from 0 to 10 (with 0 meaning no pain at all and 10 meaning the worst imaginable pain); no pain reduction with persistent functional impairment after initial standard therapy. Exclusion criteria were: pregnancy, coagulation disorders, general infection, fever or local infection at the puncture site, drug or alcohol abuse, an implanted pacemaker, diabetic polyneuropathy or any other disease that may account for signs and symptoms mimicking CRPS. Patients with an immune deficiency or patients using immunosuppressive drugs were also excluded. The study was approved by the medical ethics committees of the Maastricht University Medical Centre, the Netherlands and the St. Elisabeth Hospital in Tilburg, the Netherlands. All patients gave written informed consent.

\section{Variables}

Average week pain scores were derived from numerical pain ratings (NRS), assessed 5 days in a row, three times a day. ${ }^{13,14}$ We asked patients to fill in a pain assessment diary at home at baseline and for the SCS treated group at 6 weeks, 3, 6, and 12 months after the implantation.

Clinically important change was assessed using the Patient Global Impression of Change (PGIC), a seven-point ordinal scale used after treatment as an external criterion of clinical change (1 worst ever- 2 much worse- 3 worse- 4 no change- 5 improved- 6 much improved -7 best ever). The PGIC was translated into Dutch in accordance with international guidelines. ${ }^{15,16}$ PGIC measures have been demonstrated to be valid indicators of important change in CRPS patients. ${ }^{15,17}$

Evoked pain was registered at baseline in three ways: the allodynia for touch by stroking the skin of the dorsal aspect of the affected foot or hand with a cotton 
wisp, the allodynia for pressure by gently squeezing the ankle fork or styloid processes of wrist and the allodynia for movement by passive movement of the involved foot or hand. Tests were considered positive if they caused pain.

Quality of life (QoL) was assessed by means of the Dutch language version of the Short Form 36 (SF36). ${ }^{18}$ Functional status was assessed with the Walking Questionnaire (WQ) and the Questionnaire Rising an Sitting down (QRS). ${ }^{19}$ The WQ consists of two scales, 'walking inside the house' and 'walking outside', it measures the walking activity limitations at home living patients with lower-extremity disorders. ${ }^{20}$

\section{Standard therapy}

According to CRPS treatment guidelines, ${ }^{21}$ all patients received early physical therapy aimed at active mobilization, according to a fixed protocol which consisted of graded exercises aimed at restoring strength, mobility and function of the affected extremity. Physical therapy was applied twice a week with a minimum duration of 30 minutes. Exercises were adjusted so that an increase of pain occurring during and after exercise returned to pre-session levels within 24 hours. ${ }^{22}$ Topical application of the free radical scavenger dimethyl sulfoxide 50\% (DMSO-50\%) three to five times daily was given as anti-inflammatory therapy. The physical therapy was supplemented with oral analgesic medication such as NSAID's, acetaminophen and tramadol. If no pain relief was obtained with at least three weeks of the analgesic medication, gabapentin was given in doses up to $1800 \mathrm{mg}$ daily. No pain relief was defined as NRS unchanged or maximal one point improvement. If no pain relief was obtained after at least three weeks of gabapentin, transcutaneous electrical stimulation (TENS) was applied during two weeks. If there was insufficient pain relief with these interventions sympathetic blockade, i.e. stellate ganglion block for the upper extremity and lumbar sympathetic block for the lower extremity was applied. ${ }^{23,24}$ If patients had moderate to good pain relief after a test SB, the SB was repeated at least three times with one week interval. Spinal cord stimulation was offered if there still was considerable pain (NRS of five or more) with persistent functional impairment despite the standard therapy.

\section{Test stimulation and implantation of the spinal cord stimulator}

All patients eligible for SCS received a test spinal cord stimulation according to our in hospital standard practice for a period of one week home testing with a temporary percutaneous lead. This electrode (model 3861, Medtronic, Minneapolis) was placed epiduraly under fluoroscopic guidance with the patient in the prone position. For lower extremity CRPS-1 the tip of the electrode was placed at the Th10-11 level and for upper extremity CRPS-1 the tip of the electrode was placed at the C3-4 level. After the testing period the electrode was removed. A spinal cord stimulator 
was implanted within four weeks after the test stimulation period if patients responded to SCS therapy. Patients who did not respond to SCS therapy were treated with physical therapy alone. Standard implantation techniques as described earlier were used. ${ }^{25}$ Again in the prone position, a quadripolar electrode (model 3487A, Medtronic, Minneapolis) was inserted in approximately the same location as the temporary lead but this time through a $5 \mathrm{~cm}$ vertical midline incision in the skin overlying the upper thoracic (for CRPS of the hand) or lumbar spine (for CRPS of the foot). After obtaining adequate stimulation patterns, the electrode was fixed to the lumbar fascia with an anchor after which the patient was placed in a left or right lateral decubitus position. General anesthesia was induced with propofol and sufentanil. A laryngeal mask was introduced subsequently. The electrode was connected by means of a tunneled extension lead (model 7495, 51/66, Medtronic, Minneapolis) to an Itrel III pulse generator (model 7425, Medtronic, Minneapolis) implanted in the right or left lower abdominal wall. The pulse generator was set at a frequency of $80 \mathrm{~Hz}$ and a pulse width of $210 \mu \mathrm{sec}$. The patient could control the amplitude of the stimulator from 0 to $10 \mathrm{~V}$ with a patient programmer (model 7434, Medtronic, Minneapolis) The patient was discharged the next day after adequate electrode positioning confirmation by $\mathrm{X}$-ray and patient report of paresthesias covering the painful area of the involved limb.

\section{Definition of a responder to SCS therapy}

A responder is defined as a patient with a mean NRS pain score reduction of at least $50 \%$ during the last 4 home testing days of trial SCS and a PGIC score of 6 or 7 (much improved or best ever) on a seven point scale.

\section{Data collection and follow up of the spinal cord stimulated group}

Patient characteristics and variables were measured at baseline, 6 weeks, and 3, 6, and 12 months after implantation. We asked the patients to fill in the diary and questionnaires at home and requested to bring the completed forms to the pain center.

\section{Statistical analysis}

Mean weekly pain scores were calculated per patient. In the SCS treated group mean total scores and change scores were calculated of the WQ and QRS. The data were processed and analyzed using the Statistical Package for the Social Sciences, version 15.0 (SPSS Inc., Chicago, II). 


\section{Results}

Out of 147 patients with presumed CRPS, referred for this study between June 2005 and October 2008, 74 patients fulfilled the inclusion criteria. These 74 patients with CRPS-1 in one extremity and with a disease duration of less than 12 months (mean duration 17 weeks, range 2-50 weeks) received standard therapy with the possibility of early treatment with SCS in case of failure of this standard therapy. Fifty-five (74\%) patients improved to a mean pain score of 2.1 (range 0 to less than 5) with standard therapy. Two patients with persistent severe pain scores of more than 5 after standard therapy were excluded because all other symptoms totally subsided and they did not meet the IASP CRPS-1 criteria anymore. One patient was excluded because, after standard therapy, symptoms existed for more than one year. Of the 12 patients, eligible for early SCS, 6 patients (50\%) refused the SCS treatment and withdrew from participation in the study. The remaining 6 patients underwent a test spinal cord stimulation (figure 1 ).

All 6 patients in the SCS treated group were women with CRPS located in the lower extremities (table 1).

Mean age was 35 year (SD 17.5), mean disease duration was 7.5 months with a range of $5-10$ months. The initiating event for CRPS was surgery, fracture, sprain or the symptoms occurred spontaneously. Patients 1-3 did not meet the criteria for permanent SCS implantation (negative trial stimulation); patients 4-6 were implanted with a permanent device after a successful one week trial. No complications requiring re-intervention occurred during the one year follow up period.

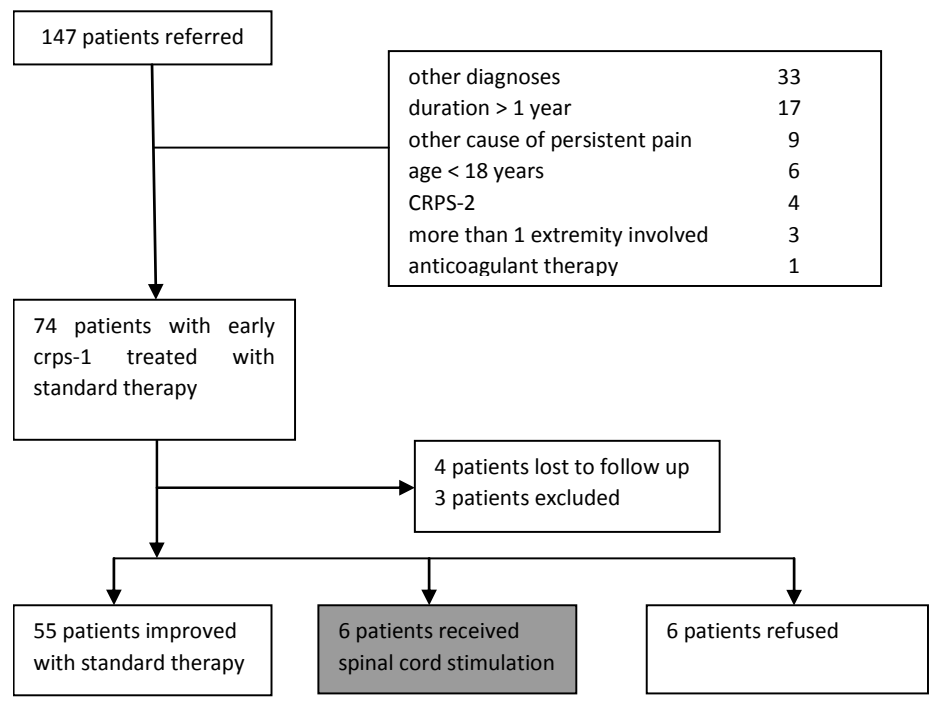

Figure 1: Flow chart of referred patients 
Table1: Patient characteristics

\begin{tabular}{llllllll}
\hline Patient & Gender & $\begin{array}{l}\text { Age } \\
\text { (Years) }\end{array}$ & $\begin{array}{l}\text { CRPS } \\
\text { Location }\end{array}$ & $\begin{array}{l}\text { Duration CRPS } \\
\text { (months) }\end{array}$ & $\begin{array}{l}\text { Initial trauma } \\
\text { Relial pain }\end{array}$ & $\begin{array}{l}\text { Endpoint } \\
\text { pain relief } \\
(1 \text { Year) }\end{array}$ \\
\hline 1 & Woman & 55 & Right leg & 5 & Surgery & $13,3 \%$ & $20,7 \%$ \\
2 & Woman & 60 & Right leg & 7 & Fracture & $45,1 \%$ & $30,7 \%$ \\
3 & Woman & 21 & Left leg & 10 & Sprain & $10,1 \%$ & $37,4 \%$ \\
4 SCS & Woman & 27 & Left leg & 5 & Surgery & $60,1 \%$ & $47,0 \%$ \\
5 SCS & Woman & 23 & Left leg & 9 & Spontaneously & $52,4 \%$ & $36,6 \%$ \\
6 SCS & Woman & 25 & Left leg & 9 & Sprain & $50,6 \%$ & $38,7 \%$ \\
\hline
\end{tabular}

$\mathrm{SCS}=$ treated with Spinal Cord Stimulation after a positive trial period

\section{Spinal cord stimulated group}

\section{Pain}

The evoked pain/allodynia at baseline was tested positive for pressure and movement in all six patients and for touch in 3 of the 6 patients.

After the SCS trial period of one week 4 out of the 6 patients had an improvement in mean pain score (figure 2).

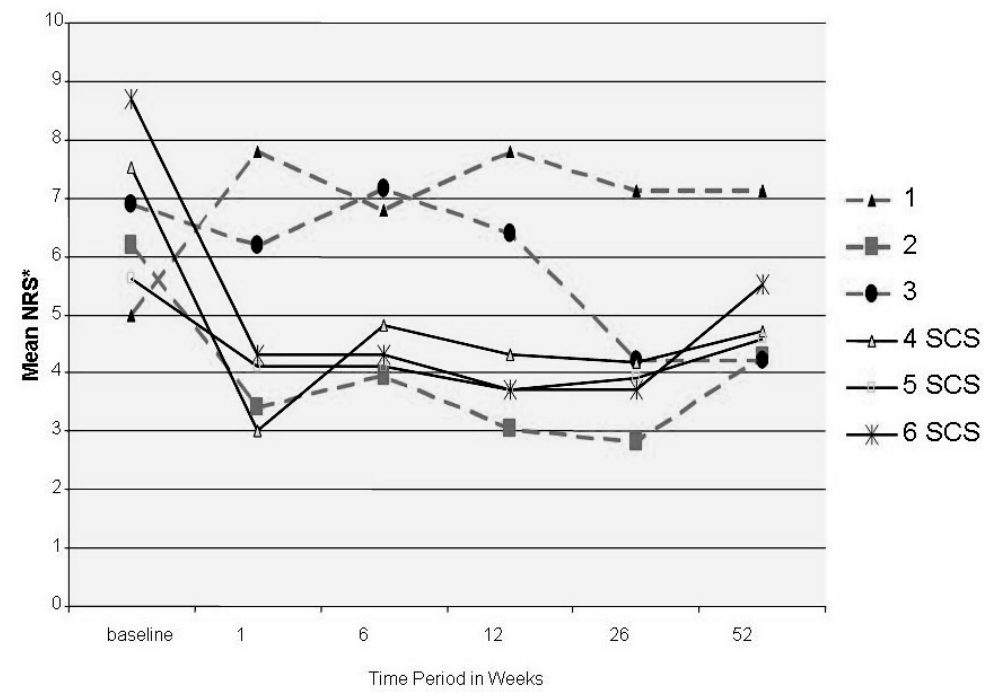

Figure 2: Mean pain scores (NRS) assessed at baseline and 1,6,12,26 and 52 weeks after trial SCS.

Three patients met the more than $50 \%$ pain reduction inclusion criterion for permanent implantation. There was an overall mean pain relief of $35 \%$ after one year. Four patients had a mean pain reduction of at least 2 points, in one patient pain decreased with 1 point and one patient had an increase in mean pain $(+2.1)$. The 
initially observed greater pain reduction in the patients with a permanent SCS, compared to the patients not permanently treated with SCS, evened out after one year.

\section{Patient Global impression of change (PGIC)}

PGIC was assessed by patients at 6 weeks, 3, 6, and 12 months after trial spinal cord stimulation. After one year, two patients scored much improved and one patient scored unchanged in the implanted group. In the not implanted group two patients scored much improved and one patient scored worse.

\section{Quality of life}

In patients treated with SCS in the early phase of the disease there was improvement in mental wellbeing as measured by the SF36 Mental Component Summary. There was no clear effect on physical functioning (SF36 Physical Component Score). (table 2)

Table 2: SF 36 quality of life

\begin{tabular}{lllllllll}
\hline & \multicolumn{2}{l}{ Baseline MHS } & \multicolumn{2}{l}{ MHS 1 Year } & \multicolumn{2}{l}{ Baseline PHS } & \multicolumn{2}{l}{ PHS 1 Year } \\
& Mean & SD & Mean & SD & Mean & SD & Mean & SD \\
\hline SCS & 50,7 & 13,1 & 64,0 & 8,7 & 23,7 & 12,7 & 23,7 & 2,5 \\
NI & 56,5 & 14,8 & 46,7 & 11,7 & 35,5 & 12,7 & 35,3 & 2,1 \\
\hline
\end{tabular}

NI not implanted; MHS Mental Component Summary; PHS Physical Component Summary

\section{Functional status}

Functional status was assessed with the Walking Questionnaire and Questionnaire Rising an Sitting down (table 3).

One (not implanted) patient showed an improvement in walking function outside the house but not in walking in the house. All others showed no improvement in walking function neither in the house, nor outside. It is noticeable that all patients show worsening of function in rising and sitting down (QRS) after one year of treatment. 
Table 3: Total scores and difference scores of baseline and endpoint measurement for changes in functional impairment

\begin{tabular}{|c|c|c|c|c|}
\hline \multirow[t]{2}{*}{ Patient } & & \multicolumn{2}{|l|}{ WQ/QRS } & \multirow{2}{*}{$\begin{array}{l}\text { Endpoint comparison } \\
\text { Difference }^{\#}\end{array}$} \\
\hline & & Baseline & Endpoint (1 year) & \\
\hline \multirow[t]{3}{*}{1} & WH & 5,2 & 5,9 & $-0,7$ \\
\hline & wo & 8,9 & 6,5 & 2,4 \\
\hline & RS & 1,8 & 8,4 & $-6,6$ \\
\hline \multirow[t]{3}{*}{2} & WH & 6,5 & 5,9 & 0,6 \\
\hline & wo & 8,7 & 8,7 & 0,0 \\
\hline & RS & 8,4 & 10,0 & $-1,6$ \\
\hline \multirow[t]{3}{*}{3} & WH & 7,6 & 7,6 & 0,0 \\
\hline & Wo & 10,0 & 10,0 & 0,0 \\
\hline & RS & 6,3 & 6,8 & $-0,5$ \\
\hline \multirow[t]{3}{*}{4 SCS } & WH & 10,0 & 10,0 & 0,0 \\
\hline & wo & 10.0 & 10,0 & 0,0 \\
\hline & RS & 10,0 & 10,0 & 0,0 \\
\hline \multirow[t]{3}{*}{$5 \mathrm{SCS}$} & WH & 4,7 & 7,1 & $-2,4$ \\
\hline & Wo & 6,1 & 7,0 & $-0,9$ \\
\hline & RS & 3,2 & 9,5 & $-6,3$ \\
\hline \multirow[t]{3}{*}{$6 \mathrm{SCS}$} & WH & 5,3 & 5,9 & $-0,6$ \\
\hline & Wo & 6,1 & 7,0 & $-0,9$ \\
\hline & RS & 3,2 & 7,9 & $-4,7$ \\
\hline
\end{tabular}

$\mathrm{WH}=$ Walking in the house $\mathrm{WO}=$ Walking outside; RS=Rising and sitting down

\#-Values reflect worsening of functional impairment

\section{Discussion}

Of the 74 patients with early CRPS-1, 55 (74\%) patients improved to a mean pain score of 2.1 (range 0 to less than 5) after the initial standard treatment, thus no longer qualifying for early intervention with SCS therapy. Only six patients during a three year period could eventually be included for early SCS making the study underpowered and making it impossible to draw firm conclusions as to the effectiveness of SCS in the early stage of CRPS-1. The standard therapy as described in the methods section could take up to 9 weeks before patients were offered SCS treatment. The positive outcome of so many early CRPS-1 patients after standard therapy i.e. 74\% was unanticipated at the start of the study. The power analysis for a randomized controlled trial comparing early SCS treatment to a control group, estimated a sample size of 64 patients. To include 64 patients without improvement after standard treatment, about 800 patients with early CRPS-1 should be screened. Given the incidence rate of approximately 16 (5-26) per 100,000 person years and the referral area of our institutions for early CRPS-1 patients of 500000 persons, 10 years of inclusion would be needed. We therefore conclude that the feasibility of performing a proper RCT that questions the efficacy of early SCS is low. ${ }^{2,3}$ 
In the patients treated with early SCS a mean $35 \%$ pain reduction was obtained, and an improvement in mental but not in functional outcome was seen. These observations are comparable to earlier observations in a chronic CRPS- 1 population. ${ }^{8}$ Moreover, we found no indication that the percentage of responders (three out of six) to SCS therapy in the early phase of CRPS-1 (mean duration of CRPS-1 of 7.5 months, range 5-10 months) is any different than in the chronic CRPS-1 population (mean duration of CRPS-1 of 40 months, range 12-68 months) where two out of three patients were responder to SCS therapy. ${ }^{8}$ It should be noted that all our patients had no pain relief after sympathetic block and thus could be qualified as having sympathetically independent pain. In a study of 29 chronic CRPS-1 patients of more than one year duration with sympathetically maintained pain (SMP), demonstrated by a positive short lasting pain relieving response to sympathetic block, patients showed not only pain relief but also improvement in functional status after treatment with SCS. ${ }^{26}$ The positive effect of SCS in SMP was demonstrated by the reversal of the vasoconstriction and reduced blood flow with activation of the SCS. ${ }^{26}$ This effect on the microcirculation however, could not be demonstrated in patients with CRPS-1 associated sympathetically independent pain. ${ }^{27}$ In our study we used the older quadripolar electrodes because the newer octapolar electrodes were not yet routinely available at the time of inclusion. We doubt however that results would be any different if the newer octapolar electrodes had been used, because the area of pain was adequately covered by paresthesia in all SCS treated patients.

The large number of drop outs in our patient group (six out of twelve or 50\%) may be due to the relatively brief duration of CRPS-1, at the time when patients are offered to be treated with SCS. There seems to be considerable hesitation to undergo such a kind of invasive treatment early in the course of the disease. Our findings raise questions about the better outcome of CRPS-1 patients with associated sympathetically independent pain when intervention with SCS is applied early in the course of the disease. Others found SCS to be extremely successful in the treatment of early CRPS. ${ }^{12}$ The degree of pain reduction obtained with SCS in a group of ten consecutive CRPS patients was considerably higher with a mean $79 \%$ pain reduction (pain score $7.8 \pm 1.3$ to pain score $1.6 \pm 1.5$ ) versus only $35 \%$ in our implanted group. The higher pain reduction indeed would allow for a better compliance with physical therapy and a better functional outcome. ${ }^{12}$ Again, eight out of ten patients were qualified as having SMP. The lesser pain reduction in our early stimulated patients could also be related to an early onset of central sensitization. All six patients indeed showed clinical signs of central sensitization as measured by the baseline allodynia testing. From surgical postoperative pain research we know that nociceptioninduced central sensitization mediated through the involvement of excitatory amino acids via the $\mathrm{N}$-methyl-D-aspartate receptor may start during and in the first hours after surgery. This process moves from activation and modulation of the central nervous system (CNS) to modification of the CNS and chronic pain. ${ }^{28}$ Experimental 
work has shown that central sensitization is a key event during the development of neuropathic pain. Central sensitization of somatosensory neurons in the dorsal horn of the spinal cord refers to an increased synaptic activity established in these neurons. ${ }^{29}$ This activity dependent central sensitization, which often is initiated by an increased glutamate release in the dorsal horn, can develop within hours-days. ${ }^{30}$ The modulatory effect of SCS on neuropathic pain is suggested to act via a temporal decrease in glutamate concentrations in the dorsal horn, as was found in neuropathic rats. ${ }^{31}$ Early SCS-treatment within the first days, when central sensitization is characterized by only short term reversible changes, may result in a better outcome. Results from the laboratory indicate that SCS in Seltzer injured rats 24 hours after injury and development of neuropathic pain results in a better outcome as compared to the treatment after 16 days. ${ }^{32}$ Long-term more permanent changes, related to central sensitization, may also underlie the fact that SCS is less effective when brush evoked allodynia is present. ${ }^{25}$ In clinical practice however it is impossible to treat CRPS-1 patients with SCS within days after development of the syndrome because it usually takes weeks or months before a diagnosis is made.

Another issue is the good clinical improvement with standard care. In our group, 74\% of patients improved with standard therapy. In another study of 168 patients, diagnosed with CRPS according to the modified IASP criteria, 121 (= 72\%) had a successful outcome with physical therapy, medical therapy and sympathetic blockade. ${ }^{33}$ Whether this improvement reflects the effects of therapy or the natural course of the disease is hard to tell because there are no prospective studies on the outcome of early CRPS-1. This excellent improvement within one year after onset of CRPS using standard therapy, i.e. physical and analgesic therapy, TENS and sympathetic blockade, together with the possible lack of additional benefit from the SCS argues against any early intervention with SCS therapy in CRPS-1 with associated sympathetically independent pain. If the pain and disability persist at one year after onset of the syndrome, the chance of successful recovery is significantly reduced, and SCS may be considered. In a group of 656 patients with CRPS of at least one year duration none showed spontaneous remission with high average pain intensity scores of $6.91 \pm 0.5$ which increased significantly with disease duration to $7.92 \pm$ 0.6 . ${ }^{4}$ So the need for early intervention remains; however if this intervention should be early treatment with SCS is not yet established.

We conclude that the feasibility of doing a study on SCS therapy in early CRPS- 1 is low because of the good improvement of the disease with standard therapy. This study raises questions about the need to use SCS early in the course of CRPS-1 because of the possible lack of additional benefit compared to SCS in chronic CRPS-1. 


\section{References}

1. Merksey, Bogduk N. Descriptions of Chronic Pain Syndromes and Definitions of Pain Terms, 2 Edition ed. Seattle, Washington: IASP press; 1994.

2. de Mos M, de Bruijn AG, Huygen FJ, Dieleman JP, Stricker BH, Sturkenboom MC. The incidence of complex regional pain syndrome: a population-based study. Pain. 2007;129:12-20.

3. Sandroni P, Benrud-Larson LM, McClelland RL, Low PA. Complex regional pain syndrome type I: incidence and prevalence in Olmsted county, a population-based study. Pain. 2003;103:199-207.

4. Schwartzman RJ, Erwin KL, Alexander GM. The natural history of complex regional pain syndrome. Clin J Pain. 2009;25:273-280.

5. de Mos M, Huygen FJ, van der Hoeven-Borgman M, Dieleman JP, Ch Stricker BH, Sturkenboom MC. Outcome of the complex regional pain syndrome. Clin J Pain. 2009;25:590-597.

6. Stanton-Hicks MD, Burton AW, Bruehl SP, Carr DB, Harden RN, Hassenbusch SJ, et al. An updated interdisciplinary clinical pathway for CRPS: report of an expert panel. Pain Pract. 2002;2:1-16.

7. Taylor RS, Van Buyten JP, Buchser E. Spinal cord stimulation for complex regional pain syndrome: a systematic review of the clinical and cost-effectiveness literature and assessment of prognostic factors. Eur J Pain. 2006;10:91-101.

8. Kemler MA, Barendse GA, van Kleef M, de Vet HC, Rijks CP, Furnee CA, et al. Spinal cord stimulation in patients with chronic reflex sympathetic dystrophy. N Engl J Med. 2000;343:618-624.

9. Stanton-Hicks M. Complex regional pain syndrome: manifestations and the role of neurostimulation in its management. J Pain Symptom Manage. 2006;31:S20-24.

10. Harney D, Magner JJ, O'Keeffe D. Early intervention with spinal cord stimulation in the management of a chronic regional pain syndrome. Ir Med J. 2005;98:89-90.

11. Saranita J, Childs D, Saranita AD. Spinal cord stimulation in the treatment of complex regional pain syndrome (CRPS) of the lower extremity: a case report. J Foot Ankle Surg. 2009;48:52-55.

12. Verdolin $\mathrm{MH}$, Stedje-Larsen ET, Hickey $\mathrm{AH}$. Ten consecutive cases of complex regional pain syndrome of less than 12 months duration in active duty United States military personnel treated with spinal cord stimulation. Anesth Analg. 2007;104:1557-1560, table of contents.

13. Jensen MP, McFarland CA. Increasing the reliability and validity of pain intensity measurement in chronic pain patients. Pain. 1993;55:195-203.

14. Jensen MP, Turner JA, Romano JM. What is the maximum number of levels needed in pain intensity measurement? Pain. 1994;58:387-392.

15. Forouzanfar $T$, Weber WE, Kemler $M$, van Kleef $M$. What is a meaningful pain reduction in patients with complex regional pain syndrome type 1? Clin J Pain. 2003;19:281-285.

16. Streiner D, Norman G. Health measurement scales. A practical guide to their development and use. 2nd ed. New York: Oxford University Press; 1998.

17. Farrar JT, Jr. JPY, LaMoreaux L, Werth JL, Poole RM. Clinical importance of changes in chronic pain intensity measured on an 11-point numerical scale. Pain. 2001;94:149-158.

18. Aaronson NK, Muller M, Cohen PD, Essink-Bot ML, Fekkes M, Sanderman R, et al. Translation, validation, and norming of the Dutch language version of the SF-36 Health Survey in community and chronic disease populations. J Clin Epidemiol. 1998;51:1055-1068.

19. Perez RS, Roorda LD, Zuurmond WW, Bannink, II, Vranken JH, de Lange JJ. Measuring perceived activity limitations in lower extremity Complex Regional Pain Syndrome type 1 (CRPS I): test-retest reliability of two questionnaires. Clin Rehabil. 2002;16:454-460.

20. Roorda LD, Roebroeck ME, van Tilburg T, Molenaar IW, Lankhorst GJ, Bouter LM, et al. Measuring activity limitations in walking: development of a hierarchical scale for patients with lower-extremity disorders who live at home. Arch Phys Med Rehabil. 2005;86:2277-2283.

21. Stanton-Hicks M, Baron R, Boas R, Gordh T, Harden N, Hendler N, et al. Complex Regional Pain Syndromes: guidelines for therapy. Clin J Pain. 1998;14:155-166. 
22. Oerlemans HM, Oostendorp RA, de Boo T, Goris RJ. Pain and reduced mobility in complex regional pain syndrome I: outcome of a prospective randomised controlled clinical trial of adjuvant physical therapy versus occupational therapy. Pain. 1999;83:77-83.

23. Albazaz R, Wong YT, Homer-Vanniasinkam S. Complex regional pain syndrome: a review. Ann Vasc Surg. 2008;22:297-306.

24. van Eijs F, Stanton-Hicks M, Van Zundert J, Faber C, Lubenow T, Mekhail N, et al. Complex Regional Pain Syndrome Pain Pract. 2010;10.

25. van Eijs F, Smits $H$, Geurts JW, Kessels AG, Kemler MA, van Kleef M, et al. Brush-evoked allodynia predicts outcome of spinal cord stimulation in complex regional pain syndrome type 1. Eur J Pain. 2010;14:164-169.

26. Harke H, Gretenkort P, Ladleif HU, Rahman S. Spinal cord stimulation in sympathetically maintained complex regional pain syndrome type I with severe disability. A prospective clinical study. Eur J Pain. 2005;9:363-373.

27. Kemler MA, Barendse GA, van Kleef M, Egbrink MG. Pain relief in complex regional pain syndrome due to spinal cord stimulation does not depend on vasodilation. Anesthesiology. 2000;92:16531660.

28. Wilder-Smith $\mathrm{OH}$, Arendt-Nielsen L. Postoperative hyperalgesia: its clinical importance and relevance. Anesthesiology. 2006;104:601-607.

29. Cook AJ, Woolf CJ, Wall PD, McMahon SB. Dynamic receptive field plasticity in rat spinal cord dorsal horn following C-primary afferent input. Nature. 1987;325:151-153.

30. Ji RR, Kohno T, Moore KA, Woolf CJ. Central sensitization and LTP: do pain and memory share similar mechanisms? Trends Neurosci. 2003;26:696-705.

31. Cui JG, O'Connor WT, Ungerstedt U, Linderoth B, Meyerson BA. Spinal cord stimulation attenuates augmented dorsal horn release of xcitatory amino acids in mononeuropathy via a GABAergic mechanism. Pain. 1997;73:87-95.

32. Truin $M$, van Kleef $M$, Linderoth $B$, Smits $H$, Janssen $S$, Joosten $E$. Increased efficacy of early spinal cord stimulation compared to late spinal cord stimulation in an animal model of neuropathic pain. Submitted.

33. Duman I, Dincer U, Taskaynatan MA, Cakar E, Tugcu I, Dincer K. Reflex sympathetic dystrophy: a retrospective epidemiological study of 168 patients. Clin Rheumatol. 2007;26:1433-1437. 
CHAPTER VI

Ketamine therapy in lower extremity

Complex Regional Pain Syndrome type 1

patients with intractable pain.

Effect on pain and functional impairment

Frank van Eijs MD, Jan Van Zundert MD, PhD, José Geurts MSc, Maarten van Kleef $\mathrm{MD}, \mathrm{PhD}$, Alfons G.H. Kessels MD, MSc, Catharina G Faber MD, PhD 


\begin{abstract}
Introduction: Intravenous ketamine has the ability to diminish spontaneous pain in complex regional pain syndrome type 1 . Its effect on brush evoked pain and exercise-induced pain together with its effect on physical functioning however, is not extensively studied.

Methods: Fourteen patients with complex regional pain syndrome type 1 of more than one year duration, with intractable pain in one lower extremity were treated with 10-30 mg hour ${ }^{-1}$ of intravenous S-ketamine during a maximum of 12 days. Pain scores for spontaneous, brush evoked and exercise induced pain were obtained. The timed ten meter walking test was performed as a measure of walking function.

Outcome measures were obtained at $t=0$, during therapy, and after 1,3 and 6 months.

Results: Eight patients had significant decrease of spontaneous pain, brush-evoked pain and exercise-induced pain at one, three and six months follow up. Walking speed was significantly improved and reached normal values. Two patients developed liver enzyme abnormalities which resolved after terminating the infusion and four patients did not experience pain relief or improved walking function.

Conclusion: Intravenous ketamine may abolish spontaneous and brush-evoked allodynia pain, reduce exercise-induced pain, and restore the ability to walk, up until 6 months after therapy, in a subgroup of lower limb CRPS-1 patients with otherwise severe therapy resistant pain. Transient liver enzyme abnormalities occurred in two patients.
\end{abstract}




\section{Introduction}

Complex Regional Pain Syndrome type 1 (CRPS-1) is a potentially disabling disease characterized by severe pain, functional impairment, sensory disturbances, vasomotor abnormalities, sudomotor abnormalities and motor impairments. Excruciating pain and marked loss of extremity function are hallmarks of the disease, and lead to restriction in activity, participation and reduced quality of life. While many treatment regimens have been suggested, no single therapy has proven successful in all patients. Adequate pain management has, consistently, proven extremely difficult. $^{1,2}$

Reduction of spontaneous pain in CRPS-1 by intravenous ketamine therapy was reported, ${ }^{3}$ though long term studies are scarce. Ketamine treatment effectively causes relief of spontaneous pain that typically outlasts the pharmacokinetic action of the drug. ${ }^{4,5}$

The effect of intravenous ketamine on brush evoked pain (dynamic mechanical allodynia) and exercise induced pain however, is not extensively studied in CRPS-1. Some case studies indeed report a relief of allodynia, ${ }^{6,7}$ but larger studies on the effect of intravenous ketamine on allodynia in CRPS-1 subjects are lacking. Topical application of ketamine at the symptomatic limb inhibited allodynia, which probably can be attributed to a peripheral action since plasma levels were undetectable. ${ }^{8}$ As ketamine acts via desensitisation of the $\mathrm{N}$-methyl-D-aspartate receptor (NMDAR), reduction of the allodynia by ketamine may indeed be caused by reduction of central sensitisation. ${ }^{9}$

The effect of ketamine on exercise-induced pain, an important factor in rehabilitation of CRPS patients is unknown. Reduction of exercise-induced pain might lead to improvement of function, though functional improvement was not found in a previous study. ${ }^{10}$ In another report however, the CRPS associated movement disorder and ability to work was improved by ketamine, which might imply a functional improvement, but unfortunately the authors did not specify this. ${ }^{11}$ The assessment of the effect of an intervention on different important aspects of pain in CRPS-1 requires measurement of pain intensity and physical functioning. ${ }^{12}$

We expanded on an earlier study, where ketamine, when given in gradual titration against its side effects in low dosage levels of 10-30 mg hour ${ }^{-1}$, successfully decreased pain in $94 \%$ of CRPS patients. ${ }^{13}$ The aims of our study were to assess the effect of subanesthetic doses of iv ketamine in lower limb refractory CRPS-1 on the intensity and duration of three different components of pain: spontaneous pain, brush-evoked pain and exercise-induced pain, as well as the effect on physical func- 
tioning as measured by the timed ten meter walking test. Secondly, we studied the possible adverse effects of this therapy.

\section{Patients and methods}

\section{Patients}

Patients attending the pain management centre of the St Elisabeth general hospital in Tilburg, the Netherlands, with CRPS-1 of one lower extremity were included in the study. All patients were diagnosed according to the criteria of the International Association for the Study of Pain: (1) The presence of continuous pain, allodynia or hyperalgesia disproportional to the inciting event; (2) evidence at some time of edema, abnormal skin blood flow and sudomotor abnormalities in the region of pain; (3) other causes of pain or dysfunction are excluded. ${ }^{14}$ Other inclusion criteria were disease duration of at least 12 months and no response to previous standardized conservative medical therapy with analgesics such as non-steroidal antiinflammatory drugs, acetaminophen, tramadol and gabapentin, as described in CRPS treatment guidelines. ${ }^{15,16}$ All patients received physical therapy, which consisted of graded exercises with the objective of restoring strength, mobility, and function of the affected extremity according to a fixed protocol. ${ }^{17}$ Transcutaneous electrical stimulation therapy was applied for at least two weeks with no effect on pain. After initial conservative therapy, patients were offered treatment with sympathetic blockade (SB) If SB gave no pain relief or if patients refused the $\mathrm{SB}$, a trial spinal cord stimulation (SCS) for two weeks was offered. Intravenous ketamine therapy was undertaken if patients had no pain relief after this treatment scheme and had persistent severe pain at rest as measured by the 4-point verbal pain score (no pain, mild pain, moderate pain and severe pain). Exclusion criteria were known contraindications for ketamine therapy, like significant hypertension, arterial or cerebral aneurysms, ischemic heart disease, glaucoma, allergy to the substance and pregnancy. The study was approved by the medical ethics committee of the St Elisabeth hospital Tilburg, the Netherlands.

\section{Outcome measures}

Numerical pain rating scale (NRS) was used for measurement of the different types of pain (spontaneous, brush-evoked and exercise-induced pain). The NRS is reliable, has been extensively validated ${ }^{18,19}$ and allows for rapid measurement of clinically relevant improvement of chronic pain in therapy trials. ${ }^{20}$ This study focuses on three aspects in CRPS pain: spontaneous pain, brush-evoked pain (allodynia), and exercise-induced pain. 
Spontaneous pain is measured by asking the patient to rate his pain at rest, before any activity was undertaken. The neuropathic pain component (allodynia) is characterized by a painful response to a normally non-painful stimulus, ${ }^{21}$ and was assessed by the SENSElab ${ }^{\mathrm{TM}}$ brush no. 5 (Somedic, Hörby, Sweden) which exerts a force of $200 \pm 100 \mathrm{mN}$ when applied to the skin for a period of one second and moved over a distance of four $\mathrm{cm}$ with the brush hairs slightly bend. First the brush is applied to the non-affected side. The patient is asked whether he feels the brush and if it hurts. The expected response is that the brush is felt but that it does not hurt. The maneuver is then repeated at the site of maximal pain on the involved extremity. Again the patient is asked if he feels the brush and if it hurts. If it hurts the patient is asked to rate the evoked pain using the NRS. ${ }^{21}$ To rate exerciseinduced pain we used the standardized timed ten meter walking test, which also reflects limb function. For the walking test the patient is asked to walk the ten meter distance in a comfortable pace. The time from departure to the first foot crossing the second line is timed. After turning around, the patient is instructed to walk back as quickly as possible without running. This is also timed. ${ }^{22}$ From these measurements, the comfortable walking speed and quick walking speed can be calculated. Immediately following the exercise (after the second 10 meters walk) the third NRS (exercise-induced pain) is obtained. We obtained NRS scores at baseline, just before treatment, every day of the treatment period, and post treatment during every out-patient visit (at 1, 3 and 6 months after start of therapy). All testing procedures were performed by a study nurse after schooling and instruction.

\section{Ketamine therapy}

Patients were admitted for in-hospital treatment. Following baseline testing, continuous S-ketamine therapy was started via a peripheral intravenous access at a rate of $10 \mathrm{mg} \mathrm{hr}^{-1}$. The S-ketamine dosage was increased daily by at least $5 \mathrm{mg} \mathrm{hr}^{-1}$ to a maximum of $30 \mathrm{mg} \mathrm{hr}^{-1}$ or until the patient experienced unacceptable side effects. The highest tolerated dose producing analgesia was continued. In order to emphasize physical therapy, the ketamine infusion rate was not increased above that causing a feeling of slight drowsiness for reasons of not interfering with daily physical therapy. Plasma levels of the liver enzymes alanine transaminase, aspartate transaminase, alkaline phosphatase, gamma-glutamyl transferase and lactate dehydrogenase were obtained at baseline, three times weekly during therapy and at the end of the S-ketamine infusion.

Patients were treated to a maximum of 12 days or until they were free of spontaneous or brush-evoked pain for 24 hours. 


\section{Follow up}

Every weekday during treatment NRS scores and walking tests were obtained in a standardized way. After the inpatient treatment was stopped, further measurements were obtained at the consultation office, at one, three and six months after start of therapy.

\section{Statistical analysis}

Patients that achieved total abolishment of their brush-evoked or spontaneous pain on the last day of their ketamine infusion therapy were considered responders to intravenous ketamine therapy. Mean and standard deviations of the pain scores for spontaneous pain, brush-evoked pain and exercise-induced pain were calculated for both the responder and the non-responder groups. Mean walking speeds for comfortable and quick walking were obtained for both the responder and the nonresponder groups. The paired samples student's $T$ test was used to calculate improvement of pain rating scores and walking speeds at the last day of ketamine therapy and at one, three and six months after start of ketamine therapy. Analyses were performed with the Statistical Package for the Social Sciences, version 16.0 (SPSS Inc., Chicago, II). Two-tailed p-values of less than 0.05 were considered statistically significant.

\section{Results}

Patients were recruited from the pain management centre of the department of anaesthesiology for a period of one year between June 2008 and July 2009. Fourteen patients with CRPS- 1 of the leg, of at least 12 months duration, had intensive physical and conservative medical therapy without pain relief. Most patients also had one or more interventional treatments without pain relief (12/14 patients had sympathetic blockade and 6/14 patients also underwent trial spinal cord stimulation). The 14 patients were included for treatment with intravenous ketamine. From these 14 patients two developed elevated liver enzymes after 10 days of treatment. The liver function abnormalities disappeared within weeks after stopping the ketamine. A prolonged hospital stay was not necessary. Of the 12 remaining patients, seven patients had total abolishment of allodynia at the end of the infusion period and one patient without initial allodynia had total abolishment of spontaneous pain. These eight patients were considered responders to ketamine treatment. Four patients had insufficient pain reduction at the end of the infusion period and were considered non-responders to ketamine treatment. (figure 1 ) 


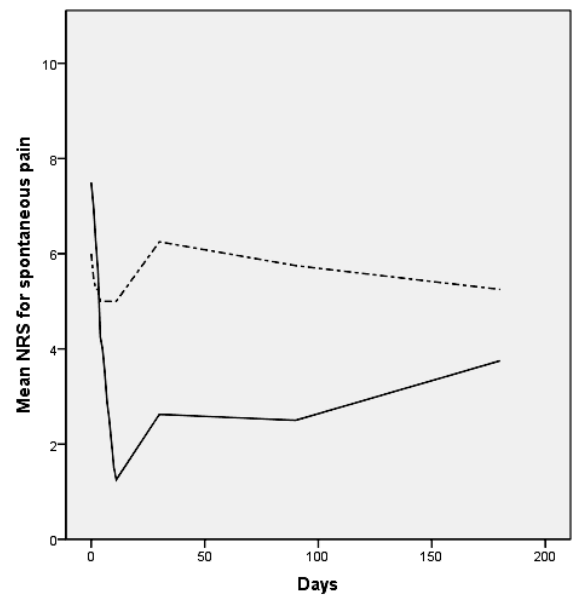

Figure 1: Mean numerical pain rating scores after intravenous ketamine treatment in responder and non-responders groups. (A: spontaneous pain; $B:$ brush-evoked pain; C: exercise induced pain)
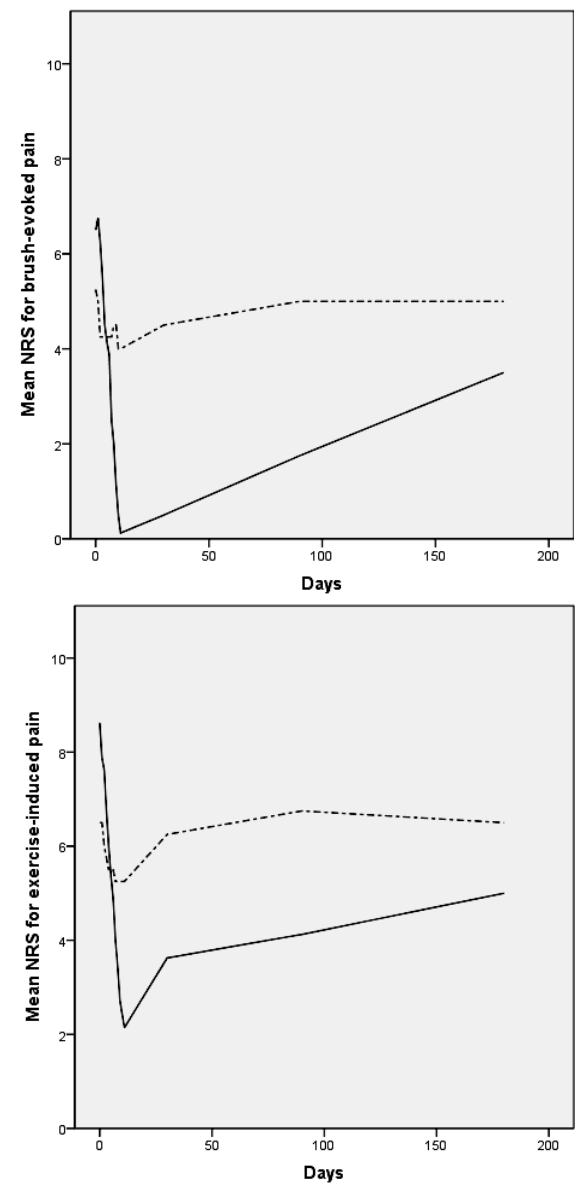
The demographic data are shown in table 1.

There were no significant differences between the responder and the nonresponder group with regard to baseline pain scores and walking speeds. In the nonresponder group walking speeds did not change significantly from about 2.9 kilometres hour ${ }^{-1}$ at baseline to about 3.5 kilometres hour ${ }^{-1}$ after 6 months. In the responder group, spontaneous pain, brush-evoked allodynia and exercise-induced pain improved at the end of intravenous ketamine therapy at day 12 , and on follow up at one, three and six months compared to baseline (table 2).

Table 1: Baseline demographic data

\begin{tabular}{lll}
\hline $\mathrm{N}=12$ & Responders & Non responders \\
\hline Mean age in years (min-max) & $\mathrm{N}=8$ & $\mathrm{~N}=4$ \\
Disease duration in months (min-max) & $29(17-58)$ & $47(24-60)$ \\
Duration of infusion in days (min-max) & $28(13-45)$ & $75(27-195)$ \\
Male gender & $9.4(5-12)$ & $8.8(7-12)$ \\
Precipitating event & $\mathrm{N}=1$ & $\mathrm{~N}=0$ \\
Fracture & & \\
Surgery & 1 & 2 \\
Sprain & 2 & 1 \\
Contusion & 3 & 0 \\
Variables & 2 & \\
Baseline spontaneous pain & & $6.0(2.4)$ \\
Baseline brush-evoked pain (allodynia) & $7.5(1.3)$ & $5.3(3.7)$ \\
Baseline exercise-induced pain & $6.5(2.7)$ & $6.5(2.4)$ \\
Comfortable walking speed & $8.6(1.1)$ & $2.7(1.4)$ \\
in kilometers/hour (SD) & $1.7(1.4)$ & \\
Quick walking speed in kilometers/hour (SD) & $2.4(1.8)$ & $3.1(1.6)$ \\
\hline
\end{tabular}

Table 2: Differential pain scores and walking speed in responders to ketamine treatment

\begin{tabular}{|c|c|c|c|c|c|}
\hline & Baseline & Day 12 & Month 1 & Month 3 & Month 6 \\
\hline Mean spontaneous pain 0-10 (SD) & $7.5(1.3)$ & $1.2(1.2)$ & $2.6(2.0)$ & $2.5(2.6)$ & $3.7(2.9)$ \\
\hline$P$ - value & & 0.0001 & 0.0001 & 0.001 & 0.006 \\
\hline Brush evoked pain 0-10 (SD) & $6.5(2.7)$ & $0.1(0.3)$ & $0.5(1.4)$ & $1.7(3.4)$ & 3.5 (3.9) \\
\hline$P$ - value & & 0.0001 & 0.001 & 0.016 & 0.07 \\
\hline Exercise induced pain 0-10 (SD) & $8.6(1.1)$ & $2.1(1.2)$ & $3.6(2.4)$ & $4.1(2.9)$ & $5.0(3.3)$ \\
\hline$P$ - value & & 0.0001 & 0.001 & 0.002 & 0.02 \\
\hline Comfortable walking speed $\mathrm{km} \mathrm{hr}^{-1}$ (SD) & $1.7(1.4)$ & $2.7(1.4)$ & $3.0(1.2)$ & $3.2(1.5)$ & $2.9(1.7)$ \\
\hline$P$ - value & & 0.03 & 0.002 & 0.02 & 0.03 \\
\hline Quick walking speed $\mathrm{km} \mathrm{hr}^{-1}$ (SD) & $2.4(1.8)$ & $3.9(2.1)$ & $4.1(1.7)$ & $4.2(2.0)$ & $4.1(2.4)$ \\
\hline$P$ - value & & 0.012 & 0.001 & 0.04 & 0.03 \\
\hline
\end{tabular}




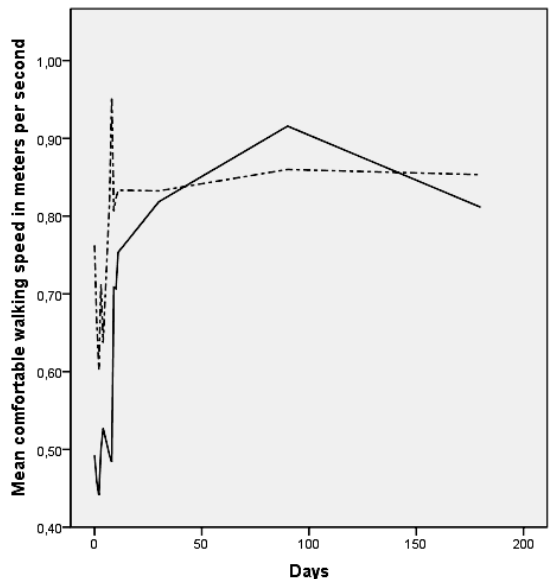

\section{Non-responders}

Responders

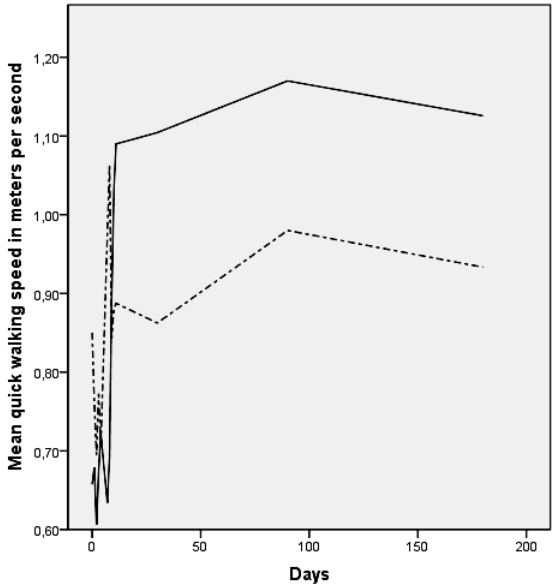

Figure 2: Mean walking speed (A: comfortable; B:quick) after intravenous ketamine treatment in responder and non-responder groups

Side effects are summarized in table 3.

Table 3: Adverse effects

\begin{tabular}{ll}
\hline Total patients & $\mathrm{N}=14$ \\
\hline Dizziness & $\mathrm{N}=12$ \\
Phlebitis & $\mathrm{N}=11$ \\
Nausea & $\mathrm{N}=10$ \\
Blurry vision & $\mathrm{N}=8$ \\
Headache & $\mathrm{N}=5$ \\
Liver enzyme elevation & $\mathrm{N}=2$ \\
Psychomimetic symptoms & $\mathrm{N}=1$ \\
\hline
\end{tabular}


There was a tendency for pain scores to increase again after 6 months; however, walking speeds remained significantly increased compared to baseline with approximately $75 \%$ improvement from a mean walking speed of about 2 kilometres hour $^{-1}$ at baseline to a mean walking speed of 3.5 kilometres hour $^{-1}$ after 6 months. (table 2, figure 2)

Two patients developed abnormal elevation of plasma liver enzymes. One of these two patients also had associated diffuse abdominal pain. For this reason ketamine treatment was stopped promptly and in the following weeks the liver function enzymes returned to normal pre-infusion levels. The abdominal pain disappeared after one day. Dizziness, nausea and blurry vision were expected side effects and were treated by either diminishing the dose of ketamine or the administration of oral anti-emetics. Headache was successfully treated with acetaminophen. Phlebitis occurred in the majority of patients and required change of the intravenous access site even more than once in most patients. The presence of psychomimetic effects was reported in one patient who complained of seeing the surrounding in a variety of different abnormal colors.

\section{Discussion}

In this prospective observational study we found that 8 out of 14 patients with unilateral lower limb CRPS-1 and intractable pain of more than one year duration, achieved total abolishment of allodynia and/or spontaneous pain immediately after therapy with intravenous ketamine. Patients consisted of a subpopulation of CRPS-1 patients, unresponsive to previous conservative and interventional therapies. The responder patients also responded well at long term follow up of six months, not only with regard to pain, but more importantly with regard to the walking function. The responder patients had significant pain reduction at 1,3 and 6 months follow up. At 6 months pain intensity still was significantly decreased compared to baseline, but tended to increase again slightly. The walking function at 6 months, however, remained significantly improved, with walking speeds improving to normal values. These improvements were not only statistically significant but also clinically meaningful. ${ }^{12}$ Numerical pain scores for spontaneous, brush-evoked and exerciseinduced pain all improved at 3 months follow up with at least $50 \%$ which is considered a substantial improvement of pain intensity. At 6 moths follow up the spontaneous pain score still was improved with $50 \%$ compared to baseline. The numerical pain scores for brush-evoked pain and exercise-induced pain at 6 months still were improved with at least $30 \%$ compared to baseline. Thirty percent pain reduction is considered a moderate improvement of pain intensity. ${ }^{12}$ 
Although there was no difference in baseline values of responder and nonresponders patients, the apparently lower baseline pain scores and higher baseline walking speeds in non-responder patients seem remarkable but did not prove to be statistically significant.

Ketamine is an anesthetic that has been used for over 30 years now. Besides its indications for use in general anesthesia and perioperative pain control ${ }^{23}$ it now is also been used in the treatment of chronic neuropathic pain e.g. CRPS- ${ }^{5}$

For chronic pain, intravenous ketamine can be given in high, anesthetic doses or in low sub anesthetic doses of $10-30 \mathrm{mg} \mathrm{hr}^{-1}$. The first option requires an intensive care setting because an artificial coma is induced. ${ }^{11}$ We therefore choose the second option which is more convenient, although it still requires a clinical setting at the hospital ward. The impressive effect of S-ketamine on the brush evoked pain reflects its ability to suppress central sensitization in patients with CRPS-1 by blocking the NMDA receptors. As shown in this study the effect of S-ketamine outlasts its pharmacokinetic action by months, implying a working mechanism directed at resetting the central nervous system in these patients with CRPS-1. This phenomenon has been demonstrated by others too. ${ }^{4,5}$ The duration of pain relief after intravenous ketamine infusion varies in the literature. ${ }^{5,11,24}$ One study reported duration of pain relief of 50 days after a five day infusion of ketamine. ${ }^{5}$ We obtained a longer duration of pain relief, lasting six months after termination of the S-ketamine infusion, in a subgroup of CRPS-1 patients. This long duration of pain relief may be due to the relatively long duration of intravenous S-ketamine infusion in our study with a mean duration of nine days, leading to total abolishment of brush evoked allodynia and/or of spontaneous pain in a subgroup of patients, perhaps by a more intense resetting of the central nervous system. Not all patients responded as well to the S-ketamine infusion. Four patients did not experience significant pain relief, a phenomenon also found by others. ${ }^{24,25}$ A possible explanation may be the existence of different pharmacogenetic profiles in responder and non-responder patients. $^{26}$

Adverse effects were seen in the majority of patients. Headache could be managed by pharmacologic treatment with acetaminophen and nausea could be managed with anti-emetics. Dizziness, blurred vision and psychomimetic effects could be managed by lowering the infusion dose of S-ketamine to previous dosage levels. The presence of psychomimetic symptoms were not as frequently seen as expected. ${ }^{27}$ Only one patient experienced a hallucinatory response with the used low dosage scheme of 10-30 mg hour ${ }^{-1}$, an observation that was also seen by others. ${ }^{25} \mathrm{~A}$ major concern of the treatment is the liver enzyme elevation that was seen in two patients after 10 days of S-ketamine infusion. This phenomenon is probably due to an allergic reaction and was also observed by others, especially with prolonged administra- 
tion of ketamine or repeated administration of ketamine. ${ }^{28}$ Like in other observations the liver enzyme abnormalities gradually returned to normal pre infusion levels within weeks after terminating the ketamine infusion. The abdominal pain observed in one patient with liver enzyme elevation probably also reflected this allergic hepatotoxic reaction. The abdominal pain quickly disappeared after stopping the infusion.

A limitation of this study is the design that was of an uncontrolled open label nature with a limited number of subjects. Nevertheless this study demonstrates the long term pain relieving effect of intravenous ketamine, with a marked improvement in walking function at 6 months follow up, in a subgroup of CRPS-1 patients. Future studies should be aimed at determining the most optimal dose and interval therapy of NMDA receptor antagonists (infusion every six months?). Other research may include alternative and easier administration routes of NMDA receptor antagonists, and ways to limit adverse effects, e.g. by combining with alpha 2 agonist such as dexmedetomidine. ${ }^{29}$ Basic animal research with CRPS- models, such as tibia fracture ${ }^{30}$ and ischemia reperfusion ${ }^{31}$ in rats could provide insight in the mechanisms involved in ketamine treatment of CRPS. Ultimately randomized controlled trials need to be performed which asses the long term effect of NMDA receptor antagonists not only on spontaneous pain intensity, but also brush-evoked pain and exercise induced pain as well as patient global impression of change, and physical and emotional functioning, ${ }^{12}$ in CRPS-1 patients with otherwise therapy resistant pain. We conclude that in a subgroup of lower limb CRPS-1 patients with longstanding therapy resistant pain, intravenous S-ketamine may relief spontaneous and brushevoked pain, reduce exercise-induced pain, and improve functional status of the patient by increasing the ability to walk, up until 6 months after therapy.

\section{References}

1. Stanton-Hicks M. Complex regional pain syndrome: manifestations and the role of neurostimulation in its management. J Pain Symptom Manage. 2006;31:S20-24.

2. Bruehl S. An update on the pathophysiology of complex regional pain syndrome. Anesthesiology. 2010;113:713-725.

3. Henson $\mathrm{P}$, Bruehl S. Complex regional pain syndrome: state of the art update. Curr Treat Options Cardiovasc Med. 2010;12:156-167.

4. Sigtermans M, Noppers I, Sarton E, Bauer M, Mooren R, Olofsen E, et al. An observational study on the effect of S+-ketamine on chronic pain versus experimental acute pain in Complex Regional Pain Syndrome type 1 patients. Eur J Pain. 2010;14:302-307.

5. Dahan A, Olofsen E, Sigtermans M, Noppers I, Niesters M, Aarts L, et al. Population pharmacokineticpharmacodynamic modeling of ketamine-induced pain relief of chronic pain. Eur J Pain. 2011;15:258-267. 
6. Sunder RA, Toshniwal G, Dureja GP. Ketamine as an adjuvant in sympathetic blocks for management of central sensitization following peripheral nerve injury. J Brachial Plex Peripher Nerve Inj. 2008;3:22.

7. Becerra L, Schwartzman RJ, Kiefer RT, Rohr P, Moulton EA, Wallin D, et al. CNS Measures of Pain Responses Pre- and Post-Anesthetic Ketamine in a Patient with Complex Regional Pain Syndrome. Pain Med. 2009.

8. Finch PM, Knudsen L, Drummond PD. Reduction of allodynia in patients with complex regional pain syndrome: A double-blind placebo-controlled trial of topical ketamine. Pain. 2009;146:18-25.

9. Parsons CG. NMDA receptors as targets for drug action in neuropathic pain. Eur J Pharmacol. 2001;429:71-78.

10. Sigtermans MJ, van Hilten JJ, Bauer MC, Arbous MS, Marinus J, Sarton EY, et al. Ketamine produces effective and long-term pain relief in patients with Complex Regional Pain Syndrome Type 1. Pain. 2009;145:304-311.

11. Kiefer RT, Rohr P, Ploppa A, Dieterich HJ, Grothusen J, Koffler S, et al. Efficacy of ketamine in anesthetic dosage for the treatment of refractory complex regional pain syndrome: an open-label phase Il study. Pain Med. 2008;9:1173-1201.

12. Dworkin RH, Turk DC, Wyrwich KW, Beaton D, Cleeland CS, Farrar JT, et al. Interpreting the clinical importance of treatment outcomes in chronic pain clinical trials: IMMPACT recommendations. J Pain. 2008;9:105-121.

13. Correll GE, Maleki J, Gracely EJ, Muir JJ, Harbut RE. Subanesthetic ketamine infusion therapy: a retrospective analysis of a novel therapeutic approach to complex regional pain syndrome. Pain Med. 2004;5:263-275.

14. Merksey, Bogduk N. Descriptions of Chronic Pain Syndromes and Definitions of Pain Terms, 2 Edition ed. Seattle, Washington: IASP press; 1994.

15. Stanton-Hicks M, Baron R, Boas R, Gordh T, Harden N, Hendler N, et al. Complex Regional Pain Syndromes: guidelines for therapy. Clin J Pain. 1998;14:155-166.

16. Stanton-Hicks MD, Burton AW, Bruehl SP, Carr DB, Harden RN, Hassenbusch SJ, et al. An updated interdisciplinary clinical pathway for CRPS: report of an expert panel. Pain Pract. 2002;2:1-16.

17. Oerlemans HM, Oostendorp RA, de Boo T, Goris RJ. Pain and reduced mobility in complex regional pain syndrome I: outcome of a prospective randomised controlled clinical trial of adjuvant physical therapy versus occupational therapy. Pain. 1999;83:77-83.

18. Jensen MP, Turner JA, Romano JM. What is the maximum number of levels needed in pain intensity measurement? Pain. 1994;58:387-392.

19. Clark WC, Yang JC, Tsui SL, Ng KF, Bennett Clark S. Unidimensional pain rating scales: a multidimensional affect and pain survey (MAPS) analysis of what they really measure. Pain. 2002;98:241-247.

20. Farrar JT, Jr. JPY, LaMoreaux L, Werth JL, Poole RM. Clinical importance of changes in chronic pain intensity measured on an 11-point numerical scale. Pain. 2001;94:149-158.

21. Nurmikko TJ, Serpell MG, Hoggart B, Toomey PJ, Morlion BJ, Haines D. Sativex successfully treats neuropathic pain characterised by allodynia: a randomised, double-blind, placebo-controlled clinical trial. Pain. 2007;133:210-220.

22. Wade DT, Wood VA, Heller A, Maggs J, Langton Hewer R. Walking after stroke. Measurement and recovery over the first 3 months. Scand J Rehabil Med. 1987;19:25-30.

23. Loftus RW, Yeager MP, Clark JA, Brown JR, Abdu WA, Sengupta DK, et al. Intraoperative ketamine reduces perioperative opiate consumption in opiate-dependent patients with chronic back pain undergoing back surgery. Anesthesiology. 2010;113:639-646.

24. Goldberg ME, Torjman MC, Schwartzman RJ, Mager DE, Wainer IW. Enantioselective pharmacokinetics of (R)- and (S)-ketamine after a 5-day infusion in patients with complex regional pain syndrome. Chirality. 2011;23:138-143.

25. Goldberg ME, Torjman MC, Schwartzman RJ, Mager DE, Wainer IW. Pharmacodynamic profiles of ketamine (R)- and (S)- with 5-day inpatient infusion for the treatment of complex regional pain syndrome. Pain Physician. 2010;13:379-387. 
26. Sabia M, Hirsh RA, Torjman MC, Wainer IW, Cooper N, Domsky R, et al. Advances in translational neuropathic research: example of enantioselective pharmacokinetic-pharmacodynamic modeling of ketamine-induced pain relief in complex regional pain syndrome. Curr Pain Headache Rep. 2011;15:207-214.

27. Sinner B, Graf B. Ketamine. In: Handbook of Experimental Pharmacology, Vol. 182. ed; 2008. 313333.

28. Noppers IM, Niesters M, Aarts LP, Bauer MC, Drewes AM, Dahan A, et al. Drug-induced liver injury following a repeated course of ketamine treatment for chronic pain in CRPS type 1 patients: A report of 3 cases. Pain. 2011.

29. Nama S, Meenan DR, Fritz WT. The use of sub-anesthetic intravenous ketamine and adjuvant dexmedetomidine when treating acute pain from CRPS. Pain Physician. 2010;13:365-368.

30. Wei T, Li WW, Guo TZ, Zhao R, Wang L, Clark DJ, et al. Post-junctional facilitation of Substance P signaling in a tibia fracture rat model of complex regional pain syndrome type I. Pain. 2009;144:278286.

31. Xanthos DN, Coderre TJ. Sympathetic vasoconstrictor antagonism and vasodilatation relieve mechanical allodynia in rats with chronic postischemia pain. J Pain. 2008;9:423-433. 
CHAPTER VII

\section{General discussion}




\section{General findings}

The main goal of this thesis was to find answers to the questions formulated at the end of the general introduction in chapter one.

First line treatment of complex regional pain syndrome type 1 (CRPS-1) should be conservative medical therapy and active physical and rehabilitation therapy. The actual evidence for interventional treatment of CRPS-1 suggests not to consider intravenous regional sympathetic blocks with guanethidine (2A negative recommendation). However sympathetic blockade (SB) such as ganglion stellatum block and lumbar sympathetic block may be considered although solid evidence is scarce (2B positive recommendation) Spinal cord stimulation (SCS) may be considered for chronic CRPS-1 if other options fail to give pain relief (2B positive recommendation).

SB may be performed in patients with CRPS-1, however the presence of allodynia and hypoesthesia are negative predictors for pain relief after SB. Therefore in the presence of allodynia or hypoesthesia SB is not likely to benefit the patient. A majority of $84 \%$ of patients suffered from (transient) side effects such as headache, dysphagia, nausea, hoarseness, back pain, groin pain, hematoma and a transient increase in pain. This temporary increase in pain occurs as often as pain decrease after SB.

In chronic CRPS-1 the presence of brush-evoked allodynia with a pain intensity of 2.5 or more on a 10-point scale, predicted a statistically significant lower chance (31\%) of having successful SCS treatment at one year after implantation of the spinal cord stimulator with a sensitivity of $75 \%$ and a specificity of $81 \%$.

The feasibility of performing a study on the effectiveness of SCS early in the course of CRPS- 1 is low. Nevertheless, given the finding that $74 \%$ of patients improved with standard therapy and that all patients eventually included and treated with SCS, showed no improvement in functional outcome, this study clearly questions the need to start SCS early in the course of the disease firstly because of the good improvement in the first year with standard therapy and secondly because of the lack of additional benefit as compared to SCS treatment in chronic CRPS-1 of more than one year duration.

Continuous intravenous ketamine infusion with a mean duration of 9 days ( $m$ in 5, max 12 days) may reduce spontaneous pain, brush-evoked pain, exercise-induced pain, and restore the ability to walk, up until 6 months after therapy, in a subgroup of chronic lower limb CRPS-1 patients with otherwise intractable severe therapy resistant pain. 


\section{The role of central sensitization in CRPS-1 treatment}

Central sensitization, characterized by allodynia, is a key issue in chronification of CRPS-1. Dynamic mechanical allodynia can easily be established clinically by means of stroking the skin with a simple brush. This procedure is not painful in healthy subjects. In the presence of central sensitization however, the procedure may cause pain. This allodynia pain can be quantified by letting the patient rate this evoked pain on a numerical pain rating scale from zero to ten. ${ }^{1}$

In this thesis we demonstrated that interventional treatment with SB or SCS is less likely to be successful if allodynia is present. We further showed that intravenous S-ketamine, unlike SCS or SB, indeed may be effective in reducing pain and central sensitization, by blocking the NMDA receptor, in a subpopulation of patients with CRPS-1, intractable pain and allodynia. This central sensitization is most likely located at the dorsal horn, at the level of the original injury and extending throughout the entire length of the spinal cord, as demonstrated by spinal histopathological research in patients with longstanding CRPS, which showed evidence of posterior horn neuronal cell loss and activation of astrocytes and microglia tissue. ${ }^{2}$ High intensity noxious stimuli or nerve injury may trigger chemokines, such as $\mathrm{CCl} 2$, in the spinal cord glial cells, and induce central sensitization by astroglial- to- neuronal signaling which in turn increases the NMDA receptor activity. ${ }^{3}$ This up regulation of the NMDA receptors is responsible for central sensitization and induced pain hypersensitivity in some cases of CRPS. ${ }^{4}$ The central sensitization also is reflected by primary somatosensory cortex activation, which may be enhanced by touch in some CRPS patients, as illustrated by the significantly stronger activation of the primary somatosensory cortex to tactile stimuli in chronic CRPS patients as compared to healthy individuals. ${ }^{5}$

The aim of therapy is the prevention of chronification of the syndrome. A key issue in the prevention of chronification may be the treatment of central sensitization. As such, targeting central sensitization early in the course of its onset may be crucial, if the aim is to prevent chronification of the disease. The accomplishment of this goal may imply other treatment options besides continuous intravenous Sketamine infusion, which obviously requires a clinical setting. Easier, alternative pharmacologic and non-pharmacologic interventions may also prove to be of important value in treating CRPS associated central sensitization. ${ }^{6}$

\section{Clinical implications}

Proper counseling and informing of patients with CRPS-1 is essential, not only for patients with signs of central sensitization but also for patients without signs of central sensitization. All need to be informed, and if possible reassured, about their 
prognosis and the potential results of different possible (interventional) therapies. CRPS patients need to be stimulated in the active participation of their own rehabilitation. Initial conservative medical therapy is started as soon as possible. Mechanism based therapy is the key in treating CRPS-1. First identify the possible involved mechanisms responsible for the presenting signs and symptoms of the individual patient. The patient should be treated accordingly, e.g. presence of allodynia should prompt to treat central sensitization; presence of a warm and swollen limb should lead to treatment of the associated inflammation.

Preliminary results of our outcome study on the spontaneous evolution of CRPS-1 suggest that patients with high initial pain rating scores of 7 or more and patients with allodynia may have poorer outcome and are more prone to developing chronic CRPS-1. These patients in particular should be monitored carefully and be considered for early desensitization therapy. High initial pain intensity has also been related to other types of chronic pain syndromes such as chronic non-radicular low back pain, chronic musculoskeletal neck pain and chronic post whiplash associated neck pain following rear end collisions. ${ }^{7-9}$ This may implicate the involvement of common central pathophysiological mechanisms in the development of different chronic pain disorders.

The role of SB in the treatment of CRPS-1 may not be as important as previously thought. The manifestation of sympathetic dysfunction in CRPS may be obvious as demonstrated by the presence of symptoms such as rubor, pallor, sweating and edema. ${ }^{10}$ The existence of pain driven by the sympathetic nervous system however, is not so obvious. ${ }^{11,12}$ Only one third of patients respond to SB. In our study we found that patients with impairment of central processing (e.g. central sensitization) do not seem to respond to SB. It seems logical that a peripheral procedure such as SB is not likely to benefit the patient in the presence of signs of central impairment of pain and sensory processing. The procedure may lead to pain relief as well as temporary pain increase and side effects occur in the majority of patients. Patients should be informed accordingly.

About two out of three CRPS-1 patients have pain relief with SCS. This pain relief may diminish over time. This research demonstrated that CRPS-1 patients with brush evoked allodynia (BEA) have a significantly lower chance of achieving meaningful pain relief with SCS. Therefore SCS should be applied cautiously if a patient with CRPS-1 experiences allodynia. We recommend a trial phase of at least two weeks. In this period pain relief should be objectified by pain diaries. Only if there is substantial pain relief of at least $50 \%$ obtained for the spontaneous pain as well as for the brush evoked pain one may consider to proceed with a definitive implant. However, if there is questionable pain relief after SCS in patients with BEA, then these patients should be informed of the significant lower chance of pain relief at one year after implant. In these cases we advise not to proceed with a definitive implant. Boldly stated: "If in doubt take it out". 
SCS treatment might not be the proper tool to prevent central sensitization and chronicity of CRPS-1. We found that the feasibility of performing a proper RCT to address this issue is very low. Moreover, our results suggest that application of SCS within one year after the onset of CRPS-1 may not lead to a better outcome with improved physical functioning as compared to SCS treatment in chronic CRPS-1. Central sensitization is the increased synaptic efficacy established in somatosensory neurons in the dorsal horn of the spinal cord following intense peripheral noxious stimuli, tissue injury or nerve damage. ${ }^{13}$ Theoretically, central sensitization may occur very early in the course of CRPS-1 e.g. hours or days. ${ }^{14}$ Activation of NMDAR by phosphorylation is a process that may take no more than 30 minutes. The resulting activation may trigger gene transcription that code for neuropeptides that contribute to the maintenance of central sensitization. The latter process may take several days. ${ }^{13,14}$ Experimental studies in human volunteers, injected with intradermal capsaicin demonstrated the presence of rapid onset central sensitization that lasted 2-24 hours. ${ }^{15}$ Animal studies demonstrated that successful SCS pain relief could be obtained significantly more often if SCS therapy is applied within 24 hours. ${ }^{16}$ However, in humans the application of SCS in the first day after onset of CRPS-1 to prevent central sensitization is not a realistic option in routine clinical practice. Another possibility of achieving more successful SCS was demonstrated by animal studies which showed that non responders to SCS could be turned into responders after the administration of an individually determined sub-effective intrathecal dose of ketamine. ${ }^{17}$ This combination therapy may be a good future option to improve results of interventional therapies such as SCS.

\section{Suggested future research}

The main principle of CRPS-1 therapy is to prevent the syndrome from getting chronic. Early treatment of central sensitization or preferably prevention of central sensitization, obtained by mechanism based treatments and prevention strategies probably are the best way to achieve this goal.

In order to develop adequate mechanism based (symptom oriented) treatments, clinical research should firstly identify which patients are at risk for developing chronic CRPS-1. Patients with high initial pain intensities and allodynia may well prove to be at risk for developing chronic CRPS-1. Identifying a subgroup of patients that prove to be at risk for chronification would be very valuable indeed. Research should also focus on the question as to why this subgroup of CRPS-1 patients has a worse prognosis.

After having identified those patients at risk, research should secondly focus on the immediate treatment of patients at risk. Possible pharmacotherapeutic research may involve central pain processing inhibitors, such as NMDAR antagonists (e.g 
ketamine, memantine, methadone), GABA agonists, Glycine and other, nonpharmacological treatment options (e.g. physical desensitization). ${ }^{6}$

There also is a need for clinical research in patients, in the early acute stage of CRPS-1, without obvious signs of central sensitization, but with apparent signs of (sterile) inflammation. This research may focus on the treatment of this early inflammation with anti-inflammatory medication such as steroids, TNF-alpha blockers and biphosphanates.

Robust outcome measures should not only include pain intensity measurements but also measurements of physical and emotional functioning and measurement of patient global perceived impression of change. ${ }^{18}$ Moreover, as illustrated in this thesis, pain intensity may be divided in more specific different components such as spontaneous pain, brush-evoked pain and exercise induced pain. The positive effect of SB in the treatment of CRPS-1 still needs to be proven by good quality randomized controlled trials, e.g. in a setting were a group of CRPS-1 patients treated with physical therapy and a series of SB are compared to a control group, treated with physical therapy only. Patients with signs of central dysfunction may be excluded in this RCT. However in doing so, this would inevitably lead to difficulties in the recruitment of patients.

Finally, the research in this thesis showed that patients with CRPS-1 and allodynia have significantly less pain relief from SCS therapy or from SB than patients without allodynia. This too may be related to the presence of central sensitization. Future research is warranted to elucidate why some patients do better and others not, and why some patients develop central sensitization and others not. This research should probably focus on possible genetic differences between patients that develop central sensitization and patients that do not. ${ }^{19,20}$

\section{References}

1. Nurmikko TJ, Serpell MG, Hoggart B, Toomey PJ, Morlion BJ, Haines D. Sativex successfully treats neuropathic pain characterised by allodynia: a randomised, double-blind, placebo-controlled clinical trial. Pain. 2007;133, 1-3: 210-220.

2. Del Valle L, Schwartzman RJ, Alexander G. Spinal cord histopathological alterations in a patient with longstanding complex regional pain syndrome. Brain Behav Immun. 2009;23, 1: 85-91.

3. Gao YJ, Ji RR. Chemokines, neuronal-glial interactions, and central processing of neuropathic pain. Pharmacol Ther. 2010;126, 1: 56-68.

4. Cao J, Yang X, Liu YN, Suo ZW, Shi L, Zheng CR, et al. GABAergic disinhibition induced pain hypersensitivity by upregulating NMDA receptor functions in spinal dorsal horn. Neuropharmacology. 2011;60, 6: 921-929.

5. Vartiainen NV, Kirveskari E, Forss N. Central processing of tactile and nociceptive stimuli in complex regional pain syndrome. Clin Neurophysiol. 2008;119, 10: 2380-2388.

6. Nijs J, Meeus M, Van Oosterwijck J, Roussel N, De Kooning M, Ickmans K, et al. Treatment of central sensitization in patients with 'unexplained' chronic pain: what options do we have? Expert Opin Pharmacother. 2011;12, 7: 1087-1098. 
7. Costa Lda C, Maher CG, McAuley JH, Hancock MJ, Herbert RD, Refshauge KM, et al. Prognosis for patients with chronic low back pain: inception cohort study. Bmj. 2009;339, b3829.

8. Michaelson $\mathrm{P}$, Sjolander $\mathrm{P}$, Johansson $\mathrm{H}$. Factors predicting pain reduction in chronic back and neck pain after multimodal treatment. Clin J Pain. 2004;20, 6: 447-454.

9. Pobereskin LH. Whiplash following rear end collisions: a prospective cohort study. J Neurol Neurosurg Psychiatry. 2005;76, 8: 1146-1151.

10. Evans JA. Reflex sympathetic dystrophy. Surg Clin North Am. 1946;26, 780-790.

11. Coderre TJ. Complex Regional Pain Syndrome: What's in a Name? J Pain. 2010.

12. Macefield VG. A role for the sympathetic nervous system in sympathetically maintained pain? Clin Neurophysiol. 2010;121, 7: 996-997.

13. Ji RR, Kohno T, Moore KA, Woolf CJ. Central sensitization and LTP: do pain and memory share similar mechanisms? Trends Neurosci. 2003;26, 12: 696-705.

14. Woolf CJ. Central sensitization: implications for the diagnosis and treatment of pain. Pain. 2011;152, 3 Suppl: S2-15.

15. Torebjork HE, Lundberg LE, LaMotte RH. Central changes in processing of mechanoreceptive input in capsaicin-induced secondary hyperalgesia in humans. J Physiol. 1992;448, 765-780.

16. Truin $M$, van Kleef $M$, Linderoth $B$, Smits $H$, Janssen SP, Joosten EA. Increased efficacy of early spinal cord stimulation in an animal model of neuropathic pain. Eur J Pain. 2011;15, 2: 111-117.

17. Truin $M$, Janssen SP, van Kleef $M$, Joosten EA. Successful pain relief in non-responders to spinal cord stimulation: The combined use of ketamine and spinal cord stimulation. Eur J Pain. 2011.

18. Dworkin RH, Turk DC, Wyrwich KW, Beaton D, Cleeland CS, Farrar JT, et al. Interpreting the clinical importance of treatment outcomes in chronic pain clinical trials: IMMPACT recommendations. $J$ Pain. 2008;9, 2: 105-121.

19. Faber CG, Hoeijmakers JG, Ahn HS, Cheng X, Han C, Choi JS, et al. Gain of function Na(V) 1.7 mutations in idiopathic small fiber neuropathy. Ann Neurol. 2011.

20. Dabby R, Sadeh M, Gilad R, Lampl Y, Cohen S, Inbar S, et al. Chronic non-paroxysmal neuropathic pain - Novel phenotype of mutation in the sodium channel SCN9A gene. J Neurol Sci. 2011;301, 1-2: 90-92. 


\section{CHAPTER VIII}

Summary 
Complex Regional Pain Syndrome (CRPS) remains a complex problem with a wide range of different possible pathophysiological mechanisms involved. Diagnosis is made by history and clinical examination, there are no (laboratory) tests to confirm the diagnosis of CRPS. Distinction is made between CRPS type 1 without nerve lesion and CRPS type 2 with nerve lesion. CRPS-1, also known as posttraumatic dystrophy, is characterized by persisting pain in one or more extremities and is usually initiated by a traumatic event such as fracture, operation or sprain. Other signs and symptoms include sensory abnormalities such as allodynia, hyperalgesia, hypoalgesia, hypoesthesia, abnormal skin temperature (warm or cold dystrophy), abnormal skin discoloration (red or blue), abnormal sweating, trophic signs such as abnormal hair growth on the involved limb and abnormal nail growth. Motor signs include loss of strength, tremor, myoclonus, bradykinesia and limited range of motion. Women are affected 3 to 4 times more often than men. In the early phase of the syndrome the involved limb often has an inflammatory aspect. Despite treatment, one year after onset of the symptoms, CRPS-1 becomes chronic in about $30 \%$ of patients. These patients usually develop a dysfunctional, cold atrophic limb with motor impairment. The management of CRPS-1 patients should primarily focus on the prevention of developing chronic CRPS. Therefore identification of patients at risk for developing chronic CRPS is crucial. Moreover, the identification of predictive factors for successful application of interventional pain management procedures would improve patient selection and hence treatment outcome. Research in this area is rather scarce and included only two studies. In one study no single predictor of outcome could be identified and in another study mechanical allodynia was found to be a predictor of a positive response to sympathetic blockade (SB) treatment. The research in this thesis addresses issues of chronicity and predictors of outcome. To obtain a more uniform patient selection, the research was conducted including CRPS-1 patients only.

In chapter two we present a literature review on the diagnosis and management of CRPS, with special focus on the existing evidence for various interventional therapies used in anesthesiological practice. Interventional pain management techniques may be proposed if there is no improvement of limb function together with severe persisting pain, despite adequate pharmacological pain management and physical rehabilitation. A clinical practice algorithm for the treatment of CRPS-1 is proposed. The primary treatment consists of early active mobilization physical therapy combined with pharmacological pain treatment. The use of other pharmacological agents is symptom oriented and guided by the assumed involved mechanism. With regard to interventional pain management, evidence for the use of intravenous regional blocks (IVRB) with guanethidine strongly suggests not to perform this technique. Sympathetic blocks (SB) with local anesthetics, i.e. Stellate ganglion block (SGB) for upper extremity CRPS and lumbar sympathetic block (LSB) for lower extremity CRPS may both be considered as interventional treatment of CRPS if ade- 
quate conservative therapy with medical and physical therapy fails to give pain relief or improvement of physical functioning. If SB gives inadequate pain relief, somatic (e.g. brachial plexus block) or central neuraxial block (e.g. continuous epidural infusion analgesia) may be considered. Spinal cord stimulation therapy (SCS) is recommended if the above mentioned regime fails to improve pain and dysfunction.

In chapter three we studied possible predictors for a positive response to sympathetic blockade (SB) in order to improve patient selection for this procedure. We also identified possible side effects and complications of the procedure. The study group consisted of 49 patients with CRPS-1 of less than one year duration and in one extremity only with pain not responding to conservative treatment with medication and physical therapy. Stellate ganglion block with a local anesthetic was performed for CRPS-1 of the arm and lumbar sympathetic block was performed for CRPS-1 of the leg. We found that 15 out of 49 patients had transient substantial pain relief after SB. These patients were considered responders to SB. This positive response to SB was not different in the cold or warm type group of CRPS-1, nor in the group that had more or less than 1.5 degrees Celsius skin temperature increase after SB, indicating that skin temperature increase is not correlated with pain decrease after SB. No single sign or symptom of CRPS-1 predicted a positive response to SB. Allodynia and hypoesthesia predicted a negative response to SB, indicating that, when one of these symptoms is present, SB is not likely to benefit the patient. The side effects of SB proved to be considerable. Although we had no major complications, a majority of $84 \%$ of patients suffered from (transient) side effects such as headache, dysphagia, nausea, hoarseness, back pain, groin pain, hematoma and a transient increase in pain. The latter is an unexpected finding and occurred as frequent as there was the chance of achieving pain decrease after SB. We therefore concluded that SB in CRPS-1 should be carefully balanced against possible side effects. The presence of allodynia and hypoesthesia predicted a negative response to SB. Pain increase occurs as often as pain decrease after SB.

In chapter four we identified possible predictors of outcome of spinal cord stimulation (SCS) therapy in chronic CRPS-1. Because SCS fails to give pain relief in about one third of CRPS patients and because of the relatively high amount of complications and financial costs of SCS, we tried to identify predictors of positive or negative outcome of SCS therapy. We retrospectively looked at a population of 36 chronic CRPS-1 patients treated with SCS for chronic pain and looked at the influence of the existence at baseline of allodynia, hypoesthesia, initial pain intensity and disease duration on the pain relieving effect of SCS. Successful pain relief by SCS was defined as a patient's impression of much improved change and/or pain reduction of at least 2.5 points on a visual analogue scale from 0 to 10 at one year after 
therapy. After trial stimulation 12 out of 36 patients had insufficient pain relief and did not receive a permanent implant. Twenty four patients had successful pain relief and received a definitive implant. After one year 4 out of 24 implanted patients did not experience successful pain relief anymore. These $12+4=16$ patients were considered unsuccessfully treated and were compared with the 20 patients that still were successfully treated after one year. Univariate analysis showed that patient age, duration of the disease, localization of the disease, intensity of the pain and the presence of mechanical hypoesthesia did not predict success of SCS therapy. In multivariate logistic regression analysis the presence of brush-evoked allodynia with a pain intensity of $\mathbf{2 . 5}$ or more, predicted a statistically significant negative outcome of SCS therapy with a sensitivity of $75 \%$ and a specificity of $81 \%$. When there is no brush-evoked allodynia, there is a high (81\%) chance of achieving successful SCS therapy at one year after implantation. We conclude that patients with brushevoked allodynia with a minimal pain intensity score of 2.5 on a scale from 0-10 have a statistically significant lower chance (31\%) of having successful SCS treatment at one year after implantation. These patients however should not be denied a trial SCS because there still is a chance of achieving successful pain relief. However, if there is any doubt if pain relief after trial stimulation is adequate, it is better not to proceed with the permanent implant. So the take home message regarding SCS and the presence of brush-evoked allodynia in CRPS-1 is: "If in doubt take it out"

In chapter five we investigated if application of SCS early in the course of CRPS-1 could prevent the syndrome from getting chronic. We therefore treated 74 patients with early CRPS-1 in one extremity only, and less than 12 months duration (mean duration 17 weeks, range 2-50 weeks) with standard therapy according to CRPS-1 treatment guidelines. Of these patients 55 (74\%) improved with standard therapy to a mean pain score of 2.1 (range $0-<5$ ). Three patients were excluded because they did not meet the inclusion criteria any more. Six patients refused the early SCS therapy, possibly because of the relatively brief disease duration when the patients were offered to be treated with SCS. There was considerable hesitation to undergo such a kind of invasive treatment early in the course of the disease. Despite the considerable recruitment effort, only six patients could eventually be included during the study period of at least three years (June 2005 - October 2008). This made the study underpowered and therefore impossible to draw conclusions. The calculated sample size for a randomized controlled trial that would investigate the potential benefit of early SCS therapy in CRPS-1 estimated 64 patients. In order to include these 64 patients we would have needed to screen about 800 patients with early CRPS-1. Given the incidence rate of approximately 16 patients per 100.000 person years and the catchment area of our institutions of 500.000 inhabitants, this meant a minimal of ten years of patient recruitment and screening. We concluded that the feasibility of performing a study on the effectiveness of SCS early in the course of 
CRPS-1 is low. Nevertheless, given the finding that $74 \%$ of patients improved with standard therapy and that all patients eventually treated with SCS, showed no improvement in functional outcome, this study clearly questions the need to start SCS early in the course of the disease firstly because of the good improvement with standard therapy and secondly because of the lack of additional benefit as compared to SCS implantation in chronic CRPS-1 of more than one year duration.

In chapter six we studied the long term effect of S-Ketamine on three different components of pain: spontaneous pain in rest, brush-evoked allodynia (BEA) and exercise-induced pain in chronic CRPS-1 patients. From previous studies we know the positive effect that intravenous ketamine may have on pain in patients with CRPS-1. The effect of Ketamine on brush-evoked pain and exercise-induced pain together with its effect on physical functioning however was not extensively studied. Therefore 14 lower extremity CRPS-1 patients, with disease duration of at least one year, were treated with continuous intravenous S-ketamine 10-30 mg hour ${ }^{-1}$ during a mean of 9 days ( $\min 5$ - $\max 12$ ). To study the effect of S-ketamine on the physical walking function we also measured its effect on the timed ten meters walking test which allowed us to calculate standardized walking speeds for comfortable and for quick walking. Two patients developed elevated plasma levels of liver enzymes, at the end of therapy, probably due to an allergic hepatitis. After termination of the infusion, liver enzyme plasma levels returned to normal in a few weeks. A prolonged hospitalization was not needed. Four patients had no pain relief after the infusion and were therefore considered non responders to S-ketamine treatment. The other eight patients had total abolishment of the BEA or spontaneous pain at 12 days after treatment. These patients were considered responders to $\mathrm{S}$ ketamine treatment. In this responder group, patients had statistically significant, clinically meaningful improvement of their spontaneous pain at one, three and six months follow up, the BEA at one and three months and the exercise-induced pain at one, three and six months. While, compared to baseline, spontaneous pain, brush-evoked allodynia and exercise-induced pain improved, pain scores tended to slightly increase again. The walking speeds significantly increased from about 2 kilometers hour ${ }^{-1}$ at baseline to about 3.5 kilometers hour $^{-1}$ at six months and remained significantly improved despite the returning pain. We conclude that intravenous S-ketamine may abolish spontaneous and BEA, reduce exercise induced pain, and restore the ability to walk, up until 6 months after therapy in a subgroup of lower limb CRPS-1 patients with otherwise therapy resistant severe pain.

In chapter seven we discussed our findings and reflect on the role of central sensitization in CRPS-1 and its treatment. We demonstrated that interventional treatment with SB or SCS is less effective if there is central sensitization as shown by the presence of BEA. Intravenous S-ketamine however may be effective in reducing or even abolishing this BEA. Central sensitization may be induced by high intensity pain noxious stimuli which trigger chemokines such as CCL2 in the spinal cord glial 
cells to increase the NMDAR activity in the posterior horn. This upregulation of NMDAR is the cause of the pain hypersensitivity in a subpopulation of CRPS-1 patients. We find identification and quantification of the presence of central sensitization in CRPS-1 to be extremely important. This allows the clinician to make mechanism oriented treatment decisions. All possible involved mechanisms should be identified and treated accordingly (e.g. presence of BEA: treat central sensitization, presence of a warm and swollen limb treat the inflammation).

The role of SB in the treatment of CRPS-1 may not be as important as previously thought. There are only one third of patients that respond to SB and side effects are considerable. The positive effect of SB in the treatment of CRPS-1 still needs to be proven by RCT's .

SCS needs to be applied cautiously in the presence of CRPS-1 associated allodynia. To prevent chronicity and central sensitization SCS may not be a good choice. For chronic CRPS-1, SCS remains a valuable tool. About two out of three patients have adequate pain reduction with SCS treatment, one third of patients do not respond to SCS treatment. Animal studies suggest that ketamine may turn these non-responders into responders.

Future studies should focus on this issue and on the identification of factors associated with a bad outcome of the disease. Finally research is needed to elucidate why some patients develop central sensitization and others not. This research should probably focus on possible genetic differences between patients that develop central sensitization and patients that do not. 

Samenvatting

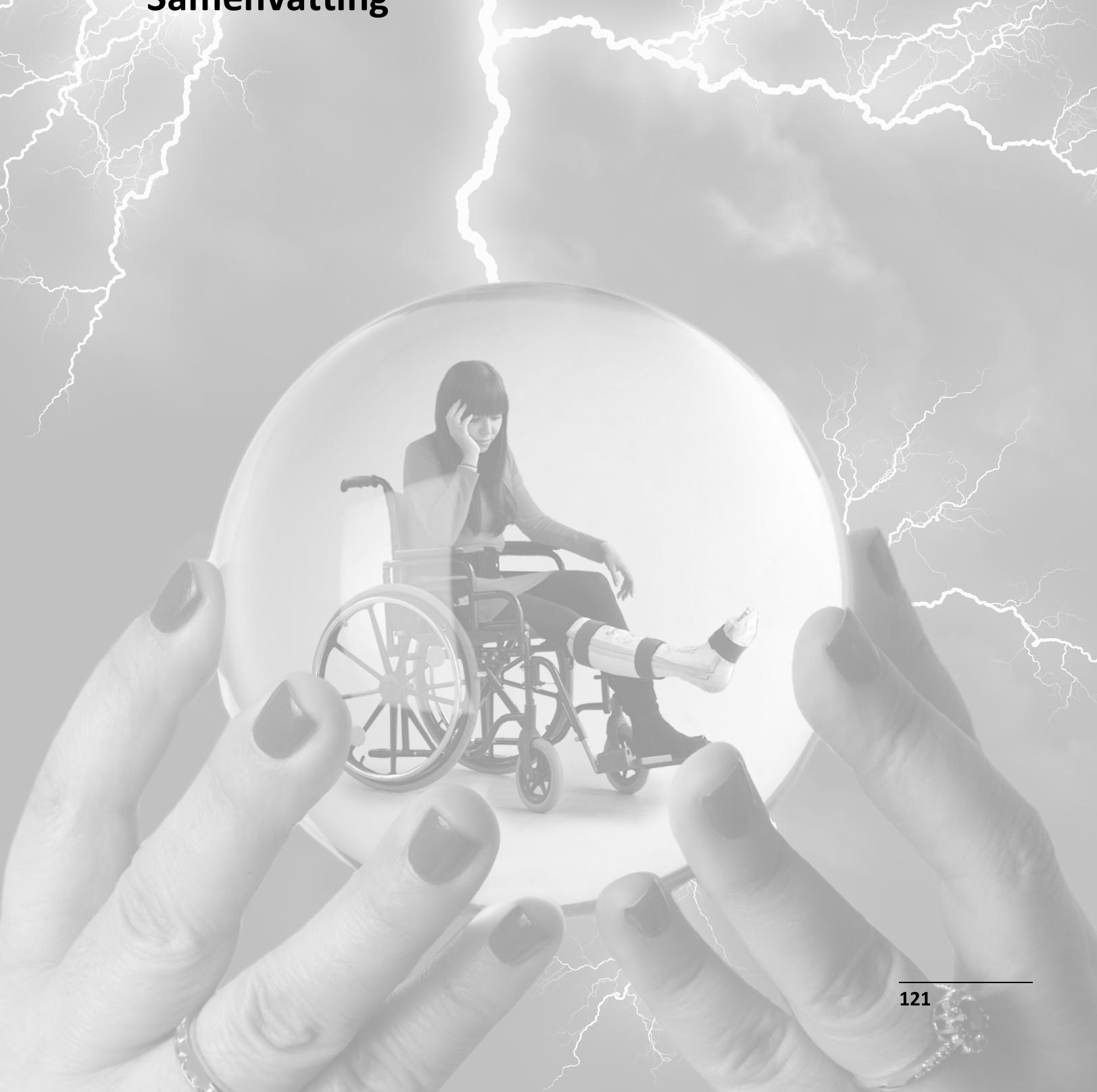


Complex Regionaal Pijn Syndroom (CRPS) blijft - de naam impliceert het al - een complex probleem waaraan een zeer breed scala aan pathofysiologische mechanismen ten grondslag ligt. Een onderscheid wordt gemaakt tussen CRPS type 1 zonder duidelijke zenuwbeschadiging en CRPS type 2 met duidelijke zenuwschade. De aandoening komt 3 tot 4 maal vaker voor bij vrouwen dan bij mannen. De diagnose wordt gesteld door anamnese en lichamelijk onderzoek, er zijn geen laboratoriumtests die de diagnose CRPS kunnen bevestigen. Om van CRPS te mogen spreken moet aan een aantal criteria worden voldaan.

CRPS-1, ook bekend als posttraumatische dystrofie, wordt gekenmerkt door persisterende pijn in één of meer extremiteiten. Het volgt vaak na een trauma zoals botbreuk, operatie of eenvoudige verstuiking. Aanvankelijk ziet de aangedane arm of het been er vaak ontstoken uit: pijnlijk, rood, gezwollen en warm aanvoelend. Andere vaakvoorkomende symptomen zijn gevoelsstoornissen zoals allodynie, hyperalgesie, hypoalgesie en hypesthesie. Allodynie is het als pijnlijk ervaren van een normaliter niet-pijnlijke prikkel, bijvoorbeeld het wrijven met een kwastje over de huid. De hierdoor opgewekte pijn kan gekwantificeerd worden door er een pijnscore tussen de 0 en 10 aan te geven. Van hyperalgesie spreekt men wanneer een normaliter gering pijnlijke prikkel als veel pijnlijker wordt ervaren. Hypoalgesie en hypesthesie zijn het tegenovergestelde, namelijk een verminderd (pijn)gevoel. Daarnaast kan het aangedane ledemaat een abnormale huidtemperatuur vertonen (warme of koude dystrofie), gepaard aan een abnormale huidskleur (rode of blauwe verkleuring), abnormaal zweten, abnormale beharing en abnormale nagelgroei. Verder zijn er motorische verschijnselen mogelijk, zoals krachtsverlies, beven, spierschokjes, bradykinesie (vertraagd bewegen) en een beperking van de beweeglijkheid van gewrichten van de getroffen extremiteit.

Ondanks behandeling kan de ziekte in circa $30 \%$ van de gevallen chronisch worden. Na ongeveer 1 jaar zien we dan veelal geen verbetering meer en ontstaat er een koud aanvoelend, atrofisch ledemaat met functieverlies. Het voornaamste behandeldoel is dan ook trachten te voorkomen dat de ziekte chronisch wordt. Om dit te bereiken moeten de patiënten geïdentificeerd worden die een verhoogd risico hebben op het ontwikkelen van de chronische vorm van CRPS. Indien een invasieve behandeling wordt overwogen moeten selectiecriteria voor deze behandelingen worden aangescherpt.

Onderzoek op dit gebied is schaars, er zijn namelijk slechts twee studies. In de ene studie konden geen predictoren gevonden worden, d.w.z. factoren die het beloop konden voorspellen. In de andere studie bleek de aanwezigheid van allodynie een predictor te zijn die een positieve respons op een sympathische blokkade voorspelde.

Het onderzoek beschreven in dit proefschrift gaat over factoren die van invloed kunnen zijn op het beloop van de ziekte en over predictoren die het effect van invasieve behandelingen zoals ruggenmergstimulatie en sympathische blokkade (SB) 
met lokaal anesthetica kunnen voorspellen. Om een meer uniforme patiëntenselectie te bewerkstelligen zijn uitsluitend patiënten met CRPS-1 onderzocht; de termen CRPS en CRPS-1 worden in het vervolg dan ook door elkaar gebruikt.

Hoofdstuk twee geeft een overzicht van het huidige medisch bewijs van de bestaande conservatieve en interventionele behandelingen van CRPS door middel van een uitgebreide literatuurstudie. Interventionele, invasieve behandeltechnieken kunnen voorgesteld worden indien er persisterende ernstige pijn is zonder functieverbetering ondanks adequate farmacotherapeutische behandeling en revalidatietherapie. Een praktisch algoritme voor de behandeling van CRPS-1 wordt voorgesteld. Als eerstelijnsbehandeling is vroege fysiotherapie met actieve mobilisatie en farmacotherapeutische pijnbehandeling geïndiceerd. Daarnaast kunnen andere farmacologische middelen toegepast worden volgens een symptoomgeoriënteerde aanpak die is gebaseerd op de betrokken mechanismen. Wat betreft interventionele behandelingen is gebleken dat er geen medisch bewijs bestaat voor de behandeling van CRPS middels intraveneuze regionale blokkade met guanethidine. Sympathische blokkades (SB) met lokaal anesthetica, bijvoorbeeld ganglion stellatum blokkade (SGB) voor CRPS van de arm en lumbale sympathicus blokkade (LSB) voor CRPS van het been, kunnen overwogen worden als eerstelijns behandeling geen verbetering brengt. Als SB geen pijnvermindering geeft kan perifere (bijvoorbeeld plexus blokkade) of centrale neuraxis blokkade (bijvoorbeeld epidurale analgesie) overwogen worden. Ruggenmergstimulatie wordt aanbevolen indien bovenstaand regime geen verbetering van pijn en dysfunctie oplevert.

In hoofdstuk drie onderzoeken we of er predictoren zijn die een positieve respons op een SB kunnen voorspellen om aldus de patiëntenselectie voor deze procedure te verbeteren. We onderzoeken ook de mogelijke bijwerkingen en complicaties van deze procedure. De bestudeerde groep bestond uit 49 patiënten met CRPS1 in slechts één extremiteit, met een ziekteduur van minder dan één jaar en ernstige pijn, die niet reageert op conservatieve therapie met medicatie en fysiotherapie. Voor CRPS-1 van de arm werden patiënten behandeld middels een SGB; bij CRPS-1 van het been werd een LSB uitgevoerd. Vijftien van de 49 patiënten hadden een tijdelijke pijnvermindering na SB, dit waren de responders. Er waren niet meer responders in de groep met een koude vorm van dystrofie dan in de groep met een warme vorm van dystrofie. De mate van huidtemperatuurstijging na SB was niet gerelateerd aan het pijnstillend effect ervan. Er waren geen symptomen van CRPS die een pijnstillend effect van de SB kon voorspellen. Aanrakingspijn, met name "brush evoked allodynia"(BEA) en hypesthesie daarentegen waren voorspellende factoren voor een niet-succesvolle behandeling met SB. Dit kan verklaard worden door een bij allodynie en hypesthesie aanwezige dysfunctie van het centrale zenuwstelsel (CZS). Bijwerkingen van een sympathische blokkade blijken vaker voor te komen dan aanvankelijk gedacht. Hoewel we geen ernstige complicaties gezien hebben bleek $84 \%$ van de patiënten last te hebben van problemen als - afhankelijk 
van uitvoering van SGB dan wel LSB - hoofdpijn, pijn bij slikken, misselijkheid, heesheid, rugpijn, liespijn, bloeduitstorting ter plaatse van de insteekopening en een tijdelijke vermeerdering van de pijn. Vooral dit laatste was onverwacht: meer pijn in de aangedane extremiteit na de SB bleek even vaak voor te komen als minder pijn. We concludeerden dat SB als behandeling voor CRPS-1 zeer zorgvuldig gewogen moet worden, waarbij rekening gehouden dient te worden met alle mogelijke bijwerkingen en complicaties. De aanwezigheid van BEA in de aangedane extremiteit, duidt op centrale sensitisatie, en voorspelt een niet-succesvolle SB. De kans op pijnvermindering is net zo groot als de kans op een periode van meer pijn na de ingreep.

In hoofdstuk vier wordt het onderzoek beschreven naar mogelijke predictoren die een positieve respons kunnen voorspellen op een behandeling met ruggenmergstimulatie bij patiënten met chronische CRPS-1. Ruggenmergstimulatie geeft in één op de drie gevallen geen pijnvermindering, terwijl ook na verloop van tijd het effect vermindert. Daarnaast kunnen er bij en na ruggenmergstimulatie relatief veel complicaties optreden. Predictoren die een eventueel wel of niet-succesvolle ruggenmergstimulatie kunnen voorspellen zouden van groot belang zijn bij de selectie van patiënten voor een dergelijke ingreep. Daarom onderzochten we bij 36 patiënten met chronische CRPS-1 of de initiële aanwezigheid van BEA, hypesthesie, hoge pijnintensiteit en ziekteduur van invloed zijn op een succesvolle toepassing van ruggenmergstimulatie. Ruggenmergstimulatie werd als succesvol beoordeeld wanneer de patiënt op een schaal die de globale indruk van verandering evalueert een score "veel verbeterd" aangaf, of een pijnvermindering van ten minste 2,5 op een schaal van 0 tot 10 één jaar na implantatie noteerde. Na proefstimulatie hadden 12 van de 36 patiënten onvoldoende pijnreductie; zij kregen dan ook geen definitieve stimulator. De overige patiënten kregen wel een stimulator geïmplanteerd. Na één jaar hadden 4 geïmplanteerde patiënten onvoldoende pijnstilling. Deze 4 , samen met de 12 niet geïmplanteerde patiënten, werden beschouwd als patiënten die niet succesvol met ruggenmergstimulatie behandeld waren. Deze patiënten werden vergeleken met de 20 wel succesvol behandelde patiënten. Uit de univariate analyse bleek dat leeftijd, ziekteduur, ziektelokalisatie, pijnintensiteit en mechanische hypesthesie het effect van de ruggenmergstimulatie niet konden voorspellen. $\mathrm{Na}$ multivariate logistische regressie bleek de afwezigheid van BEA een hoge (namelijk 81\%) kans te geven op een succesvolle ruggenmergstimulatie, d.w.z. nog steeds effectief 1 jaar na de implantatie. De aanwezigheid van BEA daarentegen, met een pijnscore van ten minste 2,5 , geeft slechts $31 \%$ kans op succesvolle ruggenmergstimulatie 1 jaar na start van de behandeling. Deze voorspelling kunnen we doen met een sensitiviteit van $75 \%$ en een specificiteit van $81 \%$. Dit betekent niet dat we elke patiënt met allodynie een proefbehandeling met ruggenmergstimulatie moeten ontzeggen. Echter, indien er twijfel is of de verkregen pijnreductie na proefstimula- 
tie groot genoeg is, dan is dit een reden om geen stimulator te implanteren bij patienten met CRPS-1 en duidelijke BEA.

In hoofdstuk vijf onderzoeken we of vroege toepassing van ruggenmergstimulatie kan voorkomen dat het syndroom chronisch wordt. Met 'vroeg' wordt dan bedoeld binnen 12 maanden na het uitlokkend moment of na het ontstaan van de symptomen. Voor dit onderzoek werden 74 patiënten met CRPS-1 met een gemiddelde duur van 17 weken (spreiding 2 tot 50 weken) behandeld volgens algemene CRPS -1 behandelrichtlijnen met fysiotherapie en standaard medische therapie. Van deze patiënten verbeterden maar liefst 55 (74\%) met deze standaardtherapie tot een gemiddelde pijn van 2,1 (spreiding 0 tot $<5$ ). Drie patiënten werden geëxcludeerd omdat ze nog wel pijn hadden maar niet meer aan de overige inclusiecriteria voldeden en dus geen CRPS-1 meer hadden. Zes patiënten weigerden de behandeling met ruggenmergstimulatie. Kennelijk bleken patiënten grote twijfel te hebben of ze wel een ruggenmergstimulator zouden laten plaatsen in deze vroege fase van de ziekte. Ondanks een initieel groot aantal mogelijke kandidaten konden er uiteindelijk slechts 6 patiënten in de studie opgenomen worden gedurende een inclusieperiode van 3 jaar. Dit maakte dat we uit deze studie statistisch gezien geen harde conclusies kunnen trekken. We berekenden vervolgens het aantal proefpersonen nodig voor een gerandomiseerde gecontroleerde studie om het mogelijke positieve effect van vroege ruggenmergstimulatie bij CRPS-1 aan te tonen. Dit aantal bedraagt volgens onze berekeningen 64 . Om deze 64 patiënten te includeren zouden we maar liefst 800 patiënten met vroege CRPS-1 moeten screenen. Gelet op de gemiddelde incidentie van 16 patiënten per 100.000 personen en het verzorgingsgebied van onze ziekenhuizen van 500.000 personen, betekent dit een minimum van 10 inclusiejaren. De uitvoerbaarheid van een dergelijke studie is derhalve gering. Desondanks, gezien het gegeven dat $74 \%$ van de patiënten verbeterden met standaardtherapie en gezien geen van de 6 met ruggenmergstimulatie behandelde patiënten functieverbetering had na 1 jaar, is er toch gerede twijfel dat het gebruik van ruggenmergstimulatie in de vroege fase van CRPS-1 een duidelijke meerwaarde heeft ten opzichte van de toepassing bij de chronische CRPS-1 patiënt.

Hoofdstuk zes beschrijft het effect van S-ketamine op de pijn en functionaliteit bij CRPS-1. Vanuit eerder onderzoek kennen we het positieve effect dat ketamine kan hebben op de pijn van CRPS-1 patiënten. Het effect van ketamine op inspanningsgebonden pijn, BEA en functionaliteit is daarentegen niet goed onderzocht. Daarom onderzochten we het langetermijneffect van S-ketamine op drie componenten van pijn: spontane pijn, inspanningsgebonden pijn en aanrakingspijn (BEA) bij 14 patiënten met chronische therapieresistente CRPS-1 en een ziekteduur van ten minste 12 maanden. Daarnaast keken we naar het effect van S-ketamine op de loopfunctie zoals gemeten met de 'tien meter looptest', waarmee we vervolgens het looptempo voor comfortabel en voor snel lopen konden berekenen. Patiënten werden behandeld met een continu intraveneus S-ketamine infuus met een gemid- 
delde duur van 9 dagen (min. 5 - max. 12). Van deze 14 patiënten ontwikkelden er twee verhoogde plasmaspiegels van een aantal leverenzymen, waarschijnlijk op basis van een allergische hepatitis. Na stoppen van de S-ketamine normaliseerden deze spiegels binnen enkele weken; een verlengde hospitalisatie bleek niet nodig. Vier patiënten ondervonden geen pijnreductie direct na de infusie en werden dus gekwalificeerd als niet-responders. Acht van de 14 patiënten hadden totaal geen BEA of spontane pijn meer na het stoppen van het infuus. Deze patiënten werden door ons beschouwd als responders voor S-ketamine therapie. De responders vertoonden een statistisch significante en klinisch relevante verbetering van hun spontane pijnscores na één, drie en zes maanden; van de inspanningsgebonden pijn na één, drie en zes maanden en van de BEA na één en drie maanden. Hoewel alle pijnscores duidelijk verbeterden t.o.v. de uitgangswaarden, was er een tendens tot wederom iets verhogen van de pijnscores na zes maanden. In tegenstelling hiermee bleven loopsnelheden in deze groep significant verhoogd van gemiddeld $2 \mathrm{~km} / \mathrm{uur}$ vóór start van de therapie tot ongeveer $3,5 \mathrm{~km} / \mathrm{uur}$ na 6 maanden. We concludeerden dat intraveneus S-ketamine de pijn kan verminderen en de loopsnelheid kan verbeteren bij een subgroep van CRPS-1 patiënten met anders therapieresistente pijn.

In hoofdstuk zeven bespreken we onze resultaten en gaan we verder in op de rol van centrale sensitisatie (d.w.z. een verhoogde gevoeligheid van het centrale zenuwstelsel) bij CRPS-1 en de behandeling hiervan. We toonden aan dat interventionele behandeling met SB of ESES minder effectief is als er sprake is van centrale sensitisatie zoals vastgesteld door de aanwezigheid van BEA. Intraveneus Sketamine daarentegen kan wel effectief zijn om de centrale sensitisatie te behandelen. Deze centrale sensitisatie kan geïnitieerd worden door noxische prikkels met hoge intensiteit waardoor chemokines, zoals CCL2 in de glia-cellen van het ruggenmerg, het zenuwweefsel aanzetten tot een verhoogde NMDAR-activiteit ter hoogte van de dorsale hoorn. Deze verhoogde receptoractiviteit is de oorzaak van de verhoogde pijnsensatie bij een subgroep van CRPS-1 patiënten. Om deze reden vinden wij het van het grootste belang om de aanwezigheid van een eventuele centrale sensitisatie al vroeg te diagnosticeren en te kwantificeren. Hierdoor kan de behandelaar een specifieke behandeling baseren op het onderliggend mechanisme. Dat wil zeggen dat hij de centrale sensitisatie behandelt indien er BEA aanwezig is, of dat hij de ontsteking behandelt in geval van een warm gezwollen ledemaat. De rol van SB bij de behandeling van CRPS-1 is waarschijnlijk minder belangrijk dan aanvankelijk gedacht. Ongeveer een derde van de patiënten heeft pijnreductie na SB en de bijwerkingen zijn aanzienlijk. Daarnaast dient het positieve effect van een behandeling met SB nog aangetoond te worden door middel van gerandomiseerd onderzoek. Bij aanwezigheid van BEA dient men eveneens alert te zijn op een verminderd pijnstillend effect van een ruggenmergstimulatie. Als men chronificatie en centrale sensitisatie wil voorkomen dan is dit wellicht geen goede behandeling. 
Twee van de drie patiënten hebben goede pijstilling met ruggenmergstimulatie, één derde echter niet. Uit dierexperimenteel onderzoek blijkt dat deze non-responders omgezet kunnen worden in responders door middel van S-ketamine. Misschien dat dit bij de mens ook van toepassing is. Dit zou nader onderzocht moeten worden. Toekomstig onderzoek zou zich ook moeten richten op de identificatie van factoren die geassocieerd zijn met een ongunstig beloop van deze aandoening. Tot slot dient uitgezocht te worden waarom sommige patiënten centrale sensitisatie ontwikkelen en andere niet; dit onderzoek zou zich kunnen toespitsen op mogelijke genetische verschillen. 
CHAPTER IX

Curriculum Vitae 
Frank van Eijs was born as the third child in a family of 5 children on January 16th 1959 in The Hague, the Netherlands. At the age of four his family moved to Spain where he started his primary education in a Spanish infant school. The rest of his primary education was given consecutively in Oosterhout, the Netherlands and at the "Deutsche Schule" in Las Palmas de Gran Canaria. In Belgium he continued his education at the Koninlijke Atheneum in Keerbergen where he obtained his degree at the age of 18 . He then went on to Ghent, Belgium, where he studied medicine at the State University and obtained his medical degree in 1984. After two years of residency in the accident and emergency department of the Ignatius hospital in Breda, the Netherlands, he started his anaesthesia specialty training at the University Hospital of Utrecht, the Netherlands under the supervision of prof. dr. Bob Smalhout. In 1991, he was a consultant anaesthesiologist at the University Hospital of Utrecht were he got interested in pain management. In 1995 he moved to the Elisabeth hospital in Tilburg, the Netherlands where he continued to work as a consultant anaesthesiologist with a subspecialty in pain management. His major occupation is the administration of general and regional anaesthesia. One or two days a week he is active as a pain specialist in the pain management department of the hospital. An essential component of his pain management training consisted of his education in musculoskeletal medicine where he obtained a degree in manual medicine in 2004. During his work as a pain specialist he got especially intrigued by chronic pain patients with Complex Regional Pain Syndrome. He started his clinical research on outcome predictors of interventional treatment of CRPS patients in 2005 which eventually led to this dissertation. Frank van Eijs also is a (reserve) lieutenant - colonel in the Dutch army where he is a member of the surgical teams and as such has been sent to Bosnia several times in different peace keeping missions: SFOR 12 in 2002, SFOR 14 in 2003 and EUFOR 1 in 2005. Hobbies include motor riding, scuba diving, skiing, wine tasting and enjoying life to the fullest. Frank van Eijs has two sons: Alexander (16-05-1991) and David (2-02-1995) 



\section{List of publications}




\section{Journal articles}

van Eijs F, Geurts J, van Kleef F, Faber CG, Perez RS, Kessels AFG, Van Zundert J. Predictors of Pain Relieving Response to Sympathetic Blockade in Complex Regional Pain Syndrome type 1. Anesthesiology (in press)

van Eijs F, Geurts J, Van Zundert J, Faber CG, Kessels AFG, Joosten EA, van Kleef M, Spinal Cord Stimulation in Complex Regional Pain Syndrome Type I of Less Than Twelve Months Duration. Neuromodulation (in press)

van Eijs F, Huygen F, Van Zundert J. In response: intravenous regional guanethidine for complex regional pain syndrome. Pain Practice 2011; vol 11(5):506-507

de Boer RDH, Marinus J, van Hilten JJ, Huygen FJ, van Eijs F, van Kleef M, Bauer MCR, van Gestel M, Zuurmond W, Perez RSGM. Distribution of signs and symptoms of Complex Regional Pain Syndrome type I in patients meeting the diagnostic criteria of the International Association for the study of Pain. Eur J Pain 2011 Epub, Feb 18

van Eijs F, Stanton-Hicks M, Van Zundert J, Faber C, Lubenow T, Mekhail N, et al. Evidence based interventional pain medicin according to clinical diagnosis. Complex Regional Pain Syndrome Pain Pract. 2011; vol 11(1):70-87.

van Eijs. An update on the pathophysiology of CRPS. S. Bruehl. Ref. Ned Tijdschr. Voor Pijnbestrijding 2010;44:60-61

de Rooij AM, Perez RS, Huygen FJ, van Eijs F, van Kleef M, Bauer MC, van Hilten JJ, Marinus J Spontaneous onset of complex regional pain syndrome. Eur J Pain. 2010 May;14(5):510-3.

Perez RS, Zollinger PE, Dijkstra PU, Thomassen-Hilgersom IL, Zuurmond WW, Rosenbrand KC, Geertzen JH; CRPS I task force. Collaborators (23) Beems T, van den Brink HR, van Eijs F , Goris RJ, Haagh WA, van Hilten JJ, Huygen FJ, Kemler MA, van Kleef $M$, van der Laan L, Oerlemans HM, Patijn J, Ruijgrok JM, Slebus FG, Strackee SD, Tibboel D, Theuvenet P, Veldman PJ, van de Ven-Stevens LA, Verhoeven AC, Versteegen GJ, Wemekamp $\mathrm{H}$, Kuis W. Evidence based guidelines for complex regional pain syndrome type 1. BMC Neurol. 2010 Mar 31;10:20.

van Eijs F, Smits $H$, Geurts JW, Kessels AG, Kemler MA, van Kleef M, Joosten EA, Faber CG. Brush-evoked allodynia predicts outcome of spinal cord stimulation in 
complex regional pain syndrome type 1. Eur J Pain. 2010 Feb;14(2):164-9. Epub 2009 Nov 25.

van Eijs F, Quantitative sensory testing for spinal Cord Stimulation in Patients with Chronic Neuropathic Pain, Ref. Ned Tijdschr. voor Pijnbestrijding 2007, nr 26 (29), pag 23

van Eijs F, Invasieve behandeling bij neuropathische pijn. Pijninfo 2007 / nummer 12 ISBN 9065027254, uitgever Bohn Stafleu van Loghum, Houten

Castagnini HE, van Eijs F, Salevsky FC, Nathanson MH. Sevoflurane for interventional neuroradiology procedures is associated with more rapid early recovery than propofol. Can J Anaesth. 2004 May;51(5):486-91.

van Eijs F, Congres verslag $10^{\text {th }}$ World Congress on Pain, 17-22 aug 2002, Pijnjournaal 1, november 2002

van Eijs F, Geurts JWM, Wassink ASM; Clinical Evaluation of neurolytic sympathtic blockade for reflex sympathetic dystrophy of the lower extremity. Abstract / Poster $7^{\text {th }}$ World Congress on Pain, Paris, 1993

van Eijs F, Ventriculaire ritmestoornissen en hypomagnesiemie, Ned.Tijdschr. v.Anesth mei 1992

van Eijs F, Hols E, Carels FW; Hematopneumothorax met spanningscomponent tijdens anesthesie; Ned.Tijdschr.v.Anesthmw. 1990, nr.5

\section{Book chapter}

van Wijk RMAW, Geurts JWM, van Eijs F, Percutaneous radiofrequency partial rhizotomy of the spinal dorsal ganglion in the treatment of chronic low back pain with segmental irradiation to the leg. In: Ernst E, Jayson MIV, Pope MH, Porter RW, eds. Advances in idiopathic low back pain. Vienna: Blackwell-MZV, 1993:288-91

\section{Guideline}

Richtlijn Complex Regional Pijn Syndroom, uitgeverij van Zuiden, 2006, Alphen a/d Rijn, werkgroeplid namens de NVA, ISBN-10: 90-8523-124-8 
CHAPTER $X$

Dankwoord 
De totstandkoming van dit proefschrift zou niet mogelijk geweest zijn zonder de hulp van velen. Ik wil hier graag een aantal van hen met name noemen en danken voor hun bijdrage.

Allereerst mijn promotor, prof. dr. M. van Kleef. Beste Maarten, ik was waarschijnlijk meer dan eens aanleiding tot ernstige hoofdpijn, vooral op tijden dat het niet ging zoals we wensten. Toch bleef je me steunen en bleef je vertrouwen houden in een uiteindelijk goede afloop. Dank hiervoor.

Dr. Faber, beste Karin, mijn dank dat je mijn copromotor wilde zijn. Je neurologische inbreng in dit onderzoek is van vitaal belang geweest; steeds weer wist je zaken helder en bondig naar voren te brengen. Je wetenschappelijke kennis en schrijfstijl hebben mij zeer geholpen. Met elk stuk dat we samen doornamen ben ik er met mijn wetenschappelijke kennis en mijn kennis van het Engels aanzienlijk op vooruit gegaan. Dank hiervoor.

Dr. Van Zundert, beste Jan, ook jou dank ik voor je copromotorschap. Je eerste voorstel als copromotor was om onze mobiele nummers uit te wisselen. Dit bleek voor mij van een onschatbare waarde, samen met je praktische kijk op de zaken. Je had altijd tijd voor me, zelfs in tijden dat je het door privégebeurtenissen erg moeilijk had. Dank hiervoor.

Van mijn onderzoeksgroep wil ik in het bijzonder José Geurts vermelden. Onverschrokken, recht door zee, no nonsens, begaafd met wetenschappelijk inzicht en altijd goede zin. Dank voor je onmisbare inbreng. En natuurlijk ook Fons Kessels, het statistisch gezicht van Maastricht. Jan Van Zundert had het bij het rechte eind toen hij betoogde, en ik citeer: "Fons heeft altijd gelijk." Je vormde met José het statistische hart van deze onderneming, dank voor alles. Uiteraard ook dr. Joosten, beste Bert, je kennis van de pathofysiologie van CRPS en de werkingsmechanismen van SCS zijn van groot belang geweest in de vele discussies. Dank voor je inbreng.

De leden van de leescommissie wil ik danken voor de tijd die ze zich getroost hebben dit werk door te nemen: prof. dr. Lodewijk van Rhijn, prof. dr. Rob Smeets, prof. dr. Frank Huygen, prof. dr. Anne Roukema, dr. Robert van Oostenbrugge. De overige leden van de beoordelingscommissie: prof. dr. Yasin Temel, dr. Roberto Perez en prof. dr. André van Zundert, dank dat u zitting wil nemen op deze voor mij zo belangrijke dag.

Van het St. Elisabeth Ziekenhuis wil ik met name danken twee nurse practitioners van het eerste uur, Gerry Aikema en Marcel Schors. Jullie stonden me bij aanvang van dit werk als eerste bij met de dataverzameling, en ook na het vertrek van Gerry kon ik op advies van Marcel blijven rekenen tot aan de slotfase van dit boekwerk. Heel erg veel dank. Maud van Hees-van Dongen en Astrid Kwakernaak, physician assistants, dank voor jullie hulp. Het was niet altijd even gemakkelijk om met mij te 
werken maar ik ben blij dat jullie volhielden en dit nog altijd doen. Josephien Backx en Jojanneke van Rossum: jullie zijn waardige opvolgers van Gerry gebleken. Zonder jullie zou het leven niet zo stimulerend zijn. Het beste secretariaat van ons ziekenhuis: Desiree Moonen, Celeste van den Brekel, Ingrid Nuijten en Femke van Kruysdijk, jullie zijn een onmisbare schakel in het geheel. Zonder jullie zou de motor niet lopen. De nurse practitioners en physician assitants van de poli anesthesie, de anesthesie- en PACU-medewerkers van het St. Elisabeth Ziekenhuis: het is door jullie inbreng dat de werksfeer is zoals die moet zijn. Het is een voorrecht met jullie te mogen werken. Eigenlijk zou ik ieder van jullie bij naam moeten noemen maar dan zou dit stukje wel heel erg lang worden; ik hoop dat jullie mij dit vergeven. In ieder geval wil ik in dit kader vooral die mensen danken die mij en mijn collega's bijstaan met de pijnbehandelingen op kamer 15. En als ik de medewerkers noem, dan mag het managementteam van de OK in dit dankwoord natuurlijk niet ontbreken. Dank voor het creëren van de juiste voorwaarden.

Van mijn maten wil ik met name dr. GJ. Noordergraaf danken; beste Gerrit-Jan, ik ben blij dat ik gebruik heb kunnen maken van je zeer gewaardeerde inbreng en adviezen. Je was en bent nog altijd voor twee FTE beschikbaar. Tegen mijn collegapijnspecialisten Frederik Callebaut, Teun van den Hurk en Herman van Middelkoop zou ik willen zeggen: samen zullen we een pijnbehandelcentrum Midden-Brabant maken waar we trots op kunnen zijn. De andere anesthesiologen van mijn maatschap: Robbert Bremer, Cathy Neetens, Joëlle Rottier, Jan Schaffers en Yzabel Vandevivere, dank voor al het extra werk dat jullie verzet hebben terwijl ik met wetenschappelijke zaken bezig was. Jullie inspanning maakte het me mogelijk dit traject te doorlopen. Daarnaast, hoewel geen maatschapslid, wil ik Pavel Majer danken voor zijn waarneming waardoor ik gedurende enige tijd ongestoord kon werken aan deze thesis.

Marc van Gestel en Herman van Middelkoop wil ik danken dat ze tijdens de verdediging van mijn proefschrift de rol van paranimfen op zich willen nemen. Ellen van de Eerden wil ik danken voor haar organisatorische inbreng.

Verder wil ik al mijn CRPS-patiënten danken. Zonder hun vertrouwen en instemming zou er van dit boekje niets terechtgekomen zijn. Ook alle huisartsen en medisch specialisten die hun patiënten naar mij verwezen: dank voor uw vertrouwen.

Nicole van den Hecke wil ik danken voor haar bekwame, toegewijde administratieve en wetenschappelijke ondersteuning. Ik wil haar bij deze aan iedereen die promoveert van harte aanbevelen.

Het TREND-consortium en met name de leden van de stuurgroep wil ik danken voor hun bijdrage en inspirerende momenten. Aan de vaste commissie is het te danken dat alle losse onderzoeken over het gehele land aan elkaar gesmeed worden tot een groter mooi geheel. $U$ heeft Nederland op de internationale kaart gezet wat betreft wetenschappelijk onderzoek naar CRPS. 


\section{List of Abbreviations}




\begin{tabular}{|c|c|}
\hline AUC & Area Under the Curve \\
\hline BEA & Brush Evoked Allodynia (aanrakingspijn) \\
\hline BTA & Botulinum Toxinum A \\
\hline C & Cervical \\
\hline CGRP & Calcitonin Gene-Related Peptide \\
\hline $\mathrm{Cl}$ & Confidence Intervals \\
\hline CCL2 & Chemokine ( $\mathrm{C}-\mathrm{C}$ motif) Ligand 2 \\
\hline CRPS & Complex Regional Pain Syndrome \\
\hline CRPS-1 & Complex Regional Pain Syndrome type 1 \\
\hline CRPS-2 & Complex Regional Pain Syndrome type 2 \\
\hline CT & Computerized Tomography \\
\hline DMSO & Dimethyl Sulfoxide \\
\hline ESES & Epidural Spinal Electro Stimulation \\
\hline ET-1 & Endothelin-1 \\
\hline GPE & Global Perceived Effect \\
\hline $\mathrm{Hz}$ & Hertz \\
\hline IASP & International Association for the Study of Pain \\
\hline IL & Interleukine \\
\hline ITT & Intention To Treat \\
\hline IVRB & Intravenous Regional Block \\
\hline L & Lumbar \\
\hline LSB & Lumbar Sympathetic Block \\
\hline MRI & Magnetic Resonance Imaging \\
\hline $\mathrm{N}$ & Number \\
\hline NE & Not Estimable \\
\hline NK-1 & Neurokinin-1 \\
\hline NMDAR & N-Methyl- D- Aspartate Receptor \\
\hline NO & Nitric Oxide \\
\hline NRS & Numerical (pain) Rating Score \\
\hline OR & Odds Ratio \\
\hline$P$ & Probability \\
\hline PNS & Peripheral Nerve Stimulation \\
\hline RCT & Randomized Controlled Trial \\
\hline $\mathrm{RF}$ & Radiofequency \\
\hline ROC & Receiver Operating Characteristics \\
\hline SCS & Spinal Cord Stimulation \\
\hline SB & Sympathetic block \\
\hline SD & Standard deviation \\
\hline SGB & Stellate ganglion block \\
\hline Th & Thoracic \\
\hline TNF- $\alpha$ & Tumor necrosis factor- alpha \\
\hline TREND & Trauma related neuronal dysfunction \\
\hline
\end{tabular}

